University of Louisville

ThinkIR: The University of Louisville's Institutional Repository

$5-2021$

\title{
The shifting role of teachers: a case study on teachers' perceptions of personalized learning in a rural school district.
}

Steve Miracle

University of Louisville

Follow this and additional works at: https://ir.library.louisville.edu/etd

Part of the Educational Methods Commons

\section{Recommended Citation}

Miracle, Steve, "The shifting role of teachers: a case study on teachers' perceptions of personalized learning in a rural school district." (2021). Electronic Theses and Dissertations. Paper 3586.

https://doi.org/10.18297/etd/3586

This Doctoral Dissertation is brought to you for free and open access by ThinkIR: The University of Louisville's Institutional Repository. It has been accepted for inclusion in Electronic Theses and Dissertations by an authorized administrator of ThinkIR: The University of Louisville's Institutional Repository. This title appears here courtesy of the author, who has retained all other copyrights. For more information, please contact thinkir@louisville.edu. 


\title{
THE SHIFTING ROLE OF TEACHERS: \\ A CASE STUDY ON TEACHERS' PERCEPTIONS OF PERSONALIZED LEARNING IN A RURAL SCHOOL DISTRICT
}

\author{
Steve Miracle \\ B.A., Kentucky State University, 1995 \\ M. A. Ed., University of Louisville, 2004 \\ A Dissertation \\ Submitted to the Faculty of the \\ College of Education and Human Development of the \\ University of Louisville \\ in Partial Fulfillment of the Requirements \\ for the Degree of
}

\author{
Doctor of Education \\ in Educational Leadership and Organizational Development
}

Department of Educational Leadership, Evaluation, and Organizational Development University of Louisville

Louisville, Kentucky

May 2021 
Copyright 2021 by Steve Miracle

\section{All Rights Reserved}



THE SHIFTING ROLE OF TEACHERS:

A CASE STUDY ON TEACHERS' PERCEPTIONS OF PERSONALIZED

LEARNING IN A RURAL SCHOOL DISTRICT

\section{By}

Steve Miracle

B.A., Kentucky State University, 1995

M. A. Ed., University of Louisville, 2004

\section{A Dissertation Approved on}

February 8, 2021

by the following Dissertation Committee:

Dissertation Chair

W. Kyle Ingle, Ph.D.

Deborah Powers, Ed.D.

B. Keith Davis, Ed.D.

Doug Stevens, Ph.D. 


\section{DEDICATION}

This dissertation is dedicated to the many students I have served over the course of my 22 years in education. They have always been the driving force behind my actions as an educator. I have long held the belief that the greatest test of our actions and decisions as educators is the question, "Is this what is best for students?" To that end, what is best for students, and most importantly, the students themselves have been what has guided me through the years.

I also dedicate this dissertation to my parents for upholding education as the most important thing and providing opportunities and resources to me at a young age to put me on a path to success. Without that foundation I would not be the first one in my family to graduate college, let alone complete a doctoral program. 


\section{ACKNOWLEDGEMENTS}

I would like to thank Dr. Debbie Powers for her guidance, support, and mentoring throughout the process of this doctoral program. Dr. Powers had already served as a mentor and friend prior to her inviting me to be a part of this program and I know that without her involvement in the program would likely not have applied to this or any other program. To Dr. Keith Davis who had enough confidence in me to offer me my first principal position. Since that time, he has been a guiding force in my career as mentor and friend. It is due to his investment in me professionally that I have had great career opportunities from which to choose. I also am very grateful to Dr. Kyle Ingle for taking me through every step of the process of completing and defending this dissertation. His feedback and direction have been invaluable, and I am honored and thankful to have had him serve as my committee chair. Finally, to Dr. Doug Stevens, who has been the greatest resource for qualitative research, particularly group level assessment, and the most accommodating mentor and guide through this doctoral program.

I am also thankful to the many great educators I have worked with over the years, many of whom left a small part of themselves in me and gave me the drive to reach for higher places. Included in this group are those within my Doctoral Cohort at the University of Louisville. We spent a lot of Saturdays together.

My final thanks goes to my wife Kathy and my children Jenna and Zach for being 
supportive of me while working through this doctoral process. The time, and sometimes the frustrations, involved require great sacrifice on their part. 


\begin{abstract}
THE SHIFTING ROLE OF TEACHERS:

A CASE STUDY ON TEACHERS' PERCEPTIONS OF PERSONALIZED LEARNING IN A RURAL SCHOOL DISTRICT
\end{abstract}

Steve Miracle

February 8, 2021

This case study will explore teacher perceptions of the implementation of personalized learning as a means of supporting teachers in the process of transitioning to a new model of teaching and learning. A review of research revealed that there are many versions of personalized learning based on as many different definitions of what personalized learning is and what it looks like in the classroom. It is due to the lack of one consistent model that implementation can be problematic for schools and districts. As teachers are on the front line of implementing personalized learning their perceptions are important to future implementation of personalized learning. Due to the rapid technological advancements in technological platforms and digital tools for education personalized learning is on the rise in the United States. This is coupled with the reality that our world has also changed rapidly, and globalization has brought the need to think about new ways to prepare our students for the future in which they will live. 
Personalized learning is utilized in order to help meet each student's individual needs based upon their own pace and level of ability outside of the "one size fits all" style of traditional education in the United States. Because the beneficiaries of personalized learning are the students most of the research on personalized learning is on whether it impacts student outcomes. There is a lack of research on the perceptions of teachers as they implement personalized learning or the ways in which their role as a teacher is changing as they transition from the traditional model to the model of personalized learning. 
TABLE OF CONTENTS

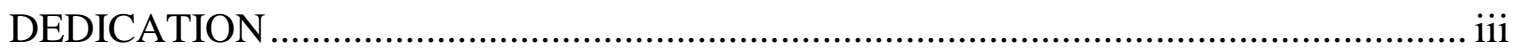

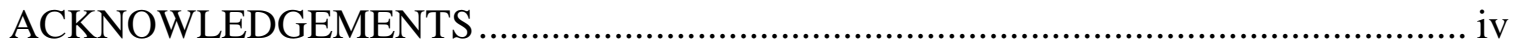

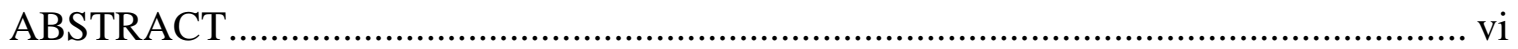

LIST OF FIGURES ....................................................................................

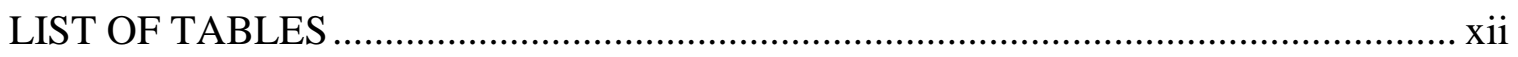

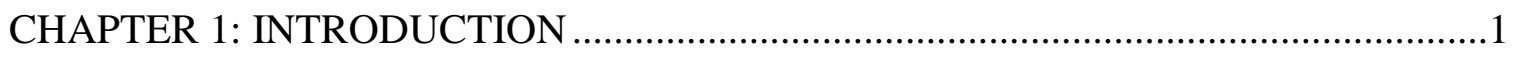

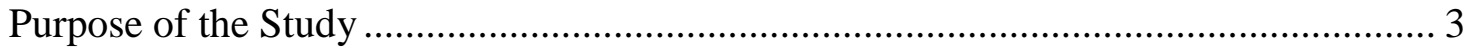

Rationale, Relevance, and Significance of the Study ......................................... 4

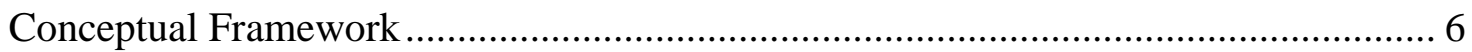

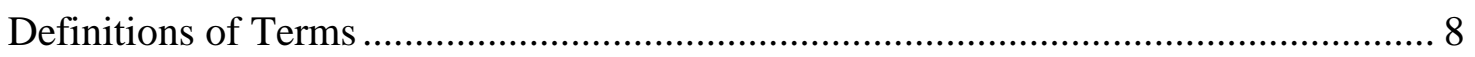

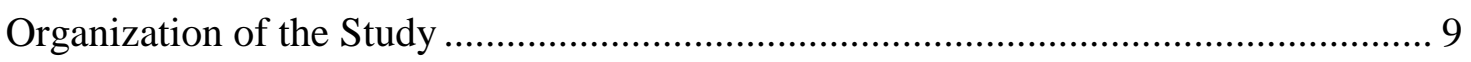

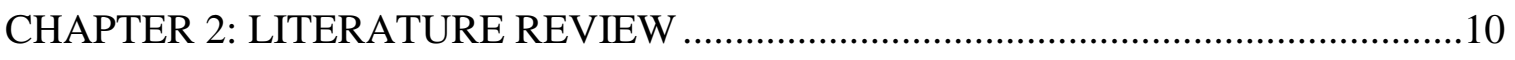

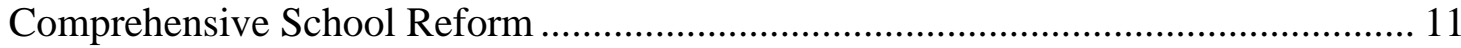

Comprehensive School Reforms Defined .............................................................. 13

Comprehensive School Reform Research ............................................................. 15

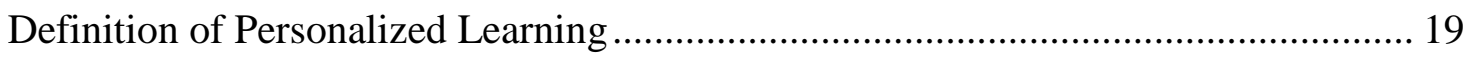

Personalized Learning as Comprehensive School Reform? ....................................... 23

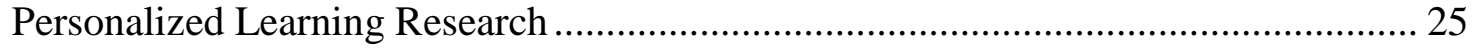

The Changing Role of the Teacher in K-12 Education.......................................... 35

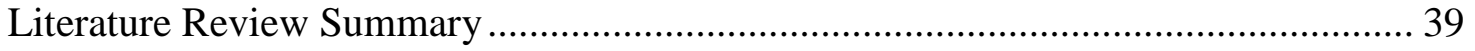

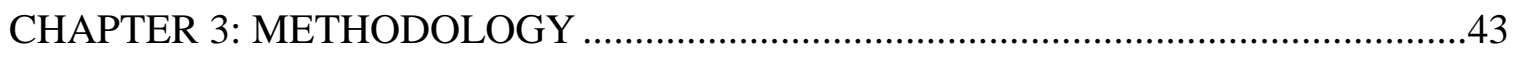

Research Methods and Design—Qualitative Case Study ........................................ 44

Strengths and Limitations of Qualitative Case Studies............................................ 47

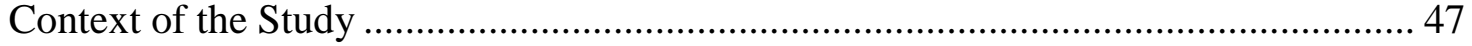

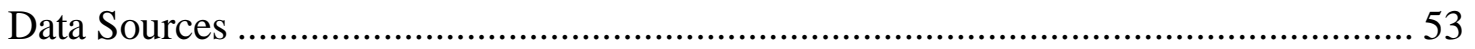

Data Collection Procedures................................................................................. 54

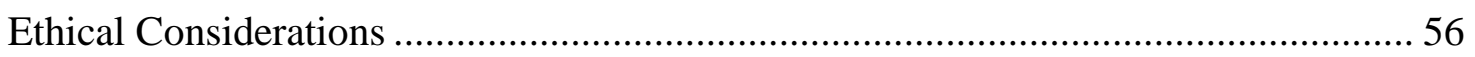




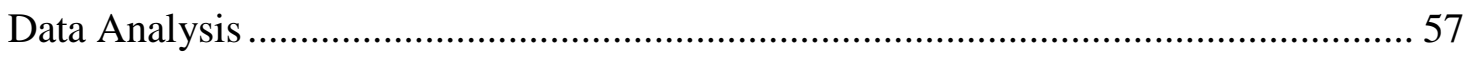

Process for Exploring Researcher Positionality ...................................................... 59

Strategies for Ensuring Credibility, Transferability, Dependability, and Confirmability 61

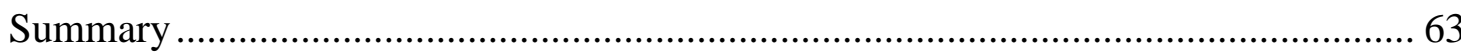

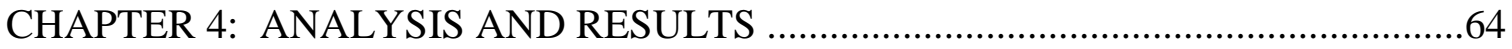

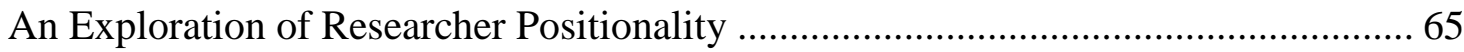

An Overview of Data Sources and Analytical Strategies .............................................. 68

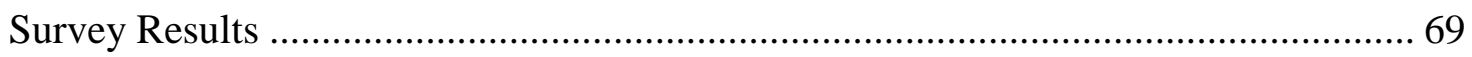

Demographics of Group Level Assessment Participants ............................................ 70

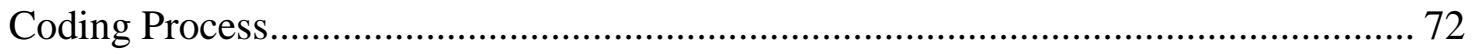

Teacher Perceptions of the Definition of Personalized Learning ................................ 74

Teacher Perceptions of their Role in the Personalized Learning Framework ............... 84

Teacher Perceptions of Successes and Challenges of Implementing Personalized

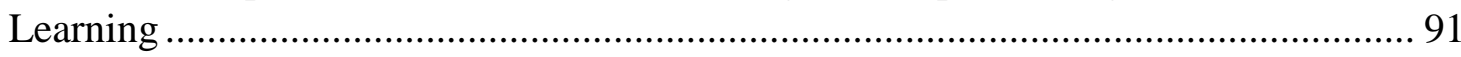

Teacher Perceptions of How Teacher Preparation Assisted/Inhibited the Transition to

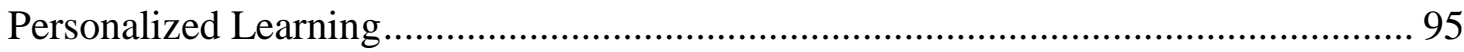

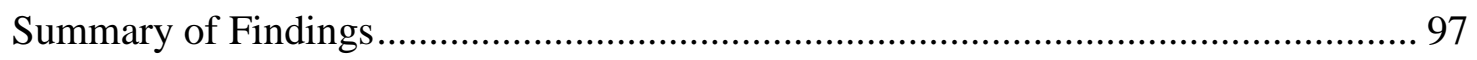

CHAPTER 5: SUMMARY OF FINDINGS AND IMPLICATIONS .............................99

RQ 1: How do teachers define personalized learning?................................................ 99

RQ 2: How do teachers describe their role within the personalized learning

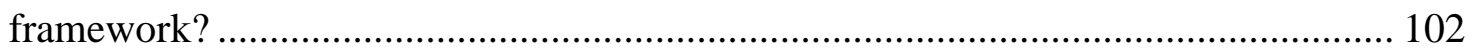

RQ 3: Why has implementing personalized learning been successful and/or

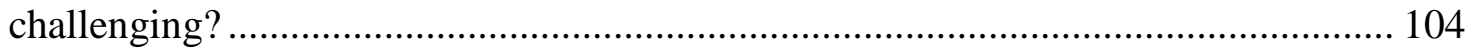

RQ 4: How did teachers perceive their preparation programs assisting or inhibiting teachers' transitions to the personalized learning model? ......................................... 105

Implications for Policy...................................................................................... 106

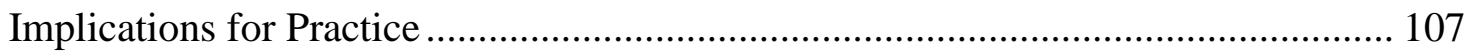

Implications for Future Research...................................................................... 109

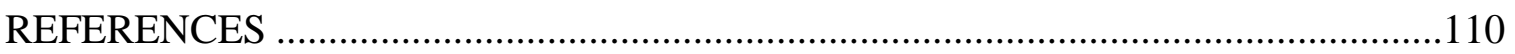

APPENDIX A: SURVEY ..............................................................................122

APPENDIX B: GROUP LEVEL ASSESSMENT PROCESS ………….......................125

APPENDIX C: GROUP LEVEL ASSESSMENT PROMPTS …………........................127

APPENDIX D: INFORMED CONSENT DOCUMENT ............................................128 
APPENDIX E: STRUCTURED ETHICAL REFLECTION

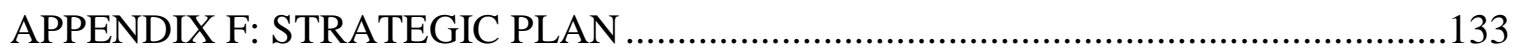

APPENDIX G: LEARNING CENTERED ANCHOR CHART ..................................136

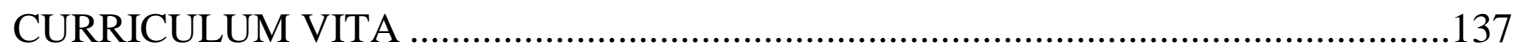




\section{LIST OF FIGURES}

Figure 1. Yin's (2018) Typology of Case Study Designs ............................................. 45

Figure 2. Depiction of Selective Coding Applied to Strauss and Corbin's Coding

Paradigm

101 


\section{LIST OF TABLES}

Table 1. Yin's (2018) Relevant Situations Different Research Methods ......................... 46

Table 2. Enrollment Trends, Trimble County School District and Trimble County

Junior/Senior High School, 2016-2017 to 2020-2021 ................................................. 49

Table 3. Demographics, Trimble County Junior/Senior High School (2018-2019)......... 49

Table 4. School Performance Indicators, 2016-2017................................................... 49

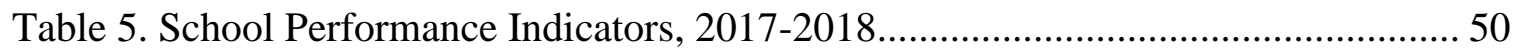

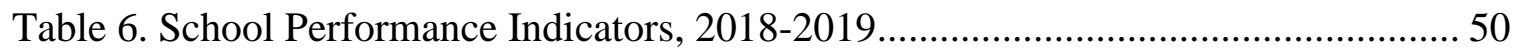

Table 7. Trimble County School District Educator Qualifications.................................. 50

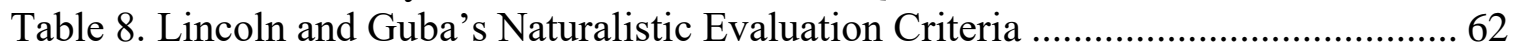

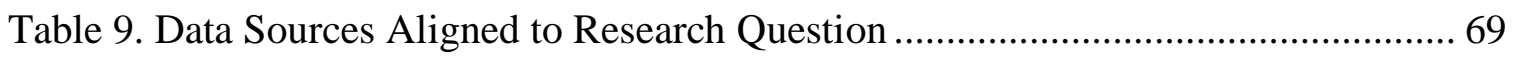

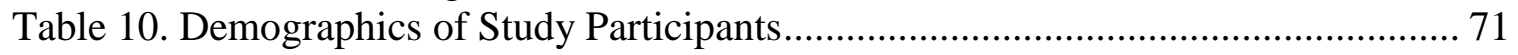

Table 11. Demographics of Individual GLA Participants ......................................... 71

Table 12. Data Sources Aligned to Coding Paradigm ................................................. 73

Table 13. Selective Codes Alignment to Research Questions ....................................... 74

Table 14. Teacher Climate/Culture Survey Most Frequent Responses ........................... 75 


\section{CHAPTER 1: INTRODUCTION}

Students entering today's classrooms come with a different style of learning in response to the changing world in which they live. Due to the technological revolution the world has undergone in the past decade students now have most of the knowledge humankind has accumulated throughout history in the palm of their hands and accessible in seconds. The need to know how and where to find the information, how to determine that the information is reliable, and how to apply that information in real world situations are now more relevant than rote memorization (Wagner \& Dintersmith, 2016).

Research suggests that there is a need to change the process of teaching and learning in U.S. schools and classrooms in response to technological innovations. Wagner and Compton (2015) found that the United States made the least progress of the 40 nations in terms of competitiveness in innovation capacity improvements over the last decade. The Department of Commerce (2012), identified education as one of the three pillars that are key to improving innovation capacity in the United States. It is imperative that educators begin to rethink how they practice in the classrooms to meet the needs of the $21^{\text {st }}$ century student. Students must develop skills for a world in which the traditional model of education does not sufficiently prepare them (Bell, 2010). Students come into the classroom with different levels of ability, motivations, and challenges, rendering a one size fits all model ineffective. If educators are to optimize learning potential, they must personalize the learning experiences for their students. This requires a change in practice to encourage innovation, creation, and greater application of knowledge. 
Teaching practice must go beyond the core content materials and allow students to develop skills and competencies through real life experiences that will help them to be successful in the $21^{\text {st }}$ century world (Wagner \& Dintersmith, 2016).

In Kentucky, current education policy supports the educational system in transitioning into innovative methods such as personalized learning; specifically, $K R S$ 158.645 Legislative declaration on goals for Commonwealth's schools (Kentucky General Assembly, 2010). This statute became effective in the Commonwealth of Kentucky on March 25, 2009, defining the school curriculum and goals for Kentucky schools. The Model curriculum framework (2009) requires that students become selfsufficient, responsible members of family, work groups and community with qualities such as altruism, citizenship, community service, and the ability to solve problems they will encounter in life. There is also the requirement that students apply, connect, and integrate experiences and new knowledge from all subject matters.

Whether the educational setting is rural, urban, or suburban, there are common barriers in the educational process. Richey and Petretti (2002) found that one of the most prevalent barriers to student achievement nation-wide is apathy. Gonzalez and DeJarnette (2012) found that the lack of teacher and student agency in the traditional model of teaching and learning creates apathy at both the student and teacher level. Students must develop skills for a world in which the traditional model of education does not sufficiently prepare them (Bell, 2010). Wagner and Compton (2015) argue that changes in our culture, society, economy, and industries have changed the students sitting in classrooms. 
Lenz, Wells, and Kingston (2015) note that, historically, public education offered in the United States was once the best in the world, but globalization and advances in technology drastically changed the future of work. Despite this rapid change, the student experience has remained relatively static. The education system is now in a position of having to adapt in order to meet the growing competitive pressures that call for more innovation in the hyper-connected world (World Economic Forum, 2016).

When there is a lack of student interest, engagement, and active participation, teachers also lose hope for their profession (Walters, 2004). Luke, Moulthrop and Gimbert (2018) identify sources of teacher apathy, which include high rates of student behavioral problems, failures, and dropouts. While teachers may struggle to motivate students to care about learning, new pedagogical models and frameworks have been developed in response to lack of motivation. Personalized learning is one such intervention.

\section{Purpose of the Study}

This qualitative study focused on learning the perceptions and experiences of teachers regarding personalized learning and the implementation of personalized learning into their classrooms. My study took place in a small, rural, Kentucky school district. District and school leaders researched personalized learning for a year in conjunction with a university and educational cooperative as partners. Through assistance from these partners, educational leaders, teachers, and parents were able to visit regional, state, and national schools that have implemented personalized learning in order to develop a model that would offer the best opportunities for students. 
The purpose of this case study was to learn the perceptions of teachers regarding the implementation of personalized learning. The specific research questions for this study are:

1. How do teachers define personalized learning?

2. How do teachers describe their role within the personalized learning framework?

3. Why has implementing personalized learning been successful and/or challenging from the teacher perspective?

4. How did teachers perceive their preparation programs as assisting or inhibiting teachers' transitions to the personalized learning model?

In this qualitative case study, I sought to gain deeper insights into the phenomenon of personalized learning through the perspectives of teachers participating in the implementation of personalized learning (Yin, 2018).

\section{Rationale, Relevance, and Significance of the Study}

Globalization is drastically changing the future of jobs and the class system in the United States of America (Lenz et al., 2015) and the educational system has not kept up with the rapidly changing world. It is imperative that it change in order to compete on the global level (Friedman \& Mandelbaum, 2012; Friend, Patrick, Schneider, \& Vander Ark, 2017). Over the past 50 years, the introduction of new technologies paired with demographic, political, and economic trends have changed work and social lives. These same trends led to the conclusion by many that the traditional model of education in America is no longer enough (Jerald, 2009). Over the past 117 years, The United States of America has seen great change in society, industry, and the workforce. The education 
system has changed very little over time (Jacobs, 2010). Prince, Swanson, and King, (2018) presented five drivers of change that will drastically reshape education over the next ten years.

1. Automating choices: Artificial intelligence and algorithms are automating many aspects of our lives. This will challenge educators to create strategies for the use of artificial intelligence without stifling student and teacher agency as well as creating more inequity in education.

2. Civic Superpowers: Engaged citizens and civic organizations are seeking to rebalance power. Technology enabled civic engagement is going to have an impact on educational governance and decision-making.

3. Accelerating Brains: People have increasing access to tools and insights that are reshaping our brains in intended and unintended ways. There will be a challenge for learners to preserve their rights of when and how to use cognitive tools meeting new educational performance expectations

4. Toxic Narratives: Outdated and misaligned systems and metrics are contributing to chronic health issues, including rising rates of mental illness in children. Educational accountability must change to support an expanded perspective on learner development and well-being.

5. Remaking Geographies: Communities are working to remake themselves in the face of deep transitions. Education must find ways to assist cities, towns, and rural communities in re-branding new identities.

Prince et al. (2018) warns that these changes will continue to reinvent relationships between people and institutions. This requires a transformation in our 
educational system to prepare students for the 21 st century (Guo, 2014). No aspect of our lives will be untouched, including teaching and learning. Education is a cultural value as well as a system. As technology and society changes, the onus is on educational leaders and teachers to transform their districts, schools, and classrooms in partnership with community stakeholders. Researchers suggest the need for a change in pedagogy in response to the changing nature of work (O’Keeffe, Brady, Conlan, \& Wade, 2006; Sahabudin \& Ali, 2013). Researchers also reveal a lack of understanding among teachers as to what personalized learning is and how to implement it in the classroom (Courcier, 2007; Waldeck 2006). Understanding the perceptions of teachers involved in the implementation of personalized learning in a school may inform future attempts to implement personalized learning in other contexts (Pane, Steiner, Baird, \& Hamilton, 2015; Wolf, 2010).

\section{Conceptual Framework}

As a researcher studying personalized learning, my underlying epistemology is constructivism, which is defined as being the view that "all knowledge, and therefore all meaningful reality as such, is contingent upon human practices, being constructed in and out of interaction between human beings and their world, and developed and transmitted within an essentially social context" (Crotty, 2015, p. 42). The root of the word constructivism — construct - illustrates the constructivist view as believing that meaning is not discovered but constructed. Objects do not simply have meaning because they exist. Meaning comes only when exposed to consciousness, or more specifically human interaction. 
Powell and Kalina (2009) state that constructivism is a concept that has a variety of meanings and that teachers must understand both cognitive and social constructivism to be successful implementing constructivist methods within the classroom. Cognitive constructivism is based on the individual and how one constructs knowledge. In the personalized learning model, this is very important for teachers to understand, as the role of teachers changes based upon the individual needs of students. This is the giving over of control of the learning to the student and the utilization of progress data used by the teacher to manage and facilitate student learning in needed areas. Social constructivism draws upon the understanding that people work together to construct artifacts through social interaction. More importantly social constructivism focuses on the learning that takes place for an individual based upon that individual's interactions with others (Kim, 2001). Research suggests that social constructivist teaching methods are highly effective and beneficial to students (Powell \& Kalina, 2009). The most powerful aspect of personalized learning may be the collaboration and interaction that is possible for teachers to facilitate for their students. I have sought to understand the viewpoints and perceptions of teachers and their experience with implementing personalized learning. It was my goal to listen to their individual responses to unpack patterns and interpret the complexity of their views. It was not about trying to solve a problem, but to understand how teachers felt about personalized learning and why.

Working from the epistemology of social constructivism, grounded theory is the foundational framework that supports this study, specifically of the Glaserian school of thought. Grounded theory is a theory that inductively results from the studied phenomenon, in this case, personalized learning. It is Glaserian in that I have begun the 
study with an "empty mind," the theory was grounded in data, and any theory developed has been revealed by the data (Zarif, 2012). My study did not seek to determine the effectiveness of personalized learning. It sought to learn the feelings and experiences of the teachers implementing personalized learning in their classrooms.

Charmaz (2008) states that constructionist grounded theory attends to what and how questions, as does my study. This study utilized inductive strategies for collecting and analyzing data. Grounded theory is also an iterative, comparative, interactive, and adductive method that allowed me to go back and forth between data collection and data analysis. Within this study, I simultaneously engaged in data collection and analysis using Group Level Assessment (GLA). Through the process of the GLA, there was a systematic inductive approach, which expanded through the subjection of the data and its analysis to rigorous tests during the GLA process (Charmaz, 2011).

\section{Definitions of Terms}

I use the following terms in the context of this study:

Personalized Learning: refers to the teacher's relationships with students, their families, and the use of multiple instructional modes to scaffold each student's learning and enhance the student's personal competencies. Personalized learning varies the time, place, and pace of learning for each student, enlists the student in the creation of learning pathways, and utilizes technology to manage and document the learning process and access rich sources of information. (Murphy, Redding, \&Twyman, 2017)

Student Agency: The capability of individual human beings to make choices and act on these choices in a way that makes a difference in their lives. (Lindgren \& McDaniel, 2012) 
Mastery Learning: A marker to demonstrate specific knowledge or skills based on objective criteria. (Redding, 2014a)

Competency: A continual accumulation of skills and capabilities. (Redding, 2014a)

Relational Suasion: A teacher's ability to influence students' learning, motivation, metacognitive competencies and social/emotional competencies through the teacher's personal knowledge and interaction with the student. (Redding, 2013)

\section{Organization of the Study}

I have organized my study as follows; Chapter 1 includes the introduction, purpose, research questions, rationale, relevance, and significance, conceptual framework, definition of terms, and an organizational summary of this chapter. Chapter 2 is a broad review of significant literature related to my topic of study. Chapter 3 relates in detail the qualitative case study methodology used to collect and analyze data. Chapter 4 is the presentation of findings from my case study. Lastly, Chapter 5 summarizes the findings of my study as well as discusses the implications for further research and suggestions for possible changes to policy and practice. 


\section{CHAPTER 2: LITERATURE REVIEW}

In this study, I explore teacher perceptions of personalized learning and their overall experience during implementation. I sought to understand how teacher perceptions of their role in the process of teaching and learning has changed (if at all) because of the personalized learning initiative. Additionally, I examined the perceptions of teachers regarding the professional support needed through the implementation of personalized learning. There are four research questions guiding this study with the first serving as an overarching driving question and the subsequent three delving into the impact on the teacher experience.

1. How do teachers define personalized learning?

2. How do teachers describe their role within the personalized learning framework?

3. Why has implementing personalized learning been successful and/or challenging?

From the teacher perspective?

4. How did teachers perceive their preparation programs as assisting or inhibiting teachers' transitions to the personalized learning model?

In this chapter, I provided a comprehensive review of the relevant literature in order to provide some historical context of the need for and development of personalized learning as an instructional strategy. I began the literature review with a 
brief background on comprehensive school reform (CSR) and the definition of CSR. I then reviewed the extant literature on CSR and their relationships with school and district outcomes, characteristics of successful CSR implementation, and how scholars and practitioners perceive personalized learning as a CSR. I then reviewed the existing literature on personalized learning and how scholars define it. I then focused on the extant research that explores the changing role of the teacher in k-12 education, the role of the teacher in the implementation of CSR, and the role of the teacher in the implementation of personalized learning. The chapter ends with a summary that captures the predominant themes of the extant research in terms of findings and methods used to arrive at these findings. I conclude this summary with a clear directive from the research literature, justifying the need for this study.

\section{Comprehensive School Reform}

During the latter decades of the 20th century, the United States educational system focused heavily on school reform. There was such a heavy focus on school reform that in many (if not most) cases, schools and district implemented and abandoned initiatives before there was any actual evidence of effectiveness. It was a race to get on to the next new initiative. Attempting to limit the jumping from one initiative to the next, funding was made available for schools to implement reforms that were able to provide high quality evidence of effectiveness. In 1998, the federal government initiated the Comprehensive School Reform Demonstration (CSRD). Title I schools across the United States were given access to $\$ 120$ million dollars and all public schools were granted access to $\$ 25$ million dollars (McChesney \& Hertling, 2000). CRSD morphed into the Comprehensive School Reform Program (CSRP). The hope was not only to help schools 
be successful in effective reform, but also to generate a great amount of research-based innovation to drive future reforms (Borman, Hewes, Overman, \& Brown, 2003).

When CSRD began schools and districts were required to meet certain qualifiers in order to receive funding. While the schools and districts were allowed to develop their own reform models, they were required to promote high standards for all children, address all academic subject areas and grade levels, be research based and research tested, share a common focus on outcomes, include professional development, align resources across all subjects and grades, and facilitate parent and community involvement. Although it is understood that meeting these requirements does not guarantee success of the reform model or the school (McChesney \& Hertling, 2000). Initially there were 17 reform models listed in the legislation without a requirement that schools use those listed (Desimone, 2002). The list of 17 models was somewhat controversial as some of the programs were unproven while others had been successful. In the end, the list was to prompt schools and districts to be careful and intentional in the selection process (McChesney \& Hertling, 2000). Regardless of any initial enthusiasm at the beginning of implementation there were problems with sustaining the reform due to poor selection or design of the reform in the beginning, lack of proper implementation, changes in state and district leadership and policies, and the constant moving on to the "next new thing" (Datnow \& Stringfield, 2000).

The federal government did not solely initiate the CSRP. In fact, there were private, non-profit organizations and foundations involved with providing the funding. By the close of the $20^{\text {th }}$ century, and only a few years into the CSRP roughly $10 \%$ of all public schools in the United States had adopted a comprehensive school reform design 
(Rowan, Miller, \& Camburn, 2009). Comprehensive school reform (CSR) designs evolved from the effective schools movement. CSR broke away from previous efforts in that it focused on whole school improvement, not just improvement for specific populations in schools. The effective schools literature identified specific characteristics of effective schools that could indicate their effectiveness such as shared goals, positive climate, building management, and strong leadership. What it did not do was provide practical methods schools could utilize to become effective. CSR attempted to remedy this (Desimone, 2002).

There have generally been two schools of thought regarding school improvement. The first is through educational policies that set high academic standards, tough accountability, and more school choice. This approach sought to motivate educators to work harder and get better results. The second is through locally driven approaches through macro-level changes in educational policy. The research on both have shown that neither have been effective in school improvement efforts (Rowan et al., 2009).

\section{Comprehensive School Reforms Defined}

Comprehensive school reform, as defined by the U.S. Department of Education in 2002, was based on 11 components that, if implemented with fidelity, represented a comprehensive and scientifically based effort at school reform. The 11 components making up the definition of CSR are:

1. Employs proven methods for student learning, teaching, and school management that are based on scientifically based research and effective practices, and have been replicated successfully in schools; 
2. Integrates instruction, assessment, classroom management, professional development, parental involvement, and school management;

3. Provides high-quality and continuous teacher and staff professional development and training;

4. Includes measurable goals for student academic achievement and establishes benchmarks for meeting those goals;

5. Is supported by teachers, principals, administrators, and other staff throughout the school;

6. Provides support for teachers, principals, administrators, and other school staff by creating shared leadership and a broad base of responsibility for reform efforts;

7. Provides for the meaningful involvement of parents and the local community in planning, implementing, and evaluating school improvement activities;

8. Uses high-quality external technical support and assistance from an entity that has experience and expertise in school wide reform and improvement, which may include an institution of higher education;

9. Includes a plan for the annual evaluation of the implementation of the school reforms and the student results achieved;

10. Identifies federal, state, local, and private financial and other resources available that schools can use to coordinate services that support and sustain the school reform effort;

11. Meets one of the following requirements: the program has been found, through scientifically based research, to improve the academic achievement of 
participating students significantly; or the program has been found to have strong evidence that it will significantly improve the academic achievement of participating children (U.S. Department of Education, 2002).

Comprehensive school reform models could be implemented internally with the funding and guidance for implementation coming from inside the district. The more common and more widely used CSR models were external programs. These external programs were purchased by a district or a school and the guidance/facilitation of implementation came through the support of the design team which would be made up of members affiliated with universities, non-profit organizations, and the company having created the CSR. During the initial stages of the CSR movement, changes in Title I regulations allowed schools and districts to allocate funding to purchase these external CSR models. Some examples of external CSR models are Success for All, High Schools that Work, Comer School Development Program, and Accelerated Schools (Datnow, 2005).

\section{Comprehensive School Reform Research}

Due to the swift expansion of CSR as a movement, initial studies which sought to gauge effectiveness were almost immediately outdated. Between the years of 1999 and 2003 there had been five major reviews by practitioners. The usefulness of these early studies was limited and failed to give comprehensive information on CSR overall (Borman et al., 2003). Desimone (2002) asserted that effective implementation of CSR was extremely vital as to whether it would have an effective impact on a school. Within the implementation process, Desimone (2002) identified five policy attributes: specificity, authority, power, consistency, and stability. Each of the five attributes 
contribute to implementation. Specificity related specifically to implementation fidelity, power related to immediate impact, and authority, consistency, and stability were the driving forces for long-term success.

Borman et al. (2003) conducted a meta-analysis of 346 CSR programs and found that there was a wide range of variability in effectiveness. Some programs performed better than others did. One of the significant findings as a predictor to effect size in CSR was that models requiring active parent engagement and community involvement in school governance consistently had worse outcomes than the models that did not require this approach. The design of the CSR is vital to effectiveness. A logic model made up of two components, the way the design organizes the school for instructional change and the type of instructional changes envisioned by the design, yield higher success. The design of CSR is delicate as it can fail due to poor implementation, an ineffective approach to instruction, or both (Rowan et al., 2009).

Implementation is only one of three phases in the life of any school reform. The other two are the adoption of the reform model and the longevity or sustainability of the reform (Datnow \& Stringfield, 2000.) Those reform models proven successful were those in which the reform adopted, whether intentionally or not, helped the educators meet the district and state requirements. It is not that the reform was based on meeting the policies of the district and the state, but there was no conflict with those policies. These reforms usually were of a less structured nature and were easier to adapt to the local circumstances of the school or district (Datnow, 2005). Conversely, there have been many schools and districts who let district and state politics drive the adoption of the reform. In these cases, very little thought was given to other options that may be better 
suited for the local context (Datnow \& Stringfield, 2000). It is more important to adopt reform models based upon proven outcomes than to simply focus on the criteria set forth to qualify for the funding (Borman et al., 2003).

Regardless of the reform adopted, as is the case with any educational initiative, successful outcomes are less likely if implementation does not occur with fidelity. In other words, implementation is everything and if not done well there is no point in analyzing the impact it has on achievement (Epstein, 2005). As with the adoption of the reform, local conditions also affect implementation. Datnow and Stringfield (2000) did not identify any instances of a reform implemented at a high level without being sensitive to the local realities of where implementation was taking place. This would coincide with the attributes of implementation identified in Desimone (2002). The first of those attributes, specificity, consists of three main points; (a) locus of development; (b) level and type of professional development; (c) information and monitoring provided by the design team or district. Slavin (2008) agrees that implementation depends on the teachers being involved with colleagues who share a common vision and have proper support offered in the process.

Both the adoption and implementation processes affect the longevity of the reform. One of the local realities of adopting and implementing a CSR is the funding required to sustain the CSR over time. More importantly, the funding source must last beyond grant funding and be able to withstand changes in leadership at both the district and state levels (Datnow, 2005). Political changes, changes in leadership, and lack of funding are just some of the reasons that CSRs discontinue. It was the lack of sustainability early in the CSR movement that limited useful CSR research because 
schools and districts moved from one to another, like a pendulum (Slavin, 2008). The attributes given by Desimone (2002) of authority, consistency, and stability are all necessary for long-term success and sustainability of CSR. There are two areas of importance regarding the balance of power and authority. The first is design choice. CSR has proven to be more effective and longer lasting when teachers had input in the design and through persuasion rather than mandate. The second area is in providing extensive information and various options from which to choose. This has proven the best method of adopting and implementing in order to get teachers to buy in whereas mandates and monetary rewards have failed. Research has shown that CSR awards have not resulted in a significant effect on student achievement through CSR implementation and in fact has had a negative impact in some cases (Gross, Booker, \& Goldhaber, 2009).

Borman et al. (2003) looked at 29 of the most widely utilized CSR models in order to determine their effectiveness on improving student achievement. They categorized and ranked them in four categories of effectiveness. The highest level was strongest evidence of effectiveness and only three of the 29 CSRs made it into this category. The second category was highly promising evidence of effectiveness, again with only three of the 29 CSRs listed in this category. The third category was promising evidence for effectiveness in which 6 of the 29 CSRs were listed, and the final category was greatest need for additional research in which the remaining 18 CSRs were listed. Just as the results of Borman et al. (2003) were wide ranging, other studies have had similar results. While Borman et al. (2003) focused on CSR aimed to influence all students, Gorey (2016) sought to determine what impact CSR had made on the blackwhite achievement gap through meta-analysis. Once again, the results varied but there 
was a narrowing of the black-white achievement gap primarily if the CSR was externally developed. Programs locally developed through Title I funding generally did not narrow the black-white achievement gap. Waldron and McKleskey (2010) were also looking at the impact of CSR on a specific population. In this case, they were looking to see how CSR allowed for the development of a collaborative culture in order to address the needs of special education students. While not looking at specific models of CSR, it was interested in the implementation and cultural development processes. Waldron and McKleskey (2010) assert that if the development of the CSR focuses on creating an allinclusive culture the potential is high for an effective instructional environment to meet the needs of students with disabilities.

The comprehensive school program funding ended in 2005. By 2007, the excitement and the enthusiasm for CSR had all but disappeared. Research on CSR dates to 1990 and continued until 2006. While research provided evidence of varying CSR effectiveness, there was moderate to strong research support for many of the models that were in use. With the ending of the funding and the lack of enthusiasm that had once existed, CSR, like so many other educational initiatives gave way to the pendulum having swung away to the next new thing (Slavin, 2008).

\section{Definition of Personalized Learning}

It is important to note that there is no one, all-encompassing definition for personalized learning and that many of those definitions come from outside of the United States. There has been a need for an operational definition of personalized learning (Zmuda, Curtis, \& Ullman, 2015). Countries such as Australia, New Zealand, and the 
United Kingdom have led the way on personalized learning, and it is from these places that the definitions originate. David Miliband, Secretary of State for Education and Skills in the United Kingdom, penned one of the earliest definitions stating:

This is what I mean by 'Personalised Learning'. High expectations of every child, given practical form by high quality teaching based on a sound knowledge and understanding of each child's needs. It is not individualized learning where pupils sit alone at a computer. Nor is it pupils left to their own devices - which too often reinforces low aspirations. It can only be developed school by school. It cannot be imposed from above. $(2004$, p. 8$)$

Sebba, Brown, Steward, Galton and James (2007) provides a more comprehensive definition of personalized learning with the statement that personalized learning is "about tailoring education to individual need, interest and aptitude so as to ensure that every pupil achieves and reaches the highest standards possible, notwithstanding their background or circumstances, and right across the spectrum of achievement" (p. 15). The U.S Department of Education (2010) moved beyond just the tailoring of education and discussed the need for the personalization of the environment as well, stating: Personalization refers to instruction that is paced to learning needs [i.e., individualized], tailored to learning preferences [i.e., differentiated], and tailored to the specific interests of different learners. In an environment that is fully personalized, the learning objectives and content as well as the method and pace may all vary (p. 12).

Maguire, Ball, and Braun (2013) defined personalized learning as an emerging method for changing from the traditional way of learning that provides flexibility for students and 
teachers in how teaching and learning occurs. It is shifting the responsibility and control from what students and teachers have traditionally done and it requires both students and teachers to shift their roles in the classroom.

Redding (2013) attempts to expand on the 2010 definition of personalized learning given by the United States Department of Education by asserting the importance of the teacher in personalized learning by asserting that there is a multi-dimensional role for the teacher and to affirm explicitly a place for the personal competencies of motivation, metacognition, and social/emotional learning. Personalized learning may or may not include the use of technology or it can be a blend of the two. The teacher's role in personalized learning goes well beyond just providing students with a path to discovery, whether it is with the use of technology or not. The teacher must also become more than a facilitator. The organization of the curriculum and a continual monitoring of progress by the teacher is still the most vital part of the learning process, as they have the power of relational suasion unmatched through any type of technology. The teacher's success at transitioning into a new role allows the student to find their voice and agency in their own learning and engagement.

Perhaps the most comprehensive and complex definition of personalized learning comes from Murphy et al. (2017) from their work with the Center of Innovations in Learning (CIL). They state:

Personalization refers to the teacher's relationships with students and their families and the use of multiple instructional modes to scaffold each student's learning and enhance the student's personal competencies. Personalized learning varies the time, place, and pace of learning for each student, enlists the student in 
the creation of learning pathways, and utilizes technology to manage and document the learning process and access rich sources of information. (p. 3) Regardless of definition, a common theme is missing in each. None of the current definitions of personalized learning specifies the exact roles of teachers or students within personalized learning. The distinctive features of personalized learning continue to be vague and represent a means to improve student motivation, engagement, and outcomes (Prain et al., 2012). Common to all the definitions of personalized learning is that it requires students to master personal competencies as a foundation to a successful experience in personalized learning.

Redding (2014a) identifies a personal competency framework made up of cognitive competency, metacognitive competency, motivational competency, and social/emotional competency. Redding (2014a) indicates that the primary purpose of schooling is for students to master skills and knowledge through the curriculum. There should also be an intentional effort by educators to develop personal competencies within students that lend to student success in the primary goal. Mastery is a marker that demonstrates specific knowledge or skills based on objective criteria. This is different from competence, which is having a specific degree of knowledge or skill to perform a functional role. Competency is not a marker but is instead continual accumulation of skills and capabilities. The intentional effort by educators to teach and develop competencies in students is what is missing in the traditional model of education. A student's ability to manage his/her learning, evaluate understanding, revise how academic goals are met, and student agency, requires routines and processes that can be learned. The four competencies therefore connect foundationally to personalized learning in that 
they help the student find a sense of self-worth, which leads to the development of habits and behaviors that lead to an enlarged capacity to learn.

Redding (2014b) moves beyond the personal competency framework and discusses how the four competencies relate to personalized learning. This literary resource provides the concept of relational suasion, which is a teacher's ability to influence a student's learning, motivation, meta-cognitive competencies and social/emotional competencies through the teacher's personal knowledge and interaction with the student. It is, in fact, this personal knowledge gained by the teacher that helps to understand the student's learning needs (McLaughlin, Talbert, Kahne, \& Powell, 1990). Relationships between students and teachers are, therefore, a very vital aspect of developing the personal competencies in students as well as in the successful implementation of personalized learning also. This need for deeper knowledge through deeper relationships means a shift in the role of the teacher from the traditional model of education.

The context in which the competencies evolve goes beyond the classroom, the school, and, to the school community. While all students have some level of personal competency supported outside the school or the classroom, it is vital that the school and teachers intentionally seek to hone and develop these personal competencies in order to provide the most benefit to all students. It becomes incumbent upon teachers to teach students the skills required to master these competencies.

\section{Personalized Learning as Comprehensive School Reform?}

During the CSR movement, personalized learning may have been a small aspect of one of the CSR models, and even then, it was more of a recommendation. The 
Coalition of Essential Schools (CES) was an external CSR model that had a set of "common principles" followed by schools adopting CES. One of those principles was that when possible, both the teaching and learning should be personalized at the maximum level possible (Rutherford, 2007). It was however one of 10 principles guiding CES. It is also important to point out the limited digital tools and platforms for online learning available during the height of the CSR movement to allow for true personalization, as a possible reason why personalized learning was not a separate CSR model.

As previously stated, the definition of personalized learning is very broad. While personalized learning as a concept has been around for many years dating back to the 1950s. Skinner (1958) stated that we cannot prepare students for one kind of life using schools organized on a totally different set of principles. He predicted that using technology or, "teaching machines," the roles of teachers and students would change. Teachers will be able to teach more efficiently, and students will be able to work at their own level and pace. What Skinner described so many decades ago, without using the term, was personalized learning. Redding (2016) asserts that personalized learning has its roots in competency-based education and that the antecedents of personalized learning are evidence in the progressive philosophies of John Dewey and many others in the early years of the 20th century. Redding (2016) further traces the evolution of personalized learning down through the passing of the Individuals with Disabilities Education Act (IDEA) through individualized learning, then differentiation, and finally to personalized learning. The concept of personalized learning, therefore, predates comprehensive school reform. 
There are, however, some commonalities between CSR and personalized learning. Just as the research shows that implementation was key to the success of CSR, the same is true of personalized learning. While many educators understand how personalized learning can transform teaching and learning there is currently minimal understanding of what it looks like in action and equally little understanding as to how to design and implement it into a classroom (Patrick, Kennedy, \& Powell, 2013). As stated by Ross and Gil (2004) there is a tendency, regarding education reform initiatives, to confuse the means and the ends. CSR was a strategy used to improve student achievement. It was not the goal in and of itself. The model, so to speak, was not the program. Like CSR, personalized learning is not a program. While there are many programs available to assist with online learning, learner profiles, and learner pathways, the use of these programs in and of themselves does not equate to personalize learning.

Personalized learning is an emerging method to change the traditional way of teaching and learning. Personalized learning provides flexibility for students and teachers in how teaching and learning occur. It is a drastic re-shifting of responsibility and control from what students and teachers are used to from the traditional model. It requires both students and teachers to shift their roles in the classroom. For educators to understand the necessary shift in the role of the teachers, it is vital to understand and define personalized learning.

\section{Personalized Learning Research}

In the last decade, it has become increasingly clear that personalized learning in the field of education has become more prevalent as a response to globalization and the end of the industrial mass production model (Peters, 2009). Over the last five years, 
educational practices have begun to shift due to innovative changes in the technological industry (Basham, Hall, Carter \& Stahl, 2016). This is due to help from federal policies such as Race to the Top, private initiatives like the Gates Foundation, and practitioners such as Edutopia (Bingham, Pane, Steiner, \& Hamilton, 2018). Over the last five years, educational practices have begun to shift due to innovative changes in technology (Basham et al., 2016). Shifts in practice are due to the accessibility of online education options, but have expanded even more through blended learning environments that, in turn, led to the rise of personalized learning (Watson, 2008).

While many educators understand how personalized learning can transform teaching and learning there is currently minimal understanding of what it looks like in action and equally little understanding as to how to design and implement it into a classroom (Patrick et al., 2013). Personalized learning is not only widely defined, but it is also diversely operationalized in the places where it is implemented (Netcoh, 2017). The potential of personalized learning comes from the possibilities of improving student engagement. When implemented effectively personalized learning can meet all students where they are, motivating and engaging them through their interests and academic level (Childress \& Benson, 2014). To improve student engagement, which is about helping students find their own fire (Ferlazzo, 2017) personalized learning is a model that relies greatly on increased voice and choice from students in the design, execution, and management of their learning (Nectoh, 2017).

Due to the lack of a consistent definition as a school model and the fact that it is a new phenomenon, there is little peer-reviewed research on personalized learning as a whole school model (Bingham et al., 2018). Some approaches to personalized learning 
lend themselves greatly to the use of technology through online programs, (Chen, 2008;

Lin, Yeh, Hung, \& Chang, 2013). Other approaches that have not relied as heavily on technology but leave it to teachers to modify the curriculum and instruction, personalizing to the needs of the students (U.S. DOE, 2010). There are also similarities in many models of personalized learning implemented in schools and districts.

Recent studies identify four essential components of most personalized learning models. Those components are: (a) learner profiles--based on student strengths, weakness, goals and interests and constantly updated; (b) personal learning paths-responsive to the needs, goals, motivation, and progress of the student; (c) mastery-either through competency-based assessment or continual assessment of students to demonstrate mastery of their defined goals; (d) flexible learning environments--allows for student needs to be met through flexible access to teachers and use of time and space (Pane, Steiner, Baird, \& Hamilton, 2017). The examination of these four components supports student voice and choice, student engagement, and use of technology. Building learner profiles and learner pathways based on student interests, goals, and needs involves the student through voice and choice. The appropriate use of technology in the implementation assists the teacher in tracking student progress and in creating a flexible learning environment.

Student voice, choice, engagement, and motivation are all part of the larger web of student agency (Rector-Aranda \& Raider-Roth, 2015) where students can make decisions on where, what, and with whom to learn (Lindgren \& McDaniel, 2012). Lindgren and McDaniel (2012) define agency as "the capability of individual human beings to make choices and act on these choices in a way that makes a difference in their 
lives" (p. 345). Student agency can influence student learning through both process and outcomes. They also clarify that agency is not freedom. There is a certain level of teacher oversight needed. The teacher must be willing to give up some control. With surveys among 96 students enrolled in an online course, Lindgren and McDaniel (2012) studied student engagement through an online course where student agency was one of the main features of the course. There was also a survey analysis among 129 students in a traditional course. The findings supported that student agency combined with narrative and learning did strengthen student engagement in the course. Student engagement is high when student motivation is high. Lindgren and McDaniel (2012) stated that the responses they received on the surveys in the online course were highly positive. Students were much more motivated due to the choice of topic or the choice of assignment. There was ownership by the student in the process and the outcome was much more successful. Lindgren and McDaniel (2012) also identify limitations within the research. There was no specific clarification on the interaction between narrative and agency. This means there is no way to determine if narrative could overshadow the effects of student choice or result in the feeling of the loss of ownership in the choice. More research on narrative and student agency individually is required in the future. While this research was primarily about online learning, it connects to personalized learning in that students had choice to move at their pace throughout the course as well as to choose the process of how they completed the course. The implication on teachers is that once again there is a need to structure a class or course non-traditionally to get at the needs of the student more effectively. Positive outcomes and attitudes for students could result in positive outcomes and attitudes for teachers. 
Gonzalez and DeJarnette (2012) also looked at student agency from the lens of the division of the labor between teacher and student. Gonzalez and DeJarnette (2012) specifically deals with agency in a geometry classroom and seeks to determine if expert mathematics teachers are more effective than novice teachers in incorporating student's ideas into review lessons. They asked: 1.) what is the division of labor between the teacher and the students? 2.) What linguistic resources does an expert teacher use to manage students' contributions? Specifically, the study wanted to learn how teachers negotiated with students the actual content they were supposed to know. The data were collected from videos and transcripts of two classes taught by the same teacher.

Deed et al. (2014) concluded that it was possible to identify how teachers and students characterize agency through the enactment of personalized learning in an open classroom setting. They also found that the shared understanding of the teacher and students produced teacher and student expectations and perceptions of their own and each other's choices and actions. There is a balance needed between teacher and student responsibility for student learning. The personalized environment allows for both student and teacher agency. Teachers in personalized learning must shift their behavior from one of controlling the lesson to one of facilitating the lesson. This is preeminently due to the need to promote student agency in the classroom, the lesson, the learning, and the process for how learning occurs. Deed et al. (2014) Infers that teacher agency holds a prevalent role in the sense that teachers may create and maintain the personalized learning environment by their own means and in their own way.

Teachers in the personalized model can focus more on specific needs of students. Students, through their own agency and voice work to solve their own problems initially. 
Deed et al. (2014) noted the teacher was involved more as the problems of the students have become more complex. It was determined that the teacher must cultivate and build the environment that promotes student ownership in their choices, actions, and learning. This is in direct conflict with the traditional model of education. While this may be challenging there was some indication of success with students and therefore the teacher could certainly measure their success based upon that of the students.

During reviews, Gonzalez and DeJarnette (2012) learned that there are certain aspects of the lesson that teachers like to have control over. While there was some opportunity for students to have some choice in the content reviewed, the teacher directed the review for most of the time. To this end they found that there was little student agency during the review and that the division of labor was more heavily weighted to the teacher. Students did have some agency in the types of resources used during the review. Division of labor followed the pattern of the teacher having the responsibility of providing the task and the students having the responsibility of applying the knowledge to the task. In other words, the teacher was the primary actor in all but one scenario in the study. There was little negotiation of the division of labor observed.

Johnson (2008) conducted a study around the research questions: 1) how do students in these traditional and non-traditional schools spend their time? 2) Do students differ in terms of general, in-school and out of school engagement? 3) Do instructional strategies differ between these schools, and if so, how do these differences relate to academic engagement especially with respect to the three components of engagement outlined above? Johnson (2008) used the experience sampling method (ESM) to collect student data on their levels of interest, enjoyment, and concentration in activities as they 
occurred. The researcher sampled 40 students at each of the schools chosen for the study. One of the schools was a traditional high school with a teacher/student ratio of 1:25 and the other school was a non-traditional high school with a student ratio of 1:17.

Johnson (2008) found that the students in the non-traditional school reported higher engagement than those in the traditional school. There was a significant difference in the types of instructional methods used in both schools, but the traditional schools subjected students to greater amounts of lecture/watching videos than was seen in the non-traditional school. They found a similar trend regarding independent work. The nontraditional school offered many more opportunities for students to collaborate and work cooperatively. Group discussion and student presentations were almost non-existent in the traditional school in comparison to the non-traditional setting. The students in the non-traditional setting were more engaged by all instructional methods than the students in the traditional setting. There was more relational learning in the non-traditional school, so students experienced the components of concentration, interest, and enjoyment in all instructional activities.

This implies yet again that the role of the teacher must change to the extent that teachers are more versed in engaging instructional methods that move away from the traditional methods of instruction. While this requires a certain effort on the teacher up front there seems to be a pay off during and after the instruction if student engagement is improved and the students and the teachers experience higher outcomes.

Johnson (2008) recommends further research into what is the content of negotiation and in who, teacher or student, has agency in the negotiation. Furthermore, 
there is a need for a better understanding of the discursive practices in instructional situations in order to find ways of supporting teachers in the engagement of students.

Biddulph (2011) concluded that the four types of talk supported the critical evaluation of the pedagogical practices around the young people's geography that attempted to give students more voice. As it relates to teachers, giving up some of the control over curriculum to students was risky as teachers become more innovative in how they teach. Biddulph acknowledged that there would need to be some policy change in order to implement student voice in this way, but the larger challenge was in getting teachers to shift radically from what they did traditionally, as they were still ultimately responsible for the curriculum. This led to the realization that there was a challenge for teachers in navigating school policy and curriculum change. There were tensions for teachers as this project proceeded. It was stated that these tensions need to be further investigated such as the reconfiguration of teaching curriculum making responsibilities and how to be vigilant about who gets heard and how their voices are accounted for.

Biddulph (2011) highlights one of the challenges to the implementation of personalized learning. It requires teachers to relinquish control of responsibilities that have traditionally been in their control. In some cases, this can be risky as it was in Biddulph (2011). In other cases, it is simply a matter of the teacher struggling to step out of the comfort zone. It does bear attention, however, that in order to help teachers in making this shift, there is some measure of attention needed in policy and procedure so that teachers feel supported in the efforts.

Courcier (2007) examined teachers' perceptions of personalized learning in the United Kingdom. Courcier notes that personalized learning is not just one specific 
learning style and it has some similarity with individualized learning and differentiation. Perhaps the more important point of this study is that personalized learning is a procedure of teaching and learning. This is a key statement because it implies that both teachers and students must take ownership for their part in the teaching and learning process.

The teachers interviewed in this study, while believing the concept of personalized learning is good, believed it is very hard to implement in practice within the classroom. Courcier concluded that implementing personalized learning without a complete understanding of what it is mitigates its effectiveness. For students to find success and develop into independent learners the teachers must have a clear understanding of personalized learning and its implementation.

In a study to determine what personalized learning means for faculty and how it should serve students, Waldeck (2006) stated that there was a need for further research when defining personalized education. The result of this study was to conclude that it is likely to get five different answers from five different faculty members on the same campus when asked for a definition of personalized learning. Redirecting the question to five students on the same campus would result in five more disparate answers. Absent is a synthesis of the common themes of personalized learning, such as student/faculty relationships, small class sizes, and collaborative learning opportunities into a model that is clear to facilitate. While Waldeck examined personalized learning on college campuses, it evinces the problems seen in public school settings, as there is great latitude in how each school implements personalized learning due to the many ways in which educators define personalized learning. In recalling the four elements of personalized programs put forth by the Gates Foundation, the fourth element is a flexible learning 
environment. The flexible learning environment is connected to student agency in how it allows students flexibility in access to teachers and how they use time and space (Bill \& Melinda Gates Foundation, 2014; Hamilton et al., 2014). While the elements of personalized learning discussed can be implemented without the use of technology, when used as a tool to enhance the personalized learning experience it can have great benefits to both the student and the teacher.

O'Keeffe et al. (2006) points out that attempting to customize courses to a learner's prior knowledge and personal preferences is not something that is new in education. There are numerous forms of computer-based programs to assist teachers in this process. In the past there has been a very important aspect of personalized learning that was left out of such programs. There has been little to no thought given to pedagogy, which would again imply a focus on the changing role of the teacher. Sahabudin and Ali (2013) focused on learning materials and learning style. Because personalized learning is flexible learning allowing students to work with learning materials, it was initially implemented due to an increased awareness of aspects of student diversity such as learning styles, attitudes, interests, thinking skills, and ability to learn to name a few. Each of these aspects may determine the personalized learning path of a particular student.

While student learning styles are vital to personalizing the learning path of a student, the absence of appropriate pedagogical strategies (O'Keeffe et al., 2006) places a limit on the effectiveness to which the student can learn. When the appropriate pedagogical strategies are utilized, O'Keeffe et al. (2006) ascribe that learning objects can be created that are not only appropriate for what the student wants to learn, but it will 
also be appropriate to how the student wants to learn. This depends on building a personalized learning path through a selector service that focuses on knowledge domains consisting of concepts with consideration of student and teacher preferences. This allows the personalized course to meet both the preferred mode of learning for the student and the preferred mode of teaching for the teacher. Neither the teacher nor the student is likely to arrive at this end without some assistance from technology.

The need for technology, however, goes beyond simply having a platform to deliver instruction. Simply getting the content taught in an online environment does not meet the full definition of personalized learning. Basham et al. (2016) affirms that more than technology is required in personalized learning environments. The more important aspects of personalized learning are highly, self-regulated learners, as well as transparent and actionable real-time data. Technology in and of itself is just the tool for implementation unless it provides the means for access to real time data. Pane et al. (2015) identified the use of data from multiple sources as a key strategy for student learning success in personalized learning. Teachers having access to real time data, analyzing that data and meeting one on one with students to set specific learning goals, and helping the student create the path to mastering those goals is a break from the one size fits all education of the traditional model of education.

\section{The Changing Role of the Teacher in K-12 Education}

Since the latter decades of the 20th century, there have been numerous efforts to reform education in the United States. This reform has usually taken the shape of programs and initiatives that have the intent of perfecting the traditional model of education instead of seeking to transform formal education through a model that is 
relevant in the world today (Johnson \& McElroy, 2012). Throughout the era of school reform, policymakers called upon K-12 teachers and educational leaders to change what they are doing — dictated by federal, state and/or district levels. It may come from the implementation of new initiatives and programs or due to the changes in the system of assessment and accountability (Finley, 2000).

In order to define the changing role of the teacher in k-12 education, it is important to look briefly at what has been the traditional role of the teacher. For most of the history of education in the United States, the role of the teacher has been as the gatekeeper of information. The only access students had to knowledge and information was through the teacher. While this was a valid and important role 30 to 40 years ago, the classroom is no longer the focal point of disseminating information to students (Johnson \& McElroy, 2012). The challenge of past school reforms is that they were often grounded in ideas and policies. There was no serious intent for a change to the "core of schooling." There were vague intentions to improve the core, but only through weak modifications. There was no change to the "core" of educational practice, that is, how the teachers understand knowledge and learning and how they operationalize it in the classroom (Elmore, 1996). It is the teacher who must bring the components of any program, initiative, or reform together with an intentional focus on having a successful impact on student learning (Finely, 2000). The traditional role of the teacher has been to change what they were doing, but not how they were doing it.

For teachers to be able to change what they are doing as well as how they are doing it, they must take on the role of being a learner, collaborator (Finley, 2000), and a leader (Johnson \& McElroy, 2012). The role of the learner may first require letting go of 
prior knowledge as it relates to teaching in order to improve professionally (Straus, 1962). Spillane, Reiser, and Reimer (2002) argue that prior knowledge can affect sense making. This determines how teachers interpret policy or reform and can lead to them misunderstanding the intent altogether. This in turn will hinder their capacity to accept and, therefore, learn, how to implement change. Johnson and McElroy (2012) describe two core skills that teachers of the 21 st century need to master in order to create the best learning environment. These are operational and interpersonal skills. The operational skills include lesson planning, multi-managing, and managing and organizing the classroom. These are not drastic changes from the traditional role of the teacher. That comes in the realization that lessons need to be relevant to the lives of students so that they will take ownership in their learning. The interpersonal skills include developing authentic relationships and creating a respectful environment.

While content knowledge is important, as it has been traditionally, the teacher must learn more than just content to be successful in the 21st century. McLaughlin (1987) asserted that in implementing any reform requires capacity and will. Capacity, knowledge, and skills are possible through training in which the teacher increases capacity through learning how to implement the reform successfully (Gross \& Goldhaber, 2006). Teachers must already possess or seek to develop collaboration, which is connected to the interpersonal skills in that the new role for teachers requires collaboration with teacher, student, and parents (Finley, 2000). In the collaborative mode the teacher can learn from colleagues, students and parents to enhance teaching and learning. Since teachers are the single, most important aspect of student learning it is important now more than ever that teachers become leaders in the field. They are the 
leaders in their classrooms, but their voices need to reach beyond the classroom. Traditionally teachers have had little to no voice in policies and reforms. While most policymakers consider teachers to be the driving force of educational reform, most reforms have been directed at teachers (Schmidt \& Datnow, 2005). If educational reform in the future is to be effective, teachers must be a part of the reform. It is their responsibility to be vocal in their school, in their community, and beyond (Johnson \& McElroy, 2012).

The role of the teacher implementing personalized learning is not very different than it is for the teacher implementing comprehensive school reform in that the teacher must become a learner, collaborator, and communicator. Personalized learning forces the role of the teacher to change as it is moving away from the teacher leading whole class instruction to teach a single lesson (Childress \& Benson, 2014). The teacher has a dual role as a teacher-coach and as a teacher-advisor (Keefe \& Jenkins, 2002). In personalized learning, the teacher is more of a facilitator of learning, managing the learning through small group and individual instruction and utilizing project-based learning and usually an online platform to some extent (Hassel \& Hassel, 2011). More importantly, teachers must learn to facilitate and monitor groups of students in the use of technology (Bingham et al., 2018). Teachers implementing personalized learning must learn new ways of planning, organizing, and managing the classroom as well as how to effectively collaborate and communicate with students. This is completely different from how most teachers have been trained (Grant \& Bayse, 2014). Although Johnson and McElroy (2012) were not referring to personalized learning, their core operational and interpersonal skills are vital to teacher success in implementing personalized learning. In 
personalized learning, the teacher provides materials to students in different forms such as playlists of audio or video to help students reach their academic goals working at their own pace. This allows the teacher to focus on the individual needs of all students and emphasizes the importance of collaboration and communication as feedback between student and teacher must be as immediate as possible (Childress \& Benson, 2014).

The role of teacher learner is the most vital for the implementation of personalized learning. Along with learning, the teaching skills required of the teacher in personalized learning, teachers must learn to surrender some of the control they would normally have in the traditional classroom. Student choice and voice become more vocal in personalized learning and teachers who have limited experience with student choice will need support (Nectoh, 2017). It is important to help teachers learn how to involve students in the learning process in order to reach the full potential of improvement to student learning and engagement though personalized learning (Ferlazzo, 2017).

\section{Literature Review Summary}

The literature review revealed that personalized learning as a model of teaching and learning has increased greatly over the last decade. This is due to federal policies such as Race to the Top and foundations such as the Gates Foundation pushing to expand personalized learning into schools across the United States. Over the last five years

advancements in technology and the development of digital tools and online learning platforms, particularly blended learning models, have led to even higher implementations of the personalized learning model throughout The United States. 
The research has also shown that personalized learning is not an easy concept to define, implement, or operationalize in the classroom. Definitions range widely. Various models of personalized learning exist in which personalization occurs with little use of technology, some that rely almost completely on technology, and others that are a blended model. Despite the unique and varied models, there are generally four components consistent across programs: learner profiles, personal learning paths, mastery learning, and flexible learning environments. It is through these components that personalized learning is potentially able to increase student motivation and engagement through student agency, which encompasses student voice and choice in their learning. Student agency is an area that creates some tension for educators since there can be a misconception that agency means "freedom". Two of the studies in this review point to the fact that student agency does not mean full autonomy for the student with no oversight for the teacher. There are boundaries that need to be set, and this once again goes back to the changing role of the teacher. The teacher must set those boundaries and must be able to release some agency to the students without giving over completely to the students. This requires both support for the teacher in methods of instruction and in policy design as well. Teachers can be reluctant to give up certain control due to risks they face due to policy and regulations.

The use of non-traditional instructional methods aids in increasing student engagement. The role of the teacher as a facilitator in the classroom, allowing students to engage in active modes of learning, is essential. In traditional settings, students are usually not the doers. It is the teacher doing the work. Non-traditional methods give students active experiences of learning. They are the doers in the classroom and therefore 
more heavily engaged. As the research shows, for these non-traditional methods to be successful there needs to be a certain degree of student agency and student voice in the lesson and the material learned. It is also important that students have agency and voice in the process of learning as well. There is a limit to how much voice they should have, as teachers are accountable for the curriculum.

The teacher's role in personalized learning must change and this greatly influences teaching in a personalized setting and therefore, greatly influences individual teachers. The studies discussed in this review have found that the personalized setting can have positive effects on the engagement of students if the teacher correctly implements the lesson and the environment for personalized learning. The role of the teacher must change for the personalized environment to garner positive results. The most notable change that teachers would need to undergo is the ability to release some of the control they have traditionally had and turn those responsibilities, to a degree, over to students. The shift is dramatic in that the teacher is no longer disseminating knowledge to their students but acting as facilitators of learning. This is completely different from how most teachers were trained.

In this literature review, I focused on the idea that educational transformation has been in the works for decades, going back to CSRP. In reviewing literature on CSRP, it is consistently apparent that regardless of the reform, implementation is extremely important to successful student outcomes as well as sustaining the reform long term. I have also approached the literature regarding the changing role of the teacher through school reform. Because teachers are the centerpiece of any instructional initiative, their role must change for implementation of any reform to have positive outcomes. The 
literature provides perspectives to understand personalized learning and the role of the teacher in school reform. The findings of this study may help schools pursuing a similar change process to engage the reflections of the teachers' experience in the implementation of any innovative change to teaching and learning.

Chapter 3 outlines the research methodology and design, including the purpose, design, data collection and data analysis procedures. The chapter also includes a discussion of the study's limitations, credibility, and ethical issues. 


\section{CHAPTER 3: METHODOLOGY}

In this study, I explored teacher perceptions of personalized learning and their overall experience during implementation. I sought to understand how teacher perceptions of their role in the process of teaching and learning have changed (if at all) because of the personalized learning initiative. Additionally, I examined the perceptions of teachers regarding the professional support needed through the implementation of personalized learning. There are four research questions guiding this study with the first serving as an overarching driving question and the subsequent three delving into the impact on the teacher experience.

1. How do teachers define personalized learning?

2. How do teachers describe their role within the personalized learning framework?

3. Why has implementing personalized learning been successful and/or challenging?

From the teacher perspective?

4. How did teachers perceive their preparation programs as assisting or inhibiting teachers' transitions to the personalized learning model?

The purpose of Chapter 3 is to describe, and supply justification of the research methodology chosen for this qualitative case study. This chapter sets forth the research 
process that I used to answer the previously stated research questions of teacher experiences with personalized learning. In terms of structure, I organized Chapter 3 as follows. First, I began by presenting and rationalizing the selection of my research design (a qualitative case study) and the limitations of this analytical strategy. I then went into the context of the qualitative case study. I next explained the various data sources and the corresponding data collection procedures that I used to collect them. I then reviewed the ethical considerations connected to my study followed by the process by which I analyzed the data collected. As a scholar-practitioner undertaking research in the school district in which I was at one time employed, I discussed the process by which I explored my positionality and relationship with the topic, teachers, school, and district in which the study took place. Lastly, I explained the strategies by which I ensured credibility, transferability, dependability, and confirmability of the findings I produced.

\section{Research Methods and Design—Qualitative Case Study}

In this study, I engaged in qualitative research in order to gain a deeper insight into the phenomenon of personalized learning through the views of the teachers participating in the process of implementation (Creswell \& Creswell, 2018). The research questions stated above relate to the purpose of the study and provided the framework for the final description of the study (Bloomberg \& Volpe, 2012). There are many characteristics involved in qualitative research such as (a) the researcher as the key instrument of data collection; (b) qualitative research normally occurs in the natural setting of the participants; (c) the researcher relies on multiple sources of data; and (d) the analysis of the data is both inductive and deductive. The qualitative process is constantly focused on learning the meanings held by the participants and the research design is 
emergent. The researcher must be reflective of personal background and the researcher is seeking to create a holistic picture with the data collected (Creswell \& Creswell, 2018).

My study is of a single case holistic design with a common rationale (See Figure 1). It is looking at one single case (a rural school district) and the perceptions of the teachers in that school district regarding the implementation of personalized learning. Because this study has an objective of trying to capture circumstances and conditions of an everyday situation, the daily perceptions of the teachers as they implement personalized learning, it follows the common case rationale of a single case study (Yin, 2018).

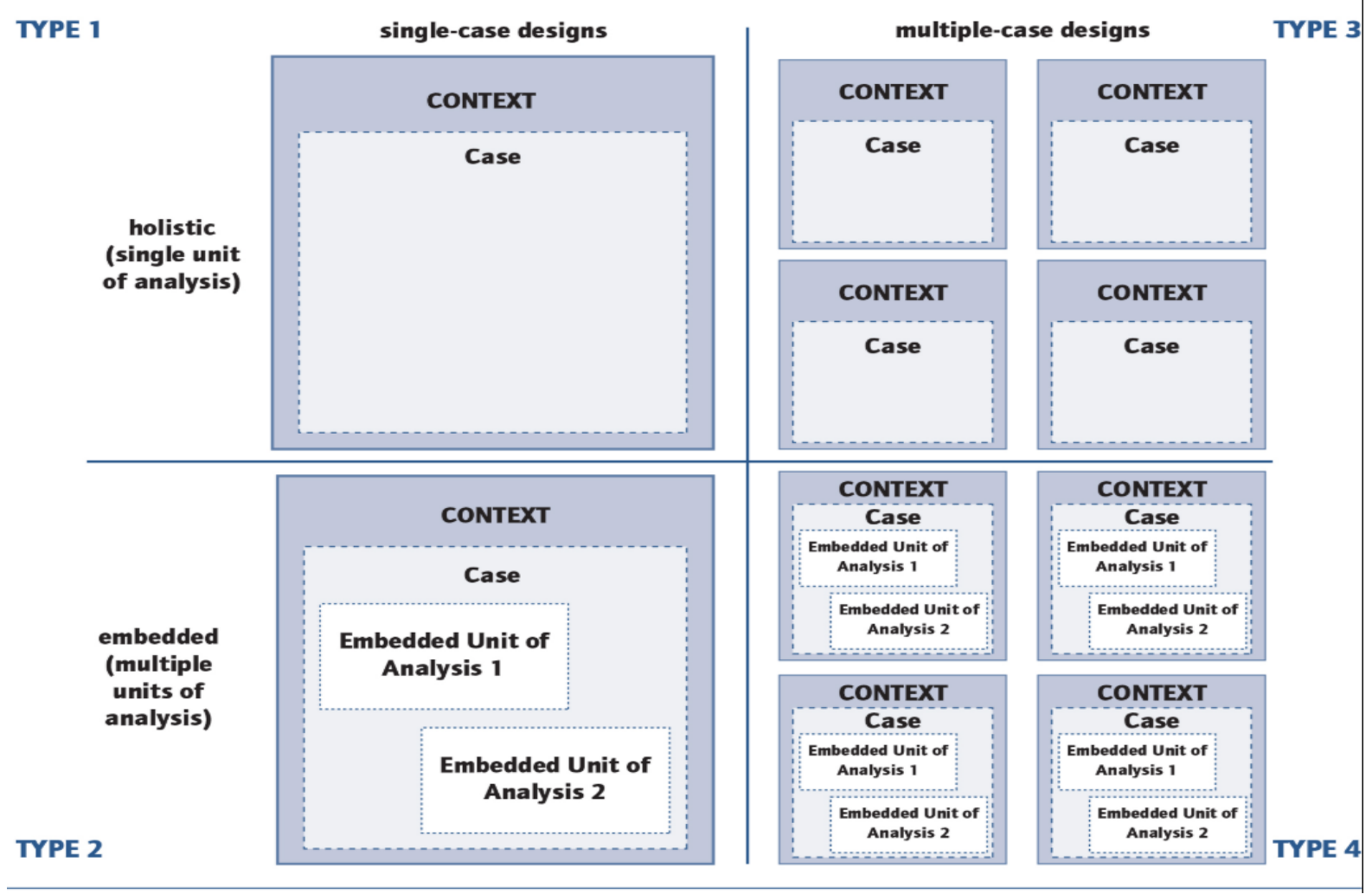

Figure 1. Yin's (2018) Typology of Case Study Designs 
The case study design focused on questions that began with the term how and why in order to provide in-depth research and exploration of teachers' experiences (Yin, 2018). It is explanatory due to the nature of the research questions, which deal with the following of an operational process - the implementation of personalized learning over time. The asking of how and why questions meets the first of three conditions for determining the type of case study. As the researcher, I have no control over the behavioral events regarding the experiences of the teachers as they implement personalized learning and the implementation of personalized learning is a contemporary event on which my study will focus. My study, therefore, meets the criteria for a case study research design (See Table 1).

Table 1. Yin's (2018) Relevant Situations Different Research Methods

\begin{tabular}{|l|c|c|c|}
\hline \multicolumn{1}{|c|}{ Method } & $\begin{array}{c}\text { Form of Research } \\
\text { Question }\end{array}$ & $\begin{array}{c}\text { Requires Control Over } \\
\text { Behavioral Events? }\end{array}$ & $\begin{array}{c}\text { Focuses on } \\
\text { Contemporary } \\
\text { Events? }\end{array}$ \\
\hline Experiment & How, why? & Yes & Yes \\
\hline Survey & $\begin{array}{l}\text { Who, what, where, } \\
\text { how many, how much? }\end{array}$ & No & Yes \\
\hline $\begin{array}{l}\text { Archival } \\
\text { Analysis }\end{array}$ & $\begin{array}{c}\text { Who, what, where, } \\
\text { how many, how much? }\end{array}$ & No & Yes \\
\hline History & How, why? & No & No \\
\hline Case Study & How, why? & No & Yes \\
\hline
\end{tabular}

In this study, I examined the perceptions of a small sample of teachers to understand how the implementation of personalized learning has changed their roles and their experiences through the process of implementation. In this study, I collected thick descriptions from a particular site, individuals, group, and occupation. Finally, the participants and I (the researcher) both played a role in constructing experiences. 


\section{Strengths and Limitations of Qualitative Case Studies}

While case studies are considered as a viable means of conducting qualitative research (Creswell \& Poth, 2018), it had long been misconceived as being research that was limited solely to conducting fieldwork (Yin, 2018). Case study research has, however, had a distinguished past across various disciplines (Creswell \& Poth, 2018). Yin (2018) defines case study as an empirical method investigating a contemporary phenomenon in depth, within its real-world context and specifically when the lines between the phenomenon and the context are not clear. Case studies, therefore, do not

just examine the studied phenomenon, but also considers the contextual implications of the phenomenon. Case study research is an approach having its own logic of design and techniques for collecting and analyzing data (Yin, 2018).

The limitations of case studies are based on rigor of the study (Creswell \& Poth, 2018; Yin, 2018), confusion with "non-research" studies, inability to generalize from case studies, and the time and effort involved (Yin, 2018). Some of the concerns with case study research are due to poor quality designs and there is existing evidence to support this concern. There has been significant growth in recognition and use of case study research over the past 30 years and it is now encouraged as a method of conducting qualitative research (Creswell \& Poth, 2018).

\section{Context of the Study}

My qualitative case study took place in a small school district in rural Kentucky that began the implementation of personalized learning in 2017. Data from the school report card and state student assessments performance historically suggested that the current system was failing to meet the needs of the students of Trimble County Public 
School (TCPS). After 3 years, the state released Trimble County Junior/Senior High School from PLA (persistently low-performing accountability) status at the beginning of the 2016-2017 school year. At that time, there was improvement in both graduation rates and overall test scores, yet elementary, middle, and high school students continued to underperform in reading, math, and overall college readiness measures by state standards. At the end of the 2017-2018 school year, the middle and high schools physically merged due to a historic trend of declining enrollment. At the start of the 2018-2019 school year, the newly consolidated school opened as Trimble County Junior/Senior High School consisting of grades 7 through 12. Students in the $6^{\text {th }}$ grade were divided among the district's two elementary schools. Based on the results from the 2017-2018 accountability cycle, the state identified the middle school as a TSI Targeted Support and Improvement (TSI) school by the state department of education due to inadequate standardized test scores of students receiving free/reduced lunch. The annual trend of declining enrollment has continued for TCPS (See Table 2), and the diversity among its student racial demographics is limited (See Table 3).

Since exiting TSI status, accountability outcomes have failed to have significant gains (See Tables 4, 5 and 6). As a means to seek improvement TCPS educational leaders engaged in a collaborative process to reimagine the structure of school and how the curriculum and instruction is delivered, seeking to personalize learning (student agency with: pace, path, place, and voice) for students and to support parents as TCPS strives to prepare learners to be successful for a rapidly changing future.

Based upon the State School Report data for the 2018-2019 school year, the teaching staff of TCPS consisted of 67 certified teachers of which 57 are female and 10 
are male. The racial/ethnic make-up of the teaching staff consists of 66 teachers of white (non-Hispanic) and one teacher identified as Asian. The average level of teaching experience of TCPS teachers is 14 years and there are 6 first year teachers. The teaching staff has a high percentage of experienced teachers with a master's degree or above (See Table 7). Of the teaching staff, $7.5 \%$ are National Board-Certified teachers and $4.2 \%$ hold an emergency/provisional credential. The teacher turnover rate in TCPS is $64 \%$ and the student to teacher ratio is $16: 1$.

Table 2. Enrollment Trends, Trimble County School District and Trimble County Junior/Senior High School, 2016-2017 to 2020-2021

\begin{tabular}{lcccccc}
\hline \multicolumn{1}{c}{ School } & $\begin{array}{c}\text { Actual 2016- } \\
17\end{array}$ & $\begin{array}{c}\text { Actual 2017- } \\
18\end{array}$ & $\begin{array}{c}\text { Actual 2018- } \\
19\end{array}$ & $\begin{array}{c}\text { Projected } \\
2020-21\end{array}$ & $\begin{array}{c}\text { Change } \\
\text { Change }\end{array}$ & $\begin{array}{c}\% \\
\text { JR/SR }\end{array}$ \\
HS & 585 & 567 & 553 & 530 & $(23)$ & $-4 \%$ \\
\hline District & 1257 & 1185 & 1180 & 1114 & $(66)$ & $-5 \%$
\end{tabular}

Table 3. Demographics, Trimble County Junior/Senior High School (2018-2019)

\begin{tabular}{|l|r|r|}
\hline \multicolumn{1}{|c|}{ Demographic } & \multicolumn{1}{c|}{ N } & \multicolumn{1}{c|}{$\%$} \\
\hline School \% White & 499 & 95 \\
\hline School \% African American & 3 & .5 \\
\hline School \% Hispanic & 13 & 2 \\
\hline School \% Asian & 3 & .5 \\
\hline School \% Native American & 1 & .2 \\
\hline School \% Hawaiian/Pacific Islander & 2 & .3 \\
\hline School \% Multiracial & 5 & 1 \\
\hline School \% Male & 272 & 52 \\
\hline School \% Female & 254 & 48 \\
\hline School \% Free/Reduced Lunch & 292 & 55.5 \\
\hline School \% ELL & 5 & 1 \\
\hline School \% ECE & 46 & 9 \\
\hline School \% Gifted & 114 & 22 \\
\hline
\end{tabular}

Table 4. School Performance Indicators, 2016-2017

\begin{tabular}{|c|c|c|c|c|c|c|}
\hline $\begin{array}{l}\text { Grade } \\
\text { Levels }\end{array}$ & Content Area & Novice & Apprentice & Proficient & Distinguished & $\begin{array}{c}\text { Proficient/ } \\
\text { Distinguished }\end{array}$ \\
\hline $7-8$ & Reading & 26.4 & 21.8 & 36.3 & 15.5 & 51.8 \\
\hline
\end{tabular}




\begin{tabular}{rlrrrrr}
\hline & Mathematics & 30.6 & 42.5 & 20.2 & 6.7 & 26.9 \\
Science & - & - & - & - & - \\
Social & 14 & 32.3 & 37.6 & 16.1 & 53.8 \\
Studies & & & & & \\
& Writing & 15.1 & 40.9 & 34.4 & 9.7 & 44.1 \\
\hline \multirow{4}{*}{$9-12$} & Reading & 41.7 & 9.3 & 40.7 & 8.3 & 49.1 \\
& Mathematics & 31.8 & 35.3 & 27.1 & 5.9 & 32.9 \\
& Science & 34.7 & 45.3 & 20 & 0 & 20 \\
& Writing & 22.4 & 32.9 & 38.2 & 6.6 & 44.7 \\
\hline
\end{tabular}

Table 5. School Performance Indicators, 2017-2018

\begin{tabular}{|c|c|c|c|c|c|c|}
\hline $\begin{array}{l}\text { Grade } \\
\text { Levels } \\
\end{array}$ & Content Area & Novice & Apprentice & Proficient & Distinguished & $\begin{array}{c}\text { Proficient/ } \\
\text { Distinguished }\end{array}$ \\
\hline \multirow{5}{*}{$7-8$} & Reading & 26.0 & 21.9 & 35.4 & 16.7 & 52.1 \\
\hline & Mathematics & 24.0 & 48.6 & 21.2 & 6.3 & 27.4 \\
\hline & Science & 18.0 & 62.0 & 18.0 & 2.0 & 20.0 \\
\hline & $\begin{array}{l}\text { Social } \\
\text { Studies }\end{array}$ & 16.7 & 30.2 & 44.8 & 8.3 & 53.1 \\
\hline & Writing & 12.5 & 49.0 & 33.3 & 5.2 & 38.5 \\
\hline \multirow{4}{*}{$9-12$} & Reading & 31.7 & 23.2 & 31.7 & 13.4 & 45.1 \\
\hline & Mathematics & 28.6 & 39.3 & 32.1 & 0.0 & 32.1 \\
\hline & Science & 28.0 & 52.4 & 18.3 & 1.2 & 19.5 \\
\hline & Writing & 18.1 & 36.1 & 36.1 & 9.6 & 45.8 \\
\hline
\end{tabular}

Table 6. School Performance Indicators, 2018-2019

\begin{tabular}{rlrrrrr}
\hline $\begin{array}{c}\text { Grade } \\
\text { Levels }\end{array}$ & Content Area & Novice & Apprentice & Proficient & $\begin{array}{c}\text { Distinguished } \\
\text { Proficient/ } \\
\text { Distinguished }\end{array}$ \\
\hline \multirow{4}{*}{$7-8$} & Reading & 25.3 & 22.1 & 35.8 & 16.8 & 52.6 \\
& Mathematics & 24.7 & 49.5 & 21.1 & 4.7 & 25.8 \\
& Science & 30.4 & 47.8 & 21.7 & 0 & 21.7 \\
& Social & 12.2 & 44.9 & 35.7 & 7.1 & 42.9 \\
& Studies & & & & & \\
& Writing & 26.5 & 53.1 & 15.3 & 5.1 & 20.4 \\
\hline \multirow{4}{*}{$9-12$} & Reading & 30.3 & 23.7 & 34.2 & 11.8 & 46.1 \\
& Mathematics & 38.7 & 30.7 & 30.7 & 0 & 30.7 \\
& Science & 31.1 & 45.9 & 23 & 0 & 23 \\
& Writing & 18.9 & 47.3 & 27 & 6.8 & 33.8 \\
\hline
\end{tabular}

Table 7. Trimble County School District Educator Qualifications

\begin{tabular}{l|l} 
Associate's & $1.5 \%$
\end{tabular}




\begin{tabular}{|c|c|}
\hline Bachelor's & $14.9 \%$ \\
\hline Master's & $56.7 \%$ \\
\hline Rank I & $25.4 \%$ \\
\hline Specialist & $0 \%$ \\
\hline Doctorate & $1.5 \%$ \\
\hline
\end{tabular}

Due to the need for TCPS to address the needs of providing the best educational experiences and opportunities for its students while facing constantly declining resources, the personalized model of education became a viable and enticing option for providing optimal educational services. District and school personnel first learned about personalized learning through a statewide leadership academy in conjunction with a major state university and a regional educational cooperative. School administrators, teachers, and parents initially researched the innovative approach of personalized learning through site visits to districts and schools within and outside of the state in order to build an understanding of personalized learning and its benefits to students.

The knowledge gained from the site visits led to the belief by district and school personnel that the traditional model of teaching and learning were no longer effective for today's students nor does it prepare students to compete successfully on the global level. Personalized Learning strategies were implemented in conjunction with a Graduate Profile that was made up of student competencies. Since the competencies were based on 21st Century learning skills it was believed the personalized learning model provided a much better opportunity for students to master not only their academic requirements, but also develop the competencies needed to compete globally. 
The personalized learning model utilized provided an online platform (Summit Learning) that allowed students to access resources, complete courses at their own pace in any place. There are, however, two other parts of the model that are much more important than the online platform. Those other parts are project time for students to apply their knowledge and work collaboratively and mentoring time. Teachers utilize data from the online platform to target instruction and help students set goals through a consistent mentoring regimen. Due to the data from the online platform, students can pretest and avoid lessons covering content they already know, and teachers can focus on planning workshop lessons to teach standards and concepts that students have not yet mastered.

Through the Summit Learning Platform TCPS in grades 5 through 12 are participating in personalized learning in each of the core content classes (English language arts, math, science, and history). The Summit Learning Platform developed was in 2004 with a mission to provide schools and districts with a curriculum aligned with state standards in the core classes for grades 4 through 12 . One of the components that was vital was the ability for teachers to customize the lessons, projects, and assessments. Competency based learning is also a foundational component of Summit Learning (Summit Learning, n.d.).

Other districts exploring the potential implementation of personalized learning may be able to make use of the findings of my study. TCPS, like most other districts, is committed to continuous improvement through improving student performance outcomes, addressing achievement gaps, and ensuring students leave school prepared for college and career success. My study focuses on the perceptions of teachers during the 
implementation of personalized learning. The district chosen is in its third year of implementation and has made various adjustments throughout the process with continuous input internally through staff reflection; and externally through seeking feedback from partners outside of the district. While the adjustments have involved teachers, the focus is on how to give the best possible experience to students through personalized learning and how to address concerns among parents and community members. There remains to be any in depth investigation as to the implementation from the perspective of the teachers.

\section{Data Sources}

I utilized data collected from three sources: a teacher survey, Group Level Assessment (GLA), and documents pertaining to district and school level curriculum and professional development. My initial data collection was through the Climate and Culture Middle and High School Teacher Survey tool (See Appendix A). I collected this survey data from three years of survey administrations. The survey tool collects data from teachers in order to make informed decisions while seeking continuous improvement. This survey provided an overall view of teacher perceptions regarding the climate and culture and their experiences as a teacher to inform questioning during the GLA. The survey measures teacher perceptions on professional practice and environment. The survey consisted of eight items related to students in their classrooms, interactions with colleagues, and their workspace.

I collected additional data through the GLA process. This is a participatory method of gathering data in place of person-to-person interviews. The number of teachers with knowledge and experience in implementing personalized learning is limited 
(Palinkas et al., 2015). I selected a purposive sample of approximately 8 teachers from across grades 5 through 12 in either their second or third year of experience implementing personalized learning in their classroom. Furthermore, I selected teachers purposely to ensure diverse representation across subpopulations; specifically, by gender, years of experience as a teacher, years of experience teaching in personalized learning, and level of education attained. The GLA process consisted of 7 steps allowing participants to respond and interact with a set of prompts (See Appendix B), on their experiences implementing personalized learning. The GLA process was conducted virtually over the course of one hour...

Finally, I analyzed school and district documents in order to identify the policies and practices set forth by the district in relation to implementing personalized learning. As this is a case study about individual teacher perceptions of their experiences implementing personalized learning, these documents may serve as a means of triangulating data from other sources (survey and GLA data).

\section{Data Collection Procedures}

The first collection of data I conducted came from the teacher climate and culture survey data administered by the school district as part of the strategic planning process of evaluating and improving all aspects of the district. Each year as a part of the continuous improvement and accreditation process, the teachers complete the 8-question online survey. The data from the survey is accessed through the eProve Survey platform. Teacher participation in the survey is voluntary and anonymous. The surveys I utilized are from the 2017-2018, 2018-2019, and 2019-2020 school years which allowed a pre and post personalized learning view of this data. 
Following the administration of the surveys I utilized the qualitative method of Group Level Assessment (GLA) as it is grounded in action research and is a participatory process that allows for equal opportunity for all participants to have input and voice in the generation of data, evaluation of the data, and action planning (Graham, Schellinger, \& Vaughn, 2015). The GLA method has proven to be a participatory alternative for large groups compared to traditional methods of qualitative research such as individual interviews and focus groups (Vaughn, 2014). The benefit of GLA is that it is a much faster way to generate data than the more conventional methods of interviews and focus groups (Vaughn \& Lohmueller, 1998). GLA represents a simple, engaging, and exciting way to generate qualitative research data publicly and visibly (Reddy, 1996).

I provided teachers with an invitation to participate and information regarding participation in the Group Level Assessment. Further information included access to information contained in the informed consent form (See Appendix D). Teachers who expressed interest in participating in interviews received consent forms, approved by the University of Louisville Institutional Review Board. Only teachers who communicated an interest in participating and returned the consent form participated in the study. Teachers were offered every opportunity to communicate with me should they have any questions about participating in the research.

The final collection of data came from an analysis of school and district documents pertaining to the implementation of personalized learning. These documents consisted of: district strategic plan, school and district continuous improvement plans, minutes and/or agendas from SBDM (School-Based Decision Making Council) and board meetings, school and district policies, and the district professional development plan in 
order to determine whether the practices and policies support the data collected from teachers in the surveys and through the GLA process. These documents provided a chronological context to the process of implementing personalized learning from the beginning to the present.

\section{Ethical Considerations}

Using Structured Ethical Reflection (SER) I used seven values to guide this study ethically (Brydon-Miller, Rector Aranda, \& Stevens, 2015). The SER process, developed by Brydon-Miller, seeks to address the needs of those working in the field of action and community-based research (Stevens, 2014). The seven values I chose were integrity, social responsibility, open mindedness, honesty, trust, responsibility, and commitment. Three of these, integrity, honesty, and trust are closely related. These values are important to me personally and professionally. They must be the foundation of any research for the research to be valid. It is my desire that this study meet the requirements of these values.

The other three values are social responsibility, responsibility, and commitment. The topic of this study, the changing roles of teachers through the implementation of personalized learning, has the potential to have some impact on society by not only helping to begin the process of changing how the educational system evolves, but how the roles of teachers will change as well. This last part has implications on teacher prep programs, which is the hole in the research regarding personalized learning.

Responsibility and commitment are vital, as I must be responsible to the university, the field of research, my profession, and the participants from start to finish. Both responsibility and commitment will help the study to be completed successfully 


\section{Data Analysis}

Data analysis in qualitative research can be challenging (Creswell \& Poth, 2018). One of the least developed aspects of case studies is data analysis (Yin, 2018). The process of analyzing data is about segregating the data, breaking it up and putting it back together in a meaningful way (Creswell, 2018). Throughout the process interacting with the goal is to identify patterns, insights, and concepts that may emerge through manipulation of the data (Yin, 2018). To facilitate this process, a researcher may employ several strategies. Ways in which to play with the data are by reflecting on themes and subthemes by putting the information into arrays, using matrices of contrasting categories, creating visual displays such as flowcharts, tabulating frequency of specific events, and sequencing information chronologically. These strategies help the researcher move toward a general analytic strategy Yin, 2018).

Survey. EProve Surveys provided the climate and culture survey that I utilized. After completing survey data collection, from the 2017-2018, 2018-2019, and 2019-2020 school years I conducted descriptive analyses of the data. I presented the data analysis as visualizations, such as tables depicting the most frequent responses given by teachers to identify any trends or patterns in the data. The table visualizations helped me to have a vague feeling of teacher perceptions toward what students were doing in their classrooms, relationships with colleagues, and their workplace in general to sum up their perceptions of the climate and culture of the school. More importantly this data gave insight to the climate and culture prior to and after the implementation of personalized learning in the district. 
Group Level Assessment (GLA). The next phase of data analysis consisted of the coding of data from the prompts used in the GLA and the transcripts from the recordings of the small group's segments of the GLA. I analyzed GLA data through open, axial, and selective coding. I used categories based upon the coding paradigm of Strauss \& Corbin (1998). In the coding paradigm there are four categories for analyzing data through coding; (a) the phenomenon being studied, in this case personalized learning; (b) conditions related to that phenomenon such as context conditions; (c) actions and interactional strategies directed at managing the phenomenon; and (d) consequences of the actions and interactions related to the phenomenon. Open coding occurred during step five of the GLA as the initial responses of the participants were collected. Those responses were then disaggregated by small groups into categories and subcategories based upon the similarities and differences of the responses. This type of coding is appropriate when there are multiple participants interviewed at different school sites (Miles, Huberman, \& Saldana 2014). The process of open coding focused mainly on looking at the phenomena of personalized learning. I utilized axial coding, as described by Saldana (2016), in step six as the whole group then compared the categories to the subcategories. The process of axial coding looked at the data through the conditions, action and interactional strategies, and the consequences contexts. Selective coding occurred after the GLA as I worked to amalgamate the categories around the central category, or the studied phenomenon. I video- and audio-recorded the GLA. I used these recordings to help in the selective coding process.

Document Analysis. I analyzed documents, such as policies, professional development plans, district strategic plan, and any other document available regarding 
curriculum, instruction, and implementation of personalized learning. As I read these documents, I made notes to categorize initial codes that I identified. I then reviewed the codes to identify relevant themes or patterns to make sense of the text (Creswell, 2018). The document review was to determine the presence or absence of any contradictory or corroboratory themes (Yin, 2018).

\section{Process for Exploring Researcher Positionality}

To date, my career in education spans 22 years. I hold a Bachelor of Arts in History Education and a Master's degree in Educational Administration. I served as a classroom teacher in both the alternative and regular classroom settings and served as a middle school assistant principal, middle school principal, high school principal, and superintendent.

I have knowledge and experience implementing personalized learning and have supported teachers in the process of implementation. Prior to implementing personalized learning, I visited many other school sites using some form of personalized learning. As a superintendent, I heavily involved myself in the implementation of personalized learning in the middle and high school levels. At the time of this study, however, I am no longer employed in the district where the study will be conducted.

My background and experience as a district leader in a small, rural, and financially challenged district is a key element to the foundation of this study. Having been a driving force in implementing personalized learning in a district led me to seek a deeper understanding of the personalized model compared to the traditional model of teaching. Knowing my own experience may cause bias it is important to determine a fair and unbiased way to seek a deeper understanding of personalized learning and it is this 
that determines the focus of this study on the experiences of teachers in the implementation process, thus a qualitative case study. The researcher has had experience with personalized learning that implies educational benefits as relates to resource allocation but the researcher realizes that the true measure of any educational benefits must come from those who are in the classroom doing the work, which connects back to the purpose of the study.

Milner (2007) developed a methodological framework to assist a researcher in examining self and positionality through four separate components. Through the four components, researching self, researching the self in relation to others, engaging in reflection, and shifting from self to system researchers can examine their own racial and cultural backgrounds, experiences, and perspectives. This framework is important in all research whether the research involves issues of race and culture or not. As Milner (2007) states, there could be unseen and unforeseen dangers related to race and culture within a research that overtly appears to have no racial or cultural elements. Researching the self allows a researcher to become aware of perspectives, positions, and philosophies that are known, unknown, and unanticipated. Researching the self in relation to others demands that the researcher reflect on the self as relates to the racial and cultural perspectives of the community and people involved in the study. It is important for a researcher to listen to self, to others, and self as it relates to others in order to provide evidence of accuracy within the research. Engaged reflection allows the researcher to reflect on what is occurring among the community and people of the study from a racial and cultural standpoint. Through engaged reflection, the voice of the researcher and the participants can be protected in the study. Shifting from self to system removes the researcher from 
the personal and individual level in order to consider policies, institutions, and society systematically for the researcher to view their research in a broader context.

\section{Strategies for Ensuring Credibility, Transferability, Dependability, and Confirmability}

It is important for the researcher to consider validity and trustworthiness in order to guarantee the reader can have confidence in the findings of this study. Creswell \& Poth (2018) offer that validation is "an attempt to assess the accuracy of the findings, as best described by the researcher, participants, and the readers" (p.259). Creswell \& Poth (2018) further state that extensive time in the field, thick description, and closeness of the researcher to the participants also add to the validity of a study. In order to do this, I have employed accepted strategies to document accuracy within this study.

One method I engaged in to ensure trustworthiness in my study was the development of a structured ethical reflection (See Appendix E). Trust is one of the values I selected to guide my study. Within that value, I have sought to ensure the anonymity of the participants, create a study that inspires trust by both participants and the audience, honor the data as collected and as an extension of the participants, and have transparency about the process of building trust with the participants from the beginning to the end of the study. By choosing the group level assessment method to collect data I have provided that both the data and the initial coding of the data was done by the participants, assigning the role of recording the data as they are presented to myself. This ensured a method of collecting data robust from internal and external bias.

I also referred to the naturalistic evaluation criteria of Lincoln \& Guba (1985). Lincoln and Guba posit that trustworthiness encompasses establishing alternative criteria 
for judging qualitative research. The alternative criteria of Lincoln \& Guba (1985) are credibility, transferability, dependability, and confirmability (See Table 8).

\section{Table 8. Lincoln and Guba's Naturalistic Evaluation Criteria}

\begin{tabular}{|c|c|}
\hline $\begin{array}{c}\text { Traditional Criteria for Judging Quantitative } \\
\text { Research }\end{array}$ & $\begin{array}{c}\text { Alternative Criteria for Judging Qualitative } \\
\text { Research }\end{array}$ \\
\hline internal validity & credibility \\
\hline external validity & transferability \\
\hline reliability & dependability \\
\hline objectivity & confirmability \\
\hline
\end{tabular}

Credibility in qualitative research is analogous to internal validity discussed in traditional quantitative research. With my immersion in personalized learning and the opportunity for constant observation of implementing personalized learning, these are initial criteria for credibility. Throughout the collection of data, I utilized the remaining techniques provided by Lincoln and Guba to ensure credibility. These include: (a) be aware of researcher bias; (b) include any negative data; (c) be attentive to conflicting data; (d) provide thick description of the data; and (e) continuous, informal testing of information by soliciting reactions of participants to my reconstruction of their responses during the data collection process; (f) triangulation of data.

Transferability is similar to external validity in traditional quantitative research, referring to the level that the results of the study are transferrable to other contexts. I am aware that previous experience with the implementation of personalized learning is an area in which to be aware of possible bias. It is due to this possibility that I ensured that all data, including negative and/or conflicting data, is included in the findings. Through thick description of the context of the study and the data, I ensured descriptive validity by refraining from embellishment or distortion of the information reported ensuring that the facts reported are indeed those that were recorded (Maxwell, 1992). 
Dependability, which is analogous to reliability in traditional quantitative research and speaks to the need of the researcher, describes the changes that may occur in the setting and how they may have affected the study. I ensured dependability through my thick description of the context and by including changes that have occurred within that description. Confirmability in traditional qualitative research refers to the level that the results can be confirmed or validated by others. In my study, I have ensured this through the group level assessment process as participants can audit and amend the final product of the data collection.

\section{Summary}

The role of teachers in the classroom is changing as the world has transitioned into the digital realm. This will become more necessary in the future as evidenced by the online learning imposed upon most, if not all, of our nation's schools due to the Coronavirus Pandemic of 2020. Implementing personalized learning requires teachers to leave their comfort zone and move away from the traditional modes of teaching. My goal in this study was to identify the perceptions of teachers through the implementation of personalized learning. I sought to collect the most valid data possible through the GLA method. Through this participatory method with a group of eight teachers, I gathered the data and analyzed the themes with the group. Chapter 4 discusses the findings of the research through a descriptive and analytical articulation of the data generated in the GLA. Chapter 5 gives the conclusion of the study by discussing how the study has informed the research questions, how the study fits into the broader realm of literature and discussion of the significance and impact on future research. 


\section{CHAPTER 4: ANALYSIS AND RESULTS}

In this study, I explored teacher perceptions of personalized learning and their overall experience during implementation. I sought to understand how teacher perceptions of their role in the process of teaching and learning have changed (if at all) because of the personalized learning initiative. Additionally, I examined the perceptions of teachers regarding the professional support needed through the implementation of personalized learning. Four research questions guided this study with the first serving as an overarching driving question and the subsequent three delving into the impact on the teacher experience.

1. How do teachers define personalized learning?

2. How do teachers describe their role within the personalized learning framework?

3. Why has implementing personalized learning been successful and/or challenging?

From the teacher perspective?

4. How did teachers perceive their preparation programs as assisting or inhibiting Teachers' transitions to the personalized learning model?

In this chapter, I present the findings of my study. I open the chapter with an exploration of my positionality as a researcher exploring perceptions of teachers 
implementing a program that I was responsible for implementing in the district where they teach. To assist me with this process I used the Structured Ethical Reflection (SER) framework, outlined previously in Chapter 3 to guide me through the investigation of my positionality as a researcher. The SER was developed in conjunction with the methodological framework to guide researchers in developing a higher level of racial and cultural awareness, consciousness, and positionality (Milner, 2007). The next section delivers an overview of the results in the form of tables and an explanation of the process of analysis. I then provide an overview of the data sources I utilized to collect data throughout the study and how they aligned to the four research questions. The next section explains the demographics of the group level assessment participants which is followed by a description of the process used to code the data after collection. I then discuss what the data has implied for each of the four research questions after the coding process was completed. The final section of chapter 4 is a summary of the findings.

The following sections of this chapter give descriptive analysis of the findings regarding the four research questions. Attention has been given to identifying the data sources (survey, group level assessment, and documents related to the implementation of personalized learning) and how they were used to answer each of the research questions. The chapter ends with a summary of the findings.

\section{An Exploration of Researcher Positionality}

In order to conduct an exploration of my positionality as a researcher, I utilized the four components of Milner's framework (Milner, 2007). This framework and its components were discussed in detail in chapter 3. For the initial step in the process of this exploration I conducted research of myself from a personal and professional perspective 
in order to fully understand how I arrived at the point of conducting this study. As individuals we all have various implicit biases based upon our lived experiences. I know that my background in rural Kentucky was one that could have initially given me strong racial biases. Growing up I was exposed to many family members who were prejudiced against certain other groups of people. Some of these were people with whom I was very close. That being said, I was not taught to think that way and it was never forced on me to think or feel that way, although it may have been assumed I would automatically "fall into line." I was fortunate enough to have classmates from other racial backgrounds (African American, Asian--specifically Vietnamese, and later Hispanic). No matter what I might hear in negative terms about these groups, I had real life experiences with these people every day and the negative things I heard conflicted with the reality of interacting with these classmates. When I graduated high school and entered the military, I was exposed to many more people from a vast array of ethnic backgrounds. These experiences reinforced in my mind how wrong those people in my family were in their way of thinking. These experiences have given me much opportunity to reflect on myself and any biases I may have in order to be aware of and overcome them. As individuals we all have various implicit biases based upon our lived experiences.

The second component of Milner's framework is for the researcher to engage in a reflection of self as related to others. Having served as the superintendent in the district in which I am conducting my study, I am in the position to understand the actions of teachers prior to implementation of personalized learning. I have done in depth research through visits, observations, and interviews regarding the implementation process and predicted outcomes with the personalized learning approach. I am keenly aware of 
potential bias with this study as I was responsible for the implementation of personalized learning and was embedded daily within the work. I believe students' success beyond our classrooms is what most defines our success as educators. To help students find that success requires educators to focus on more than just the instructional knowledge that for so long has been viewed to be the sole responsibility of the educator. Today's educator must meet the ever-changing needs of students as well as those of our society, and world. There are many aspects to true student success beyond general content knowledge. It is sometimes challenging to effectively address each of those aspects of success. The goal of this study is to step outside my role as an administrator to listen and gain understanding of the perceptions of teachers that will hopefully provide useful information to other schools and districts in the process of implementing personalized learning.

The third component of Milner's framework is engaged reflection. During this study, I have engaged in the reflective process of developing a Structured Ethical Reflection (SER) to guide me as I conduct this study. The SER is a tool that can help an individual researcher, who lacks the benefit of others to offer feedback, to keep an ethical check on practice throughout the study (Brydon-Miller et al., 2015). Working through the process of creating the SER (See Appendix E) helped me to identify the core values to guide me in this study. These were not just values that I chose arbitrarily but identified through the reflective process as I considered my responsibilities to the participants of the study and the audience to whom I would report the results. When completed I had a vision of seven values that would guide me from beginning to end. It helped me to isolate 
myself from individual bias and self-interest and to focus on conducting an honest and trustworthy study that can be reported with integrity.

\section{An Overview of Data Sources and Analytical Strategies}

I relied upon three sources of collected data to conduct this study: teacher climate/culture surveys, group level assessment, and a review of school and/or district documents pertaining to the implementation of personalized learning (See Table 9). I used the eProve Teacher Climate/Culture survey over a three-year period as a primary look into the perceptions of teachers regarding their work over the period of time personalized learning was being implemented. Utilizing the bar graphs provided by eProve I conducted a descriptive analysis to determine those survey responses that occurred with the most frequency for each question. I then created a table to display this information visually.

I then conducted a group level assessment (GLA) as my second means of collecting data (See Appendix C for the GLA prompts). The analysis of this data consisted of having the GLA participants, working in small groups, to review the initial responses to the prompts and to disaggregate the responses into categories or subcategories based upon similarities and differences. Through axial coding procedures described by Saldana (2016) the categories were looked at using the coding paradigm of Strauss and Corbin (1998) through the context of the phenomena being studied, conditions, action and interactional strategies and consequences. 
Table 9. Data Sources Aligned to Research Question

\begin{tabular}{lcccc}
\hline \multicolumn{1}{c}{ Data Source } & $\begin{array}{c}\text { Research } \\
\text { Question \#1 }\end{array}$ & $\begin{array}{c}\text { Research } \\
\text { Question \#2 }\end{array}$ & $\begin{array}{c}\text { Research } \\
\text { Question \#3 }\end{array}$ & $\begin{array}{c}\text { Research } \\
\text { Question \#4 }\end{array}$ \\
\hline $\begin{array}{l}\text { Teacher Climate and Culture } \\
\text { Survey }\end{array}$ & $\mathrm{X}$ & $\mathrm{X}$ & \\
\hline Group Level Assessment & $\mathrm{X}$ & $\mathrm{X}$ & $\mathrm{X}$ & $\mathrm{X}$ \\
\hline $\begin{array}{l}\text { Documents Pertaining to } \\
\begin{array}{l}\text { Implementation of Personalized } \\
\text { earning }\end{array}\end{array}$ & & $\mathrm{X}$ & $\mathrm{X}$ \\
\hline
\end{tabular}

The final source of data were documents related to the implementation of personalized learning specifically from the district level as implementation of personalized learning was a district initiative. I reviewed the district's graduate profile, strategic plan, and professional development plans in order to understand how personalized learning was envisioned, the strategic process for implementation, and how implementation was supported. The most important aspect of looking at these documents was to learn how they did or did not correlate to the responses on the teacher climate/culture surveys and the data collected from the group level assessment. These documents also allow a glimpse of the district perspective on the implementation of personalized learning.

\section{Survey Results}

Initially I collected data from teacher climate/culture surveys for 2017-2018, 2018-2019, and 2019-2020 (See Appendix A). These survey data provided an overall view of the teacher perceptions of the climate and culture of their school/district during 
the years that personalized learning was implemented. The survey consisted of 8 items targeting responses on: expectation for students in the school, what teachers say to students, what students do in the classrooms, how teachers feel as they do their jobs, teacher to teacher interactions, and how teachers feel at work. The survey data in isolation would not have any application toward my study but it was useful as another set of data in which to seek similar or contradictory patterns among the data collected from other sources. In total, 10 of 30 teachers $(33 \%)$ responded to the survey in $17-18 ; 26$ of $30(87 \%)$ responded to the survey in $18-19$ and 25 of $30(83 \%)$ responded to the survey in 19-20.

\section{Demographics of Group Level Assessment Participants}

I invited all of the grades 5 through 12 teachers from elementary, middle, and high school levels in Trimble County Schools who had experience in both the traditional model of education as well as personalized learning to participate in a group level assessment. In total, eight teachers participated (See Table 10). The sample of participants was purposive, consisting of teachers from the elementary, middle, and high school levels (grades 5 through 12). I also wanted teachers who had had experience in both the traditional model of education as well as personalized learning. I also sought a wide range of teaching experience and education level in the sample of participants as this could be a determining factor in the individual perspective of each teacher regarding the implementation of personalized learning. Table 10 displays percentages of the participants as a whole proportionally across the sampling criteria. 
Table 10. Demographics of Study Participants

\begin{tabular}{clll}
\hline Gender & $\begin{array}{c}\text { Years of Teaching } \\
\text { Experience }\end{array}$ & $\begin{array}{c}\text { Years of Experiences } \\
\text { with Personalized } \\
\text { Learning }\end{array}$ & Level of education \\
\hline $\mathrm{M}-25 \%$ & $1-5$ years-12.5\% & 2 years-62.5\% & Bachelor-50.0\% \\
F-75\% & 6-10 years-25.0\% & 3years-37.5\% & Masters-37.5\% \\
& $11-15$ years-25.0\% & & Above Masters-12.5\% \\
& $16-20$ years-37.5\% & & \\
\hline
\end{tabular}

The sample of participants consisted of $2(25 \%)$ male teachers and $6(75 \%)$

female. The level of experience in years of teaching was fairly consistent across each of the criteria and proved to be in large an experienced group of teachers with only 1 participant falling in the 1-5 years designation. Therefore, the participating teachers had many years of experience teaching in the traditional model and all had at least 2 years of experience teaching in the personalized learning model. The distribution of participants regarding grade level taught was also fairly consistent across the elementary, middle, and high school level. Half of the participants held a master's degree or higher as their level of education. Table 11 displays how participants measured to these criteria individually

Table 11. Demographics of Individual GLA Participants

\begin{tabular}{lccccc}
\hline & Gender & $\begin{array}{c}\text { Teaching } \\
\text { Level }\end{array}$ & $\begin{array}{c}\text { Years in } \\
\text { Teaching }\end{array}$ & $\begin{array}{c}\text { Years in Personalized } \\
\text { learning }\end{array}$ & $\begin{array}{c}\text { Level of } \\
\text { Education }\end{array}$ \\
\hline Teacher 1 & F & Elementary & $16-20$ & 2 & Master's \\
\hline Teacher 2 & F & Middle & $11-15$ & 2 & Bachelor's \\
\hline Teacher 3 & F & Elementary & $6-10$ & 3 & Masters \\
\hline Teacher 4 & F & Elementary & $11-15$ & 3 & $\begin{array}{c}\text { Above } \\
\text { Master's }\end{array}$ \\
\hline Teacher 5 & F & Elementary & $6-10$ & 2 & Bachelor's \\
\hline Teacher 6 & F & High & $16-20$ & 2 & Master's \\
\hline Teacher 7 & M & High & $1-5$ & 2 & Bachelor's \\
\hline Teacher 8 & M & Middle & $16-20$ & 3 & Master's \\
\hline
\end{tabular}




\section{Coding Process}

The data collected through the group level assessment provided insight into each teacher's experiences since implementing personalized learning in their classroom. It also gave insight into their perceptions of how their roles as teachers changed during and after implementation. Their perspectives will be discussed in the remaining sections of this chapter. These perspectives were arrived at through an inductive coding process that was aligned to the four research questions of the study. The beginning stage of the coding process was reviewing the responses from the participants on 15 open-ended prompts that were aligned to the research questions. The participants had identified themes from the responses of each prompt during the GLA. This open coding was the first level of data analysis that focused on the conceptualization and categorization of the phenomena (personalized learning) and breaking the data into smaller parts (concepts). The second part of the open coding process was to compare the concepts with respect to similarities and differences. Through this process those concepts that were similar were assigned to one code while those that were different remained as separate codes. This allowed me to have a foundation of categorical concepts with which to begin axial coding.

Axial coding is necessary in order to examine relationships between concepts and categories developed through the open coding process (Vollstedt \& Rezat, 2019). In order to accomplish this task, I utilized the coding paradigm to identify the relationships between the categories (Strauss \& Corbin, 1990). The categories of data identified in the open coding were then viewed in relation to the phenomenon being studied, conditions related to the phenomenon such as conditions, actions and interactional strategies directed 
at managing the phenomenon, and consequences of those actions and interactional

strategies related to the phenomenon (See Table 12).

Table 12. Data Sources Aligned to Coding Paradigm

\begin{tabular}{|c|c|c|c|c|}
\hline GLA Prompt & $\begin{array}{l}\text { A. The } \\
\text { phenomenon } \\
\text { being studied }\end{array}$ & $\begin{array}{l}\text { B. The conditions } \\
\text { related to that } \\
\text { phenomenon such as } \\
\text { context conditions }\end{array}$ & $\begin{array}{c}\text { C. Actions and } \\
\text { interactional strategies } \\
\text { directed at managing } \\
\text { the phenomenon }\end{array}$ & $\begin{array}{l}\text { D. Consequences of the } \\
\text { actions and interactions } \\
\text { related to the } \\
\text { phenomenon. }\end{array}$ \\
\hline Student Pace & $\mathrm{X}$ & & & $\mathrm{X}$ \\
\hline Student Agency & $X$ & & $X$ & $X$ \\
\hline $\begin{array}{l}\text { Individualized } \\
\text { instruction }\end{array}$ & $X$ & & & $\mathrm{X}$ \\
\hline Small Group & $\mathrm{X}$ & & $\mathrm{X}$ & $\mathrm{X}$ \\
\hline Student Led Learning & $\mathrm{X}$ & & & $X$ \\
\hline $\begin{array}{l}\text { Data Driven } \\
\text { Instruction }\end{array}$ & X & & $\mathrm{X}$ & $\mathrm{X}$ \\
\hline Reflection & & & $\mathrm{X}$ & $X$ \\
\hline Goal Setting & $\mathrm{X}$ & & $\mathrm{X}$ & $X$ \\
\hline $\begin{array}{l}\text { Teachers as } \\
\text { Facilitator/Guide }\end{array}$ & $\mathrm{X}$ & & & $X$ \\
\hline Challenging & & $\mathrm{X}$ & $\mathrm{X}$ & $\mathrm{X}$ \\
\hline Rewarding & & & & $X$ \\
\hline $\begin{array}{l}\text { Difficult Lesson } \\
\text { Planning }\end{array}$ & & $X$ & $X$ & $X$ \\
\hline $\begin{array}{l}\text { Need for } \\
\text { Training/Resources }\end{array}$ & & $\mathrm{X}$ & $X$ & $X$ \\
\hline $\begin{array}{l}\text { Difficult for } \\
\text { Elementary Students }\end{array}$ & & $X$ & & $X$ \\
\hline
\end{tabular}

Engaging in this process allowed me to see how the perceptions and experiences of the teachers with personalized learning interacted across the paradigm and related to the research questions. In the final stage, I engaged in selective coding in order to narrow the categories of data developed in open coding into core categories to determine how they contributed data toward answering my research questions. When this was completed, I was able to develop a visual depicting how each core value (selective code) 
related to each individual research question as well as identifying the overlap each

core value may have had across all four research questions. (See Table 13).

Table 13. Selective Codes Alignment to Research Questions

\begin{tabular}{|c|c|c|c|c|c|}
\hline $\begin{array}{l}\text { Core Value (Selective } \\
\text { Code) aligned with } \\
\text { the literature }\end{array}$ & $\begin{array}{c}\text { Research } \\
\text { Question \#1 } \\
\text { Frequency }\end{array}$ & $\begin{array}{c}\text { Research } \\
\text { Question \#2 } \\
\text { Frequency }\end{array}$ & $\begin{array}{c}\text { Research } \\
\text { Question \#3 } \\
\text { Frequency }\end{array}$ & $\begin{array}{c}\text { Research } \\
\text { Question \#4 } \\
\text { Frequency }\end{array}$ & $\begin{array}{c}\text { Frequency } \\
\text { Across all } \\
\text { Research } \\
\text { Questions } \\
\end{array}$ \\
\hline Student Pace & 13 & 2 & 1 & 0 & 16 \\
\hline Student Agency & 13 & 2 & 5 & 0 & 15 \\
\hline $\begin{array}{l}\text { Individualized } \\
\text { instruction }\end{array}$ & 18 & 4 & 2 & 0 & 24 \\
\hline Small Group & 5 & 5 & 0 & 0 & 10 \\
\hline Student Led Learning & 3 & 2 & 3 & 0 & 8 \\
\hline $\begin{array}{l}\text { Data Driven } \\
\text { Instruction }\end{array}$ & 2 & 5 & 1 & 4 & 12 \\
\hline Reflection & 3 & 9 & 0 & 0 & 12 \\
\hline Goal Setting & 5 & 2 & 1 & 1 & 8 \\
\hline $\begin{array}{l}\text { Teachers as } \\
\text { Facilitator/Guide }\end{array}$ & 4 & 7 & 0 & 0 & 11 \\
\hline Challenging & 3 & 18 & 0 & 0 & 21 \\
\hline Rewarding & 0 & 4 & 1 & 0 & 5 \\
\hline $\begin{array}{l}\text { Difficult Lesson } \\
\text { Planning }\end{array}$ & 0 & 7 & 5 & 0 & 12 \\
\hline $\begin{array}{l}\text { Need for } \\
\text { Training/Resources }\end{array}$ & 0 & 0 & 5 & 19 & 24 \\
\hline $\begin{array}{l}\text { Difficult for } \\
\text { Elementary Students }\end{array}$ & 0 & 3 & 1 & 0 & 4 \\
\hline
\end{tabular}

\section{Teacher Perceptions of the Definition of Personalized Learning}

Questions 1 and 2 of the teacher survey (See Table 14) align with the first research question of this study and offer insights into how teachers were feeling during the implementation phase of personalized learning. These questions asked teachers to respond regarding the expectations of students in the school and what teachers generally say to students in the school. The response regarding student expectations that appeared most frequently across all three years of the survey was students are learning. The 
percentage decreased each year, but it remained as the top response. The students are able to explain was the second most frequent response all three years the survey was taken. The other response that appeared most frequently in the top three over the course of the three years was students understand. When responding to what teachers generally say to students, the three responses that appeared most frequently were, we will be working on, explain it, and what are you thinking? For the most part the percentages for both questions went up and down across all three years without any consistent pattern. The fact that there is no consistent movement in the percentage of responses suggests that personalized learning as a model had little impact on how teachers defined student expectations in the school nor did personalized learning seem to give consistency to the kinds of things teachers say instructionally to students as measured by the survey. This implies that during this period there was not a consistent vision or model of personalized learning in place and therefore these survey questions give little indication on their own that implementation was occurring during this period. It is important to note that looking at the survey questions as the only source of data would not allow this conclusion to be made. It is only when looking at the data from the survey questions in conjunction with the data collected from the group level assessment prompts and information in the literature review that this conclusion becomes apparent.

Table 14. Teacher Climate/Culture Survey Most Frequent Responses

\begin{tabular}{lccc}
\hline $\begin{array}{l}\text { Survey } \\
\text { Question: }\end{array}$ & $2017-2018$ & $2018-19$ & $2019-20$ \\
$\begin{array}{l}\text { Which four of } \\
\text { the following }\end{array}$ & $\mathrm{N}=10(33 \%)$ & $\mathrm{N}=26(87 \%)$ & $\mathrm{N}=25(83 \%)$ \\
$\begin{array}{l}\text { words or } \\
\text { phrases best } \\
\text { describes... }\end{array}$ & & & \\
\hline
\end{tabular}




\begin{tabular}{|c|c|c|c|}
\hline $\begin{array}{l}\text { The } \\
\text { expectations } \\
\text { for students at } \\
\text { your school? }\end{array}$ & $\begin{array}{l}\text { Students are learning-100\% } \\
\text { Students are able to explain- } \\
78 \% \\
\text { Students should ask a } \\
\text { teacher-56\% } \\
\text { Students are expected to be } \\
\text { good at some things-44\% } \\
\text { Students understand- } 44 \%\end{array}$ & $\begin{array}{l}\text { Students are learning- } \\
88 \% \\
\text { Students are able to } \\
\text { explain- } 83 \% \\
\text { Students understand- } \\
58 \% \\
\text { Students are expected } \\
\text { to be good at some } \\
\text { things-54\% }\end{array}$ & $\begin{array}{l}\text { Students are } \\
\text { learning-76\% } \\
\text { Students are } \\
\text { able to explain- } \\
60 \% \\
\text { Students } \\
\text { Understand- } \\
52 \% \\
\text { Students are } \\
\text { expected to be } \\
\text { good at some } \\
\text { things-40\% } \\
\text { Students should } \\
\text { find it } \\
\text { themselves- } \\
40 \% \\
\text { Students should } \\
\text { ask a teacher- } \\
40 \%\end{array}$ \\
\hline $\begin{array}{l}\text { The kinds of } \\
\text { things you say } \\
\text { to your } \\
\text { students? }\end{array}$ & $\begin{array}{l}\text { What are you thinking- } 67 \% \\
\text { Explain it- } 67 \% \\
\text { You got it right- } 56 \% \\
\text { We will be working on- } 56 \% \\
\text { I am interested in your } \\
\text { thinking- } 44 \%\end{array}$ & $\begin{array}{l}\text { We will be working } \\
\text { on- } 79 \% \\
\text { Explain it-71\% } \\
\text { What are you } \\
\text { thinking- } 50 \% \\
\text { You got it right-33\% }\end{array}$ & $\begin{array}{l}\text { We will be } \\
\text { working on- } \\
72 \% \\
\text { Explain it-52\% } \\
\text { What are you } \\
\text { thinking-48\% } \\
\text { I am interested } \\
\text { in your } \\
\text { thinking-36\% } \\
\text { I am interested } \\
\text { in your answer- } \\
36 \%\end{array}$ \\
\hline $\begin{array}{l}\text { How you feel } \\
\text { when trying to } \\
\text { complete your } \\
\text { responsibilitie } \\
\text { s at work? }\end{array}$ & $\begin{array}{l}\text { Never enough time- } 89 \% \\
\text { Hectic- } 67 \% \\
\text { Hurried-56\% } \\
\text { Tense- } 56 \% \\
\text { Rushed-44\% } \\
\text { Pressured-44\% }\end{array}$ & $\begin{array}{l}\text { Never enough time- } \\
71 \% \\
\text { Hectic- } 54 \% \\
\text { Pressured-54\% } \\
\text { Deliberate-46\% } \\
\text { Tense- } 38 \%\end{array}$ & $\begin{array}{l}\text { Never enough } \\
\text { time-56\% } \\
\text { Pressured-56\% } \\
\text { Hectic-44\% } \\
\text { Patient-44\% } \\
\text { Calm-40\% } \\
\text { Tense-36\% }\end{array}$ \\
\hline $\begin{array}{l}\text { What you } \\
\text { think of your } \\
\text { colleagues, in } \\
\text { general? }\end{array}$ & $\begin{array}{l}\text { Caring-56\% } \\
\text { Inconsistent-56\% } \\
\text { Real-33\% } \\
\text { Uninterested-33\% } \\
\text { Fake-33\% } \\
\text { Untrustworthy-33\% } \\
\text { Active-22\% } \\
\text { Fun-22\% }\end{array}$ & $\begin{array}{l}\text { Caring-88\% } \\
\text { Real-33\% } \\
\text { Active-54\% } \\
\text { Interesting-29\% }\end{array}$ & $\begin{array}{l}\text { Caring-84\% } \\
\text { Honst-60\% } \\
\text { Real-44\% } \\
\text { Interesting-40\% }\end{array}$ \\
\hline
\end{tabular}




\begin{tabular}{|c|c|c|c|}
\hline & $\begin{array}{l}\text { Interesting-22\% } \\
\text { Permissive-22\% } \\
\text { Unfair-22\% } \\
\text { Consistent-11\% } \\
\text { Lazy-11\% } \\
\text { Curious-11\% } \\
\text { Mean-11\% }\end{array}$ & & \\
\hline $\begin{array}{l}\text { What students } \\
\text { most often do } \\
\text { in your } \\
\text { classroom? }\end{array}$ & $\begin{array}{l}\text { Challenging work-78\% } \\
\text { Think-44\% } \\
\text { Work with others-44\% } \\
\text { Classroom work-33\% } \\
\text { Write-33\% } \\
\text { Work alone-33\% } \\
\text { Tests-33\% } \\
\text { Long Projects-22\% } \\
\text { Brief projects-22\% }\end{array}$ & $\begin{array}{l}\text { Challenging work- } \\
54 \% \\
\text { Classroom work-46\% } \\
\text { Long projects- } 46 \% \\
\text { Work with others-42\% } \\
\text { Think-33\% } \\
\text { Tests-33\% }\end{array}$ & $\begin{array}{l}\text { Classroom } \\
\text { work-60\% } \\
\text { Think-48\% } \\
\text { Challenging } \\
\text { work-40\% } \\
\text { Write-36\% }\end{array}$ \\
\hline $\begin{array}{l}\text { The } \\
\text { interactions } \\
\text { you have with } \\
\text { other teachers } \\
\text { at your } \\
\text { school? }\end{array}$ & $\begin{array}{l}\text { Helpful-67\% } \\
\text { Supportive-56\% } \\
\text { Brief-56\% } \\
\text { Collaborative-56\% } \\
\text { Distant-44\% } \\
\text { Useless-44\% } \\
\text { Respectful-22\% }\end{array}$ & $\begin{array}{l}\text { Supportive-83\% } \\
\text { Respectful-75\% } \\
\text { Collaborative-67\% } \\
\text { Helpful-54\% }\end{array}$ & $\begin{array}{l}\text { Supportive-92\% } \\
\text { Respectful-84\% } \\
\text { Helpful-60\% } \\
\text { Trusting-52\% }\end{array}$ \\
\hline $\begin{array}{l}\text { The physical } \\
\text { spaces in } \\
\text { which you } \\
\text { spend most of } \\
\text { your time at } \\
\text { school? }\end{array}$ & $\begin{array}{l}\text { Neglected-56\% } \\
\text { Inviting-44\% } \\
\text { Chaotic-44\% } \\
\text { Closed-44\% } \\
\text { Comfortable-33\% } \\
\text { Open-33\% } \\
\text { Bright-33\% } \\
\text { Stressful-33\% } \\
\text { Flexible-33\% } \\
\text { Plain-22\% } \\
\text { Stable-22\% }\end{array}$ & $\begin{array}{l}\text { Comfortable-75\% } \\
\text { Stable- } 67 \% \\
\text { Inviting-58\% } \\
\text { Open- } 46 \%\end{array}$ & $\begin{array}{l}\text { Comfortable- } \\
64 \% \\
\text { Flexible-44\% } \\
\text { Inviting-40\% } \\
\text { Open-36\% } \\
\text { Bright-36\% } \\
\text { Plain-36\% }\end{array}$ \\
\hline $\begin{array}{l}\text { How you feel } \\
\text { while at } \\
\text { work? }\end{array}$ & $\begin{array}{l}\text { Challenged-78\% } \\
\text { Tired-67\% } \\
\text { Pressured-67\% } \\
\text { Interested-44\% } \\
\text { Supported-33\% } \\
\text { Confused-33\% }\end{array}$ & $\begin{array}{l}\text { Challenged-71\% } \\
\text { Tired-63\% } \\
\text { Pressured-54\% } \\
\text { Interested-42\% }\end{array}$ & $\begin{array}{l}\text { Challenged- } \\
52 \% \\
\text { Pressured-52\% } \\
\text { Tired-48\% } \\
\text { Interested-40\% } \\
\text { Happy-40\% } \\
\text { Supported-40\% } \\
\text { Encouraged- } \\
28 \%\end{array}$ \\
\hline
\end{tabular}


Prompts 1, 2, 3, and 4 (See Appendix C) in the group level assessment were aligned to research question one. As was discovered from the review of literature there is not one consistent definition of personalized learning. Those definitions most visible in the literature tend to be consistent in naming student pace, student agency, and individualized learning as key aspects of personalized learning. Individualized learning appeared 18 times across the responses for prompts 1 through 4 of the group level assessment. Student pace appeared 13 times and student agency appeared 13 times as related to research question one. While there was some alignment to the definitions of personalized learning that were provided in the literature, there is greater alignment with the literature regarding the fact that definitions of personalized learning are generally vague and inconsistent. In this case each participant had a separate understanding or explanation of how personalized learning was defined, what it looks like, and what it is. There was an equal amount of inconsistency in how they explained the difference between the traditional model of education and personalized learning which requires drawing upon one's conceived definition of personalized learning.

Teacher perceptions on the definition of personalized learning included some of the key aspects of personalized learning aligned to the definitions provided in the literature; such as individualized learning, student pace, and student agency. It was clear that each of these definitions represented that particular teacher's perspective of personalized learning and was not based upon any definition, model, or vision developed by the school or the district. Teacher 1 stated that personalized learning is defined as, "Students working on assignments and advancing at their own pace and at their own level. Students work on the same set of college/career ready standards with individual 
support that they need as they learn." Teacher 4 defined personalized learning as, "the ability for students to work on their personal academic level at their pace, all while using the students' learning styles and strengths in order to grow as a learner." Both of these teachers have a strong understanding of the importance of pace in personalized learning and even hint at individualized learning without specifically stating it. Teacher 7 was more specific in the individualized learning aspect stating that personalized learning is, "an approach to meet the needs of each individual student where they are at, their performance level/learning modality, and set high standards for each student to achieve proficient outcomes using personalized pathways." There is no mention of pace of learning or student agency. Teacher 5 gave a definition focused mainly on student voice and choice, which is a component of student agency (Rector-Aranda \& Raider-Roth, 2015), stating that, "Personalized learning is giving students voice and choice about what they are learning, how they demonstrate learning." Teacher 8 offered the most comprehensive definition of the participants with, "Personalized learning is the process that allows students to learn at their own pace using specific tools individually needed to be successful (relative to grade level of reading, etc.). For some students this is using visual materials, for others is it hands-on, and so on." This definition speaks to pace, individualized learning, and, indirectly, student agency.

When looking at how teachers describe the difference between the traditional model of education and personalized learning there was much more consistency in their descriptions as compared to each other but still limited in how they were defining personalized learning in contrast to the traditional model. The consistent aspects across the descriptions given were highlighting individualized learning at a high frequency, 
small group instead of whole group learning, and student pace was present minimally. Small group appeared in coding only 5 times as related to research question 1 . Teacher 2 contrasted the two models with, "The definition of a traditional model is 'whole group' in which students work on the same assignments at the same time to produce the same outcomes. Personalized learning is individualized instruction which is tailored to meet the educational needs of different students." Teacher 5 responded with "The traditional model of learning is done in a whole group setting. Personalized learning allows students to learn at their own pace." Teacher 8 and Teacher 9 added another aspect that had not been brought up by any other teacher in contrasting the two models. Teacher 8 stated, "Personalized learning allows the student to control the pacing of content rather than in a traditional setting where the teacher controls the pacing." Teacher 9 expanded this with "Traditional tends to focus on the class as a whole, and at the pace of the instructor rather than that of the individual student. If a student can keep up, great, but if not, then they are often left behind because the instructor is moving more at their own pace rather than that of everyone in the class." What both of these teachers added to the contrast was that the teacher is not the driver of the pace. While the teachers were consistent in describing small groups as a major difference between the traditional and personalized models of learning, there was inconsistency with how they had actually defined personalized learning. This inconsistency continued as teachers answered the question of what personalized learning looks like in action.

Teachers added goals and goal setting into their description when discussing what personalized learning looks like. Coding identified a pattern linked to goal setting only 5 times as related to research question 1 . The responses of teachers in this description were 
once again inconsistent with each other holistically. Teacher 5 described how personalized learning looks stating that, "Personalized learning looks like students setting goals, making a plan to reach their goals, using learning methods that work best for them (individual study, partner, small group, teacher-led, workshop model), demonstrate their learning, and then reflect upon the learning process." Teacher 7 offered this description, “A personalized learning environment involves small group instruction with varying intensity depending on the student as well as student choice. You will see students working at stations, small group lessons, with others working independently with support when needed. Basically, varying pathways to achieve the desired end result." In describing what personalized learning looks like, another important aspect of personalized learning that had not yet been identified, student led learning, was brought to light. While student led learning did not have a heavy pattern in the selective coding, appearing only 3 times regarding research question one, it is a very important part of personalized learning.

Inconsistency among teacher perceptions of personalized learning continued as they answered a prompt about what personalized learning is. This is where student voice and choice were most frequently stated with pacing becoming a frequent part of the responses as well. There was some mention of goals, student led learning and individualized learning, but these were not consistently mentioned across all of the responses. Teacher 5 explained, "Personalized learning is more engaging because the students are intrinsically motivated (sometimes) to meet their own goals (voice and choice). Students need to have a growth mindset and be okay with failure and learning from experiences." There is a glimpse in this response of a teacher perceiving that 
personalized learning is a more engaging model of learning. Teacher 6 offered a more comprehensive description of what personalized learning is when compared to the literature, stating, "Personalized learning is engaging, challenging, and differentiated on the needs of the students. Personalized learning looks like student choice. Students using tools and creating tools that they need to meet the task in front of them. Personalized learning is student led achievement that works at a rate that is appropriate for the learner."

When looking at the selective coding core values and the patterns that were identified over the first four prompts of the group level assessment, there were five core values that appeared with the most frequency. Goal setting and small groups both only appeared 5 times in the coding, while six other core values appeared less. From the perspective of the teachers individualized learning, student pace, and student agency are the aspects teachers most recognized when defining personalized learning. The outcome of this data collection does not differ from that of other studies highlighted in the literature review. Teachers in Trimble County among elementary, middle, and high school levels, were unable to give consistent descriptions or definitions of personalized learning.

The third source of data I utilized was a review of documents that may also connect to the research questions. The first document I reviewed was the Trimble County Public Schools Strategic Plan (See Appendix F). This plan has been communicated throughout the schools and community of Trimble County. One of the key elements of the plan is a glossary page to help any lay person understand the educational language. The second definition from this plan is a definition for personalized learning. The 
definition used in the TCPS Strategic plan explains that personalized learning refers to a diverse variety of educational programs, learning experiences, instructional approaches, and academic-support strategies that are intended to address the distinct learning needs, interests, aspirations, or cultural background of individual students. Within the strategic plan it is stated that all students will have access to personalized learning. The definition provided to the district implies that the district has a vision of what personalized learning should be and that it has been communicated to staff and community. The definition is, as has been seen many times though the literature, vague in nature. It does give an overall specificity to individualized learning but is filled with many other aspects that are not specific such as "diverse variety of educational programs, learning experiences, instructional approaches, and academic support strategies. These are all broad concepts that are not spelled out in the definition or in the strategic plan. From the review of the strategic plan it is apparent that there was an effort by the district to define personalized learning. Furthermore, the teachers in this study were consistent with the most specific part of the district definition, individualized learning, and likewise inconsistent and vague in most other aspects that define personalized learning.

Another document I reviewed was the Learning Centered Anchor Chart (See Appendix G), which was the product of a guided approach by school and district leaders to give vision and direction to what personalized learning consisted of and more importantly how it fit in with other vital initiatives in the district such as supporting student social and emotional needs and the district graduate profile. This document and the process that TCPS educators went through to create it did not change, revamp, or narrow the district's definition or vision of personalized learning, it simply provided a 
visual chart to help teachers see the many moving parts. While it certainly shows that the district was aware of the need to help teachers grasp the model of personalized learning, it is also further evidence of why there are inconsistencies among the teachers as to the definition of personalized learning.

\section{Teacher Perceptions of their Role in the Personalized Learning Framework}

The second research question of my study investigates the perceptions of teachers as to the way their role has changed through the implementation of personalized learning. Questions 3 and 8 from the teacher climate/culture survey can be connected to research question two also. These questions ask teachers to respond to how they feel when they complete their responsibilities at work and how they feel at work. These are important questions to ask during a time where teachers are implementing changes that have a direct impact on their role as a teacher. As was the case with the survey as related to research question one, there was minimal change seen over the three-year period. Across all three years, when responding to how they feel when completing responsibilities at work teachers consistently listed never enough time as the most frequent answer, with hectic and pressured showing up most frequently as either the second or third most frequent response. The only other response that was consistent over all three years was tense. Across all three years, when responding to how teachers felt at work teachers listed challenged as the most frequent response with tired and pressured showing up most frequently as the second and third choice. The responses are consistent across both questions, as it makes sense that if teachers feel they never have enough time to meet their responsibilities while at work they would most likely feel challenged while they were at work. More importantly these responses are consistent with what teachers would 
feel during a time when they were adopting and implementing a new model of teaching and learning that possibly makes a drastic change in their role as a teacher. Analysis of the responses from the group level assessment provide deeper data needed to explore this question. There was nothing revealed through the document review to provide any data towards research question two.

Prompts 5, 6, 7, 8, and 9 from the group level assessment (See Appendix C) were connected to the second research question. These prompts seek to get at teacher's perceptions about what they do as teachers in the personalized learning model and how it may have changed from what they did in the traditional model of teaching and learning. These prompts sought specifically to gather responses regarding teaching, planning, the role of the teacher, meeting student's needs, and transitioning to the personalized learning model.

The pattern that appeared most frequently regarding the second research question was "challenging," which appeared 18 times through the selective coding process. There was a connection to the challenge teachers have faced with personalized learning and it was consistent with data from the survey as to how teachers were feeling at work. The core value of reflection was the second most frequent response, appearing 9 times in the coding process. The teacher changing into the role of a facilitator and difficult lesson planning tied as the third most frequent, appearing 7 times each. As research question two is related to the role of the teacher in the personalized learning framework and given the role of the teacher revolves greatly on planning and delivering instruction, these responses are also consistent with the responses on the correlating questions of the survey. Responses from the survey and the five prompts related to research question two 
indicate that teachers perceive a major change in their role as a teacher. They have become more of a facilitator, or guide, of instruction. This transition has been challenging and wearing on the teachers through the process of implementation.

After teaching in the personalized learning framework, Teacher 5 stated the need to, "Reflect upon the process - Did I provide enough modeling and scaffolding? Did I provide enough support to help students reach their goals? I meet with students to discuss how they feel about their progress and develop a plan together to move forward." Teacher 7 had a similar response connected to lesson planning with, "I review student responses and collect data for different student groups to identify student strengths and weaknesses and to assess the effectiveness of the lesson. I then use this information for lesson planning to create small groups to target specific areas of weakness in upcoming lessons.” Teachers find that after teaching in the personalized learning framework reflection of the process, student data, and student work are essential to the planning process. The challenge this creates when trying to effectively personalize a lesson is felt through the response of Teacher 8 , "I feel it is important to use data to drive instruction. For some students, this is an easy process, for others it is an immense struggle. I do not feel that personalized learning is truly a one-size-fits-all approach." While planning was only specifically stated in one response for prompt 5 , the struggles teachers identified are all related to the planning process, which almost all stated as being a challenge in the personalized learning model.

When teachers discussed the need for much reflection in the personalized process it was greatly connected to the planning process. Unlike in the traditional model, teachers must develop lesson plans that get at the needs of every student, where they are at the 
time of the lesson. It is not planning for whole group lessons as the primary mode of teaching. Teacher 8 stated, "At first glance it seems that it would be easier because the student is the lead, but in reality, the timing and the flow of the classroom is so hard to put together so that each student stays up with whatever is assigned. Planning for this type of classroom is time consuming, and better be planned out well otherwise not only will the students fall behind, but so will the instructor." This statement gives insight into the challenge these teachers face with planning. Instead of planning one lesson for a class of students they are planning individual lessons for each student, and sometimes also planning whole group and small group lessons as students may need them. Teacher 6 speaks to this challenge with, "Planning for personalized can be brutal. Being able to meet the needs of all students is time consuming and tricky. Furthermore, being able to plan for multiple tiers of learners in a personalized learning environment is a reflective process that must include the student voice in the planning process." Individualized instruction was a consistent theme among the teacher's responses that make planning such a challenge. There is such a time commitment to reviewing student data, identifying their strengths, planning for their weaknesses, and the constant need to give feedback to students to ensure their success. These aspects are seen in the response of Teacher 5 , "Challenging because you are constantly looking at formative data, identifying needs, planning for small groups, and trying to give effective feedback. You want to support students who need more help while, at the same time, push students who are ready to perform at higher levels." Based upon this dramatic change in the lesson planning process, the challenges it has created, the role of the teacher is shifting in the process. 
Because the shift of teaching and learning in the personalized learning framework moves from the traditional teacher-centered model of instruction to a more studentcentered approach, the role of the teacher is impacted. The teachers consistently felt that their role has shifted from the leader of the lesson, in the front of the room, lecturing to the role of facilitator, guide, and support for learning. Teacher 4 defined the role of the teacher in personalized learning with, "My role during personalized learning is to be the facilitator. I am there when the student needs me. I push them further than what they thought they could go. I support those who need me. I reflect with the student throughout the process." Teacher 7 had a similar statement, "Is as a facilitator of instruction. Rather than the traditional classroom of whole group lecture, it is a process of using student choice, observation, student performance and data collection to provide varying support and resources for specific student needs." The teachers perceive themselves to have a "backseat role" now as they guide students through the learning process. The ultimate goal is to reach the point where students gradually take full responsibility for their learning as stated by Teacher 2, "My goal as a teacher is more support. The gradual release of responsibility to the students is the ultimate goal." It is clear from the responses that the role of the teacher has changed, teachers feel challenged with this new role, but when discussing how personalized learning helps them meet the needs of students the responses are consistently positive despite the challenge.

As teachers responded to personalized learning regarding teachers meeting the needs of students, teachers feel that there are great advantages and opportunities for students in the personalized framework. There was, however, some who feel that it is difficult for elementary students to transition to this model and also difficult for students 
to make the transition when they are older if they did not do it as younger students. It was also pointed out that personalized learning platforms can be of great use to teachers in managing student performance data and helping to ensure that student needs are met. Teacher 6 sums up the most positive aspects of personalized learning, "In regards to meeting the students' needs, personalized learning has paved a way for learners to start taking ownership over when their learning breaks down and how to apply fix it strategies to overcome the learning breakdowns. Student ownership in personalized learning is more pronounced." Teacher 4 gave a similar response with, "Personalized learning has pushed students to own their learning. They are in charge of their grade; they can push further without being held back. They can review without feeling they can't catch up. They are in charge of their outcomes."

These teachers believe that personalized learning has empowered students. It is easier to identify their individual needs and help them find success. It is, however, also felt that student success and/or lack of success is also individualized in the personalized learning framework. There is some feeling among the teachers that personalized learning at the elementary level is very much a challenge as described by Teacher 2, "Meeting students' needs has been very difficult in the lower grades. Students have difficulty transitioning from the primary grades to this model because they have relied on teacher lead instruction. I have found using small groups during this transition has helped quite a bit. Student motivation is a big key in having success in this model as well." There is also some thought that if it is not started at a younger age, it is more difficult as well, as seen in the response of Teacher 8, “As I mentioned before, for some this model works, but overall it is not as effective I would hope it to be. I believe that part of that is because it is 
not a model that most students have from their early years of school. They are so used to the teacher doing it one way that when they first come into contact with this model of learning, it is hard for them to adjust and therefore they become frustrated and lose motivation because everything becomes overwhelming." Clearly there are perceptions that personalized learning provides great opportunities for teachers to meet the needs of students yet there is valid belief that how, when, and with whom it is implemented are important factors to consider in regards to how well student needs are met in the personalized learning framework.

The perceptions of teachers regarding their own transition to the personalized learning framework were consistent across all answers. Their responses also connect back to the responses on the corresponding survey questions. Transitioning to the personalized model was and still is a challenge for teachers. There were, however, some perceptions of reward from the transition, regardless of the challenge. In the transition process the difficulty was not identified as planning as it was earlier but mainly the struggle teachers have in giving up the control they have in the traditional model. This is consistent with research in the literature review. Teacher 5 stated, "Transitioning from traditional teaching to personalized learning is still a work in progress for me. I struggle with giving up that feeling of "control." In the long-run, I know that I am helping my students become more independent, life-long learners." Teacher 6 agreed but was somewhat more specific, "Transitioning from traditional to personalized learning is both rewarding and difficult. First, you stop being in control of the learning pathways and sometimes that can be extremely difficult to step away from. As teachers, we tend to be great at giving "directions" to others and not so well with taking a backseat! It takes time not to take 
over when your student is struggling. It takes practice to coach a student who has no implicit motivations and is falling behind. The transition to personalize takes time, patience, and great resources." There is also the understanding that students undergo this same difficulty of assuming control as the teacher relinquishes it as seen in the statement from Teacher 8, “A balancing act. Students go from having a teacher lead the instruction to being responsible for learning at their own pace in their own way. This leaves room for some to get behind that normally would not until they are used to this method of learning. I feel like it leaves a lot of room for students who require just facilitation to fall behind."

There is certainly evidence from my data to support the supposition that teachers perceive their role to have changed through the implementation of personalized learning. The entire way teacher's approach their work has changed from how they plan for individual needs instead of the whole group, the level of student data they must review daily, and the shifting from the leader of instruction to the facilitator of instruction. Given that all of the teachers in this study have multiple years' experience in the traditional model their perceptions of struggle and challenge in the transition are based upon valid experiences.

\section{Teacher Perceptions of Successes and Challenges of Implementing Personalized}

\section{Learning}

Questions 4, 5, and 6 from the teacher climate/culture survey provide some insights into research question three. As in the other sections, looking at the survey data in isolation does not offer a deep enough view in which to draw any conclusions from these data alone. As in the other sections the survey data were combined with data collected from the group level assessment process in order to illustrate findings. 
These three questions ask what teachers think of their colleagues, what students most often do in class, and the kinds of interactions they had with other teachers in the school. For the question of what students most often do in class the response that was in the top three answers across all three years was challenging work. This response did decrease each year, but it remained in the top three. Classroom work and think were the only other responses to be consistently in the top three responses over the three-year period. As relates to successes of personalized learning it would be expected to see challenging work be prominent. The responses to what teacher's think of their colleagues is more telling to what would be hoped over a three-year period in which teachers have already expressed the feeling of being challenged. The top response all three years was caring. This is important as it is stated in the literature review, in what may be the most comprehensive definition of personalized learning, that relationships are vital. In order to have this component in the personalized model the teachers must be caring, both to each other and to their students. Over the last two years of the survey, this response was over $80 \%$. The question regarding teacher interactions with colleagues is consistent with the caring aspect of teachers. Supportive was in the top three responses each year, and the top response over the last two years. Respectful was in the top three over two of the three years. Both of these responses also saw an increase in percentage over the past two years. In considering that the teachers have expressed the feeling of being challenged and pressed for time it bodes well for the personalized model that teachers are respectful to and supportive of each other. It is certainly conceivable that during a period that is professionally challenging colleagues could become adversarial, unhappy, or disgruntled. My data do not suggest that such was the case with these teachers. 
Prompts 10,11, and 12 of the group level assessment were aligned with research question 3. These prompts asked teachers to identify success and challenges of personalized learning and how implementation could be improved. In the selective coding process, there were three values that appeared most frequently, a total of 5 times each. Those three values were student engagement, difficult lesson planning, and the need for more training and resources.

Teachers responded very positively to the success of personalized learning and the most notable success stated was student engagement. This occurs due to a higher level of student ownership in their work, becoming more independent as learners, and becoming better goal setters. It also comes from experiencing success. Teacher 4 stated, "Students become more engaged in their learning. Students are more independent. Students become great goal setters and know how to reach their goals." It is also stated in the responses that students can celebrate their struggles and how they learned to overcome them. Teacher 6 explained this in detail, "Successes of personalized learning are students owning their own learning. Students celebrating their own struggles and ways that they worked to overcome them. Successes are students able to articulate when their learning is breaking down and knowing when to call for help and what that 'help' should look like (because sometimes it won't just be the teacher)." This connects back to the corresponding survey questions. Challenging work connected with high student engagement are highlights of success for the personalized learning model.

When responding to what are the challenges of personalized learning lesson planning was obviously the primary issue identified. In the response to this prompt however, there were some other challenges stated. One of the challenges stated by 
Teacher 5 was, "Getting everyone (students, teachers, parents, and community) to shift their mindset from traditional education." It is important to note that while this study is only looking at the perceptions of teachers in the implementation of personalized learning, students, parents, and community members also have their own perceptions about success and challenges to personalized learning. In the response made by Teacher 5 it is evident that these perceptions can be a challenge for teachers as they make the transition. A good example of this can be seen in the response from Teacher 7, "Challenges of personalized learning lie within the student. A student who is apathetic to learning is going to struggle. Students who simply struggle in school are going to have a difficult time knowing what to do next. It is challenging for the teacher to meet 100 different kids, in my position, where they are every single day." There are other perceived challenges for these teachers as they implement personalized learning. Most in some way come back to how teachers plan their daily lessons, but some come back to how implementation is planned prior to initiation.

With regard to improving implementation there was one consistent perception that nearly every teacher specifically stated, the need for more training and more resources. Those who did say this specifically state it in terms that equated to the same result. There were suggestions of ensuring that there was an exemplary model of personalized learning to follow. Another teacher stated that there needs to be a rethinking of the traditional school day. As has already been determined there is not a consistent understanding or definition of personalized learning among these teachers so the statement of an exemplary model to follow is very real to them and connected to their need for more training to understand what they are working to achieve. In the absence of this, based 
upon the survey and data that will be discussed in the next section teachers have supported each other in this process.

In the review of documents, I was able to determine that the district has made a strong commitment to providing training for the teachers. The strategic plan has a clear focus on personalized learning. As stated in the plan all students are expected to have opportunities for personalized learning and that even professional learning for teachers will be personalized. A definition of personalized learning is provided in the strategic plan that was communicated throughout the district and community. The strategic plan was sent out to each parent, it is posted on the district website, and is available in all buildings. At the end of the 2018-2019 school year district leadership was aware of the need to reinforce the vision of personalized learning so professional development was centered on this effort. The result was creating a visual depiction of the components of personalized learning to assist all stakeholders in developing a better understanding of the district's vision of personalized learning.

\section{Teacher Perceptions of How Teacher Preparation Assisted/Inhibited the Transition to Personalized Learning}

The final research question of my study sought to examine the perceptions of teachers regarding how their teacher preparation program assisted or inhibited their transition to the personalized learning framework. There were no questions on the survey that would align to this research question. Therefore, I relied primarily on the responses from the group level assessment to uncover the perceptions of the teachers in this regard. 
Prompts 13,14, and 15 of the group level assessment were aligned to research question four. These prompts sought teacher responses regarding how teachers were prepared to teach in the personalized learning model and how that transition was either assisted or inhibited. There were three primary responses to how teachers were prepared to teach in the personalized model; Trial and error, working with experienced teachers, and seeing it implemented in other schools. For the most part teachers felt they had to prepare on their own. Some stated that there had been no specific training or model provided to guide them such as Teacher 6, "Preparing me to teach in the personalized model is best learned through trial and error. No specific strategy or model has prepared me, instead my experiences and own learning have guided me to find resources specific to what I need as a personalized teaching instructor." In some cases, teachers learned from other teachers who had some experience in personalized learning. There were no responses that stated any type of formal training in their teacher preparation programs or professional development that had helped prepare them for the personalized model.

When responding to how they were assisted in the transition to personalized learning the teachers once again stated that they relied on trial and error and help from more experienced teachers. One teacher explained that having been a special education teacher earlier in her career had assisted her for the work of individualized instruction and progress monitoring, which are crucial aspects of personalized learning. Teacher 6 explained trial and error in specific detail, "My transition through personalized learning was assisted through my own failures and successes. Again, these struggles helped me to learn how to personalize them without being the driver in their academic pathway." Once again, there was no mention of any formal training either through their teacher 
preparation or through professional development that assisted them in the transition to personalized learning.

As I reviewed documents, I found evidence that the district had made efforts in providing training and direction as to how to implement personalized learning. One document, the Learning Centered Anchor Chart (See Appendix G) has already been mentioned in a previous section as evidence that the district recognized the need to reinforce the understanding of personalized learning among the teachers. There were also professional development opportunities provided to teachers on a voluntary basis through cohorts for blended learning and project-based learning. There is also documented evidence of the district's partnership with Summit Learning and supports the fact that teachers do receive training in and out of the district throughout the school year.

The responses regarding what inhibited teachers in the transition to personalized learning identified traditional mindset, lack of formal training, the pressures of state accountability assessment, and lack of buy-in within the local community. In the face of a lack of training teachers believe they need time, patience and honest feedback to effectively make a successful transition to the personalized learning model.

\section{Summary of Findings}

My analysis of survey data, GLA data, and district documents revealed evidence of both successes and challenges in the implementation of personalized learning in Trimble County Public Schools. There are some consistent patterns across the teacher responses on the survey, teacher responses on the group level assessment prompts and the core values identified through selective coding that align with prior research as it relates to the implementation of personalized learning. Most importantly there has been a major 
shift in the role of the teacher as personalized learning has taken the place of the traditional model. Two other affirmations of previous research were identified in that there is no consistent definition of personalized learning and implementation from the teacher's perspective is very challenging. Despite these facts, however, the perception of teachers also affirmed that personalized learning is rewarding, improves student engagement, empowers students, and is a worthwhile endeavor. The most important aspect of the findings relates to the pre-planning and pre-training required prior to implementation in a school or district.

In many cases, when implementing programs or initiatives teachers are not given the opportunity to offer their perspective on how implementation could be most effective. In the implementation of personalized learning the teacher perspective can be invaluable to successful implementation and could truly help in the development of support and resources to have in place before implementation begins. Chapter 5 will provide a summary of findings in relation to implications. 


\section{CHAPTER 5: SUMMARY OF FINDINGS AND IMPLICATIONS}

In this study I sought to answer the following four research questions.

1. How do teachers define personalized learning?

2. How do teachers describe their role within the personalized learning framework?

3. Why has implementing personalized learning been successful and/or challenging?

From the teacher perspective?

4. How did teachers perceive their preparation programs as assisting or inhibiting Teachers' transitions to the personalized learning model?

In this chapter, I provide a summary of the findings for each research question. I then

Discuss the implications of my findings for policy, practice, and future research.

\section{RQ 1: How do teachers define personalized learning?}

The first research question sought to determine how teachers define personalized learning based upon their lived experiences of implementing personalized learning in their classrooms. Having seen from the review of literature that finding one, consistent definition of personalized learning is difficult; I wanted to see if teachers in a smaller 
district where personalized learning had been implemented had a consistent understanding of what personalized learning is in practice. My initial look at the survey questions related to research question one suggested that there may not be a consistent understanding of personalized learning among the teachers.

The responses of teachers during the group level assessment made it apparent that while each teacher understands certain key aspects of personalized learning, their collective understanding and definitions were inconsistent when compared to each other. The most frequent response during the GLA was individualized instruction, which appears in the most specific definitions of personalized learning (Miliband, 2004; Sebba et al., 2007; U.S. DOE, 2010). The teachers who participated in the group level assessment could not give a definition of personalized learning that was holistically consistent with the most comprehensive definitions provided in the literature, and they could not give a definition that was holistically consistent with each other's definitions. Perhaps the most telling inconsistency is the one that exists between teachers' definitions and the district's definition of personalized learning shared in Chapter 4.

As has already been stated numerous times and supported by the literature on personalized learning, finding a consistent definition is difficult. There are so many aspects to personalized learning that it is possible to adapt a different model everywhere it is implemented. Aligning the core values to the criteria of the coding paradigm (Strauss $\&$ Corbin, 1990), there were eight core values in the category of the phenomenon being studied (personalized learning). All those values are valid aspects of the phenomenon of personalized learning (See Figure 2). These elements could be useful to the district in working through a process of defining what personalized learning is in TCPS. This would 
assist them in communicating to the teachers the vision of the model and how to put it into practice. Most importantly, teachers would have a consistent understanding of their model of personalized learning and be able to communicate it and put it into practice. The teachers spoke to the definition of personalized learning from their own experiences as they have implemented it into their classrooms and based upon the direction, they have been given from the school district. Personalized learning is not a rigid model. There are so many variations of what it could be in practice that it is conceivable that there is a different model in every classroom where it is practiced. The findings of research question one were consistent with prior research and supports the complexity of the personalized learning framework as a model.

Figure 2. Depiction of Selective Coding Applied to Strauss and Corbin's Coding Paradigm

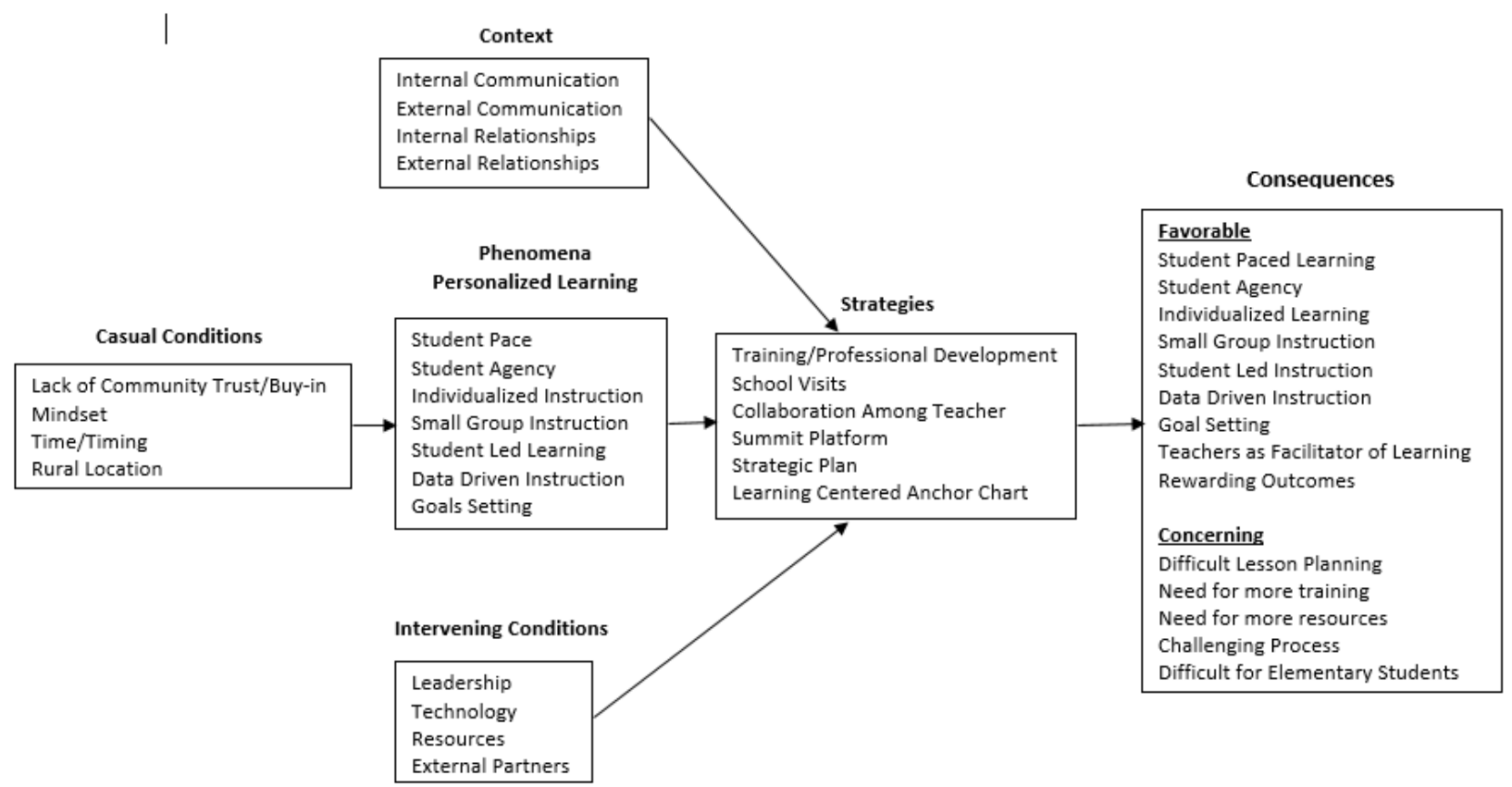




\section{RQ 2: How do teachers describe their role within the personalized learning framework?}

Research question one was vital in transitioning through the study to research question two. It was important to understand the foundational understanding of personalized learning as defined by the teachers before addressing the question of how they describe their role as a teacher in the personalized learning framework. Regarding research question two the responses of the teachers generated a consistent picture of how they defined their role in the personalized learning framework.

The teachers felt they never had enough time to complete their responsibilities at work, felt hectic and pressured in doing so. They felt challenged, pressured, and tired. These feelings were consistent with data collected in the GLA. Due to the nature of personalized learning the role of the teacher has drastically changed from that of the traditional leader of instruction in the front of a whole group classroom to that of a facilitator of learning. There are several challenges that stem from this changing of roles and some of them bridge back to research question one.

Teachers talked about the struggle of giving up control to their students. As seen in the previous research on personalized learning and as became apparent in research question one, student agency and individualized instruction were key aspects of the personalized model in Trimble County. Both of these key components call on teachers to shift responsibility to the students regarding their learning. Some of the teachers even discussed how this is also changing the role of the students which adds to the challenge faced by the teachers as they attempt to prepare students to be successful in this model. This in turn creates a change and a challenge in how teachers plan their lessons. 
Due to the nature of personalized learning and the need to individualize instruction teachers have found that lesson planning requires much more time and effort. Planning lessons that meet the needs of every student requires reflection on each lesson, student data, student work, and the teaching process. These are the challenges identified by the teachers regarding their new role in the personalized learning framework. It is not just the challenge of getting the planning completed, it is the worry of whether or not the needs of students are being met before, during, and after the lesson is taught.

When comparing the data through the coding paradigm (Strauss \& Corbin, 1990) the role of the teacher changing from a leader of whole group instruction to that of a facilitator of learning is both a part of the phenomenon of personalized learning as well as a favorable consequence of the implementation of personalized learning. One of the components of this change however is the difficulty in lesson planning and the added support needed for teachers as the make this transition. If the teachers can make the transition successfully with the proper training and support, the implementation of personalized learning could have a better outcome.

Based upon the number of challenges stated by the teachers, the level of work and fatigue it places on them there are implications for more than just whether students' needs are being met or not. The deeper implications get at the foundation of implementation and how to prepare and support teachers to do this successfully. How well this is done could result in the success or failure of implementation and the personalized learning framework. This will be supported by the findings of research questions three and four as well as discussed in the implications of practice section of this chapter. 


\section{RQ 3: Why has implementing personalized learning been successful and/or challenging?}

In looking at the successes of personalized learning there was again a consistent connection to the survey. The responses of the teachers specifically regarding the successes of personalized learning most frequently identified student engagement as the primary success. When considering that student agency and individualized learning were key aspects of the teacher's definition of personalized learning one would expect to see students become more engaged. Teachers also stated that students experience success due to the setting of goals and overcoming their struggles; and that this success helped to improve student engagement. The challenges were consistent with those discussed in research question two.

The teachers obviously feel that with their changing role in the classroom they need more training to be effective. Considering that teachers were in such a challenging implementation of personalized learning and they feel they need more training there has been a network of teachers working to support each other. While the teachers did not specifically identify this as a success of the personalized learning, it is certainly a success that is necessary to the implementation of any initiative and worth noting in this study.

There are consequences attached to the implementation of any initiative or program in the field of education. Some of these consequences are positive while others are not. Using the coding paradigm (Strauss \& Corbin, 1990) I identified 13 core values that are aligned with being consequences of the actions and interactions related to the phenomenon (See Figure 2). Eight of those consequences have been positive in nature. They include student paced learning, student agency, individualized instruction, student 
led instruction, small group learning, data driven instruction, goal setting, and a feeling of reward. Teachers as facilitators of learning, reflection, and the challenges this brings are both positive and negative as consequences. Positive in the sense that having teachers shift their role to facilitator is good for students and teachers stated there have been rewards. One of these has been the level of reflection required of teachers while the challenge of doing so has contributed to the feeling of being overwhelmed. These have also been consequently negative in that they have made lesson planning more difficult, placed pressure on teachers, and made it difficult for elementary students to make the transition.

\section{RQ 4: How did teachers perceive their preparation programs assisting or inhibiting teachers' transitions to the personalized learning model?}

The final research question sought to determine to what degree, if any, teacher preparation programs had either assisted or inhibited the teachers in their transitions to the personalized learning framework. When discussing what had prepared the teachers for the transition to personalized learning several were specific in stating that they had not had any specific program or formal training to assist them. Their transition had been through trial and error and from seeking support from other teachers. As I stated in the findings of research question three there was some connection with the findings that related to teachers supporting each other and how that had increased over the years of implementation.

The findings of this question do not specifically answer whether teacher preparation programs assisted or inhibited teachers in their transition to the personalized 
learning framework. It is evident that teacher preparation programs were completely absent from the responses of what assisted teachers in their transition. But then again, the teachers did not mention any other training as having assisted them either. When talking about what inhibited them there were some specific responses to mindset that were tied to how things have been done in education for years. What is clear from the findings of research question four is that teachers were not prepared for the transition to personalized learning through any previous experiences prior to implementation and teachers need specific training to make the transition easier and effective.

\section{Implications for Policy}

Lindgren and McDaniel (2012) note that when students are motivated, they are engaged. Traditional methods of teaching and learning are no longer engaging to the students in today's classrooms (Wagner \& Dintersmith, 2016). The implications of this study are that intentional efforts be made to implement KRS 158.6451 to its fullest in all classrooms. Schools and districts should focus on the statute as a whole and not only the academic requirements. In order to be successful schools and districts must make the commitment to changing the ways in which they approach education. Learning must be personalized and engaging, offering students with more than just academic opportunities in order to be successful beyond the halls and classrooms of the school. To effect this change there will need to be policy changes in the traditional setting of the school, moving away from brick and mortar classrooms and departing from the focus on seat time as a requirement to master any level of content. 
There are several aspects of the current education system that must be addressed in order to meet the recommendation of implementing KRS 158.6451. There must be an effort to change not only how the curriculum is delivered but to change the curriculum as well. In doing so there must be evaluative processes in place in order to seek valuable and valid feedback form teachers, students, and parents to allow for the best outcome of curriculum development. There must also be a commitment from districts and schools to convert to 1 to 1 digitally, not to simply put digital devices in the hands of students but in order to intentionally put new and up to date curriculum and engaging learning opportunities in their power.

Educators must be committed to releasing control that has been under the traditional model of education. Teacher roles must change in such a way as to empower students and facilitate learning and success. It is also important to look away from high stakes testing and test scores as a primary means of measuring success. Success can only be measured in actual success beyond the classroom and the school through success in college or career. Strategic plans and school improvement plans should begin to plan intentionally for ensuring that students are not only ready for college and career but that they are ready and prepared to be successful in college and career.

\section{Implications for Practice}

The teacher's role changes in personalized learning and teaching in a personalized setting may have a profound impact on the teachers. My analysis suggests the personalized setting and the affect it may or may not have on the engagement of students depends on whether the lesson and the environment for personalized learning are correctly implemented by the teacher. The role of the teacher must change for the 
personalized environment to garner positive results. The most notable change that teachers would need to undergo is the ability to release some of the control they have traditionally had and turn those responsibilities, to a degree, over to students. There is also a need for teachers to have more training and support in how they deal with this transition as it is not only challenging to change their mindset, but the level of work required in lesson planning and monitoring student progress also needs to be addressed. Another implication of this study is that implementation of personalized learning must be well planned out prior to beginning to move to the personalized model. It requires a collaborative process in which all stakeholders are given an opportunity to understand the complexity of the personalized learning framework in order to reach a consistent vision of what the model will look like when implemented. This requires working to develop a consistent definition of the personalized learning model that will be implemented so that training, resources, and support can be determined prior to implementation.

There is a great deal of research that is still needed but initially it appears that there could be a strong case that teaching in a personalized environment, while creating a challenge to overcome traditional practices, could have a positive impact on both teacher efficacy and motivation. The personalized learning model provides an opportunity to see positive results for both students and teachers. While studies can be done on each individually, the impact on students and teachers is strongly interconnected and dependent on one another. 


\section{Implications for Future Research}

The scope of my study was admittedly small, as it encompassed only a small district in a rural area. My study was also conducted after the implementation process and not concurrent with it. While I believe there is a need for research specifically to measure whether or not the personalized learning model is effective in improving student outcomes, I believe the more important issue is conducting further research on effective implementation of the model. As the research on comprehensive school reforms discussed in my literature review, implementation of any program or initiative is the most vital part of measuring success. In order to conduct valid research on whether personalized learning is effective or not there would need to be valid evidence of an effective implementation. I also think that it would be more beneficial if the research was conducted on a larger scale than one small school district.

It would be beneficial to identify three to five districts in which to conduct a study similar to mine but to do so as each district begins the process of implementation and conduct the study in three phases: pre-implementation, during implementation, and post implementation. The findings in each district could then be compared with each other and it could be determined where effective implementation was enacted. In each of the three phases quantitative data on student performance could be collected in real time so that at the end of the study, there could be a determination of the effectiveness of the personalized learning model, if it is determined that implementation was done effectively. It would also be beneficial to expand the qualitative aspect of the study to include the perceptions of students, parents, and educational leadership over the three phases of the study. 


\section{REFERENCES}

Basham, J. D., Hall, T. E., Carter, R. A., \& Stahl, W. M. (2016). An operationalized understanding of personalized learning. Journal of Special Education Technology, 31(3), 126-136. doi: 10.1177/0162643416660835

Bell, S. (2010). Project-based learning for the 21st century: Skills for the future. The Clearing House: A Journal of Educational Strategies, Issues and Ideas, 83(2), 3943. doi: $10.1080 / 00098650903505415$

Biddulph, M. (2011). Articulating student voice and facilitating curriculum agency. Curriculum Journal, 381-399.

Bingham, A. J., Pane, J. F., Steiner, E. D., \& Hamilton, L. S. (2018). Ahead of the curve: Implementation challenges in personalized learning school models. Educational Policy, 32(3), 454-489.

Bloomberg, L. D., \& Volpe, M. (2019). Completing your qualitative dissertation: A road map from beginning to end. Los Angeles: Sage.

Brydon-Miller, M., Rector Aranda, A. \& Stevens, D. M. (2015). Widening the circle: Ethical reflection in action research and the practice of structured ethical reflection. In H. Bradbury (ed.), Handbook of Action Research, 3rd ed. Thousand Oaks, CA: SAGE.

Borman, G. D., Hewes, G. M., Overmann, L. T., \& Brown, S. (2003). Comprehensive school reform and achievement: A meta-analysis. Review of Educational Research, $73,125-230$ 
Charmaz, K., (2008). Constructionism and the grounded theory. In J. A. Holstein and J. F. Gubrium (Eds.), Handbook of Constructionist Research (pp. 397-412). New York: the Guilford Press.

Charmaz, K., 2011. Grounded theory methods in social justice research. In N.K. Denzin \& Y. Lincoln (eds.). Handbook of Qualitative Research 4th ed. (pp. 359-380). Thousand Oaks, CA: Sage.

Chen, C. (2008). Intelligent web-based learning system with personalized learning path guidance. Computers \& Education, 51(2), 787814.doi:10.1016/j.compedu.2007.08.004

Childress, S., \& Benson, S. (2014). Personalized learning for every student every day. Phi Delta Kappan, 95(8), 33-38.

Courcier, I. (2007). Teachers' perceptions of personalised learning. Evaluation \& Research in Education, 20 (2), 59-80. doi:10.2167/eri405.0

Creswell, J. W. (2018). Qualitative inquiry \& research design: Choosing among five approaches. Thousand Oaks: SAGE.

Creswell, J. W., \& Creswell, J. D. (2018). Research design: Qualitative, quantitative, and mixed methods approaches. Los Angeles, CA: SAGE.

Creswell, J.W. and Poth, C.N. (2018) Qualitative Inquiry and Research Design Choosing among Five Approaches. 4th Edition, SAGE Publications, Inc., Thousand Oaks.

Crotty, M. (2015). The foundations of social research meaning and perspective in the research process. London: SAGE.

Datnow, A., \& Stringfield, S. (2000). Working together for reliable school reform. Journal of education for students placed at risk, 5(1-2), 183-204. 
Datnow, A. (2005). The sustainability of comprehensive school reform models in changing district and state contexts. Educational administration quarterly, 41(1), 121-153.

Deed, C., Cox, P., Dorman, J., Edwards, D., Farrelly, C., Keeffe, M., Yager, Z. (2014). Personalized learning in the open classroom: The mutuality of teacher and student agency. International Journal of Pedagogies and Learning, 9(1), 66-75.

Desimone, L. (2002). How can comprehensive school reform models be successfully implemented? Review of Educational Research, 72, 433-479.

Elmore, R. (1996). Getting to scale with good educational practice. Harvard educational review, 66(1), 1-27.

Epstein, J. L. (2005). A case study of the partnership schools comprehensive school reform (CSR) model. The Elementary School Journal, 106(2), 151-170.

Ferlazzo, L. (2017). Student Engagement: Key to Personalized Learning. Educational Leadership, 74(6), 28-33.

Finley, S. (2000). The changing role of the teacher. Southwest Educational Development Laboratory.

Friedman, T. L., \& Mandelbaum, M. (2012). That used to be us. Little, Brown.

Friend, B., Patrick, S., Schneider, C., \& Vander Ark, T. (2017). What's possible with personalized learning? Vienna, VA: International Association for K-12 Online Learning (iNACOL).

González, G., \& DeJarnette, A. (2012). Agency in a geometry review lesson: a linguistic view on teacher and student division of labor. Linguistics and Education, 23(2), 182-199. doi:10.1016/j.linged.2012.02.001 
Gorey, K. M. (2009). Comprehensive school reform: Meta-analytic evidence of BlackWhite achievement gap narrowing. education policy analysis archives, 17(25), 1.

Graham, K. E., Schellinger, A. R., \& Vaughn, L. M. (2015). Developing strategies for positive change: Transitioning foster youth to adulthood. Children and Youth Services Review, 54, 71-79. doi: 10.1016/j.childyouth.2015.04.014

Grant, P., \& Basye, D. (2014). Personalized learning: A guide for engaging students with technology. Eugene, OR: International Society for Technology in Education.

Gross, B., Booker, T. K., \& Goldhaber, D. (2009). Boosting student achievement: The effect of comprehensive school reform on student achievement. Educational Evaluation and Policy Analysis, 31(2), 111-126.

Gross, B., \& Goldhaber, D. (2006). Sticking with It: To What Extent and Why do Schools Sustain or Discontinue CSR Models?. Reteived April 20, 2020 from https://www.crpe.org/sites/default/files/wp_crpe3_csrdsustain_may06_0.pdf

Guo, L. (2014). Preparing teachers to educate for 21st century global citizenship: envisioning and enacting. Journal of Global Citizenship \& Equity Education, 4(1), 1-23.

Hassel, B. C., \& Hassel, E. A. (2011). Seizing Opportunity at the Top. Chapel Hill, NC: Public Impact.

Jacobs, H. H. (2010). Curriculum 21: Essential education for a changing world. Alexandria, VA: ASCD.

Jerald, Craig D. (2009), Report of the center of public education in America, defining a $21^{\text {st }}$ century education.

Johnson, B., \& McElroy, T. M. (2012). The changing role of the teacher in the $21 \mathrm{st}$ 
century. Teachers Net Gazzette, 9(10), 1-6.

Johnson, L. (2008). Relationship of instructional methods to student engagement in two public high schools. American Secondary Education, 36(2), 69-87.

Keefe, J. W., \& Jenkins, J. M. (2002). A special section on personalized instruction. Phi Delta Kappan, 83(6), 440-448. https://doi.org/10.1177/003172170208300609

Kentucky General Assembly. (2010, March 8). Senate Bill 1, KRS 158.6451. Original mark-up of Senate Bill 1 (2009). Frankfort, KY.

Kim, B. (2001). Social constructivism. In M. Orey (Ed.), Emerging perspectives on learning, teaching, and technology. Retrieved, from http://projects.coe.uga.edu/epltt/

Lenz, B., Wells, J., \& Kingston, S. (2015). Transforming schools using project-based learning, performance assessment. John Wiley \& Sons.

Lin, C., Yeh, Y., Hung, Y., \& Chang, R. (2013). Data mining for providing a personalized learning path in creativity: An application of decision trees. Computers \& Education, 68, 199-210. doi:10.1016/j.compedu.2013.05.009

Lincoln, Y.S., \& Guba, E. G. (1985). Naturalistic Inquiry. Newbury Park, CA: Sage Publications.

Lindgren, R., \& McDaniel, R. (2012). Transforming online learning through narrative and student agency. Educational Technology \& Society, 15(4), 344-355

Luke, J., Moulthrop, D., \& Gimbert, B. (2018). Teacher victimization in authoritative school environments. Journal of School Health, 88(4), 272-280.

McChesney, J., \& Hertling, E. (2000). The path to comprehensive school reform. Educational Leadership, 57(7), 10-15 
McLaughlin, M. W. (1987). Learning from experience: Lessons from policy implementation. Educational evaluation and policy analysis, 9(2), 171-178.

McLaughlin, M. W., Talbert, J., Kahne, J., \& Powell, J. (1990). Constructing a personalized school environment. The Phi Delta Kappan, 72(3), 230-235.

Maguire, M., Ball, S. J., \& Braun, A. (2013). What ever happened to...?'Personalised learning'as a case of policy dissipation. Journal of Education Policy, 28(3), 322338. https://doi.org/Http://dx.doi.org/10.1080/02680939.2012.724714

Maxwell, J. (1992). Understanding and validity in qualitative research. Harvard Educational Review, 62(3), 279-301. doi:10.17763/haer.62.3.8323320856251826

Miles, M.B., Huberman, A.M, \& Saldana J. (2014). Qualitative data analysis: A methods sourcebook (3rd ed.). London: SAGE.

Miliband, D. (2004). Personalised learning: Building a new relationship with schools [Pamphlet]. Belfast: Department of Education and Skills.

Milner, H. R. (2007). Race, culture, and researcher positionality: Working through dangers seen, unseen, and unforeseen.

Murphy, M., Redding, S., \& Twyman, J. (2017). Handbook on personalized learning for states, districts, and schools. Charlotte, NC: Information Age Publishing, Inc.

Netcoh, S. (2017). Balancing freedom and limitations: A case study of choice provision in a personalized learning class. Teaching and Teacher Education, 66, 383-392.

O’Keeffe, I., Brady, A., Conlan, O., \& Wade, V. (2006). Just-in-time generation of pedagogically sound, context sensitive personalized learning experiences. International Journal on E-Learning, 5(1).

Pane, J., Steiner, E., Baird, M., \& Hamilton, L. (2015). Continued progress: Promising 
evidence on personalized learning. Santa Monica, CA: RAND Corporation doi: $10.7249 /$ rr 1365

Pane, J. F., Steiner, E. D., Baird, M. D., Hamilton, L. S., \& Pane, J. D. (2017). Informing Progress: Insights on Personalized Learning Implementation and Effects. Research Report. RR-2042-BMGF. RAND Corporation.

Palinkas, L. A., Horwitz, S. M., Green, C. A., Wisdom, J. P., Duan, N., \& Hoagwood, K. (2015). Purposeful sampling for qualitative data collection and analysis in mixed method implementation research. Administration and policy in mental health, 42(5), 533-44.

Patrick, S., Kennedy, K., \& Powell, A. (2013). Mean what you say: Defining and integrating personalized, blended, and competency education. New York: iNACOL.

Peters, M. A. (2009). Personalization, personalized learning and the reform of social policy: The prospect of molecular governance in the digitized society. Policy Futures in Education, 7(6), 615-627. https://doi.org/10.2304/pfie.2009.7.6.615

Powell, K., \& Kalina, C. (2009). Cognitive and social constructivism: Developing tools for an effective classroom. Education, 130(2), 241-250.

Prain, V., Cox, P., C. D., Dorman, J., Edwards, D., Farrelly, C., Yager, Z. (2012). Personalised learning: Lessons to be learnt. British Educational Research Journal, 39(4), 654-676.

Prince, K., Swanson, J., \& King, K. (2018). Navigating the future of learning: KnowledgeWorks future forecast 5.0, Cincinnati, OH: KnowledgeWorks Foundation. 
Rector-Aranda, A., \& Raider-Roth, M. (2015). 'I finally felt like I had power': student agency and voice in an online and classroom-based role-play simulation. Research in Learning Technology, 23.

Redding, S. (2013). Through the student's eyes: A perspective on personalized learning. Philadelphia, PA: Philadelphia, PA: Center on Innovations in Learning. Retrieved from www.centeril.org

Redding, S. (2014a). Personal competency: A framework for building students' capacity to learn. Philadelphia, PA: Center on Innovations in Learning. Retrieved from WWw.centeril.org

Redding, S. (2014b). Personal competencies in personalized learning. Philadelphia, PA: Center on Innovations in Learning. Retrieved from WwW.centeril.org

Redding, S. (2016). Competencies and personalized learning. In M. Murphy, S. Redding, \& J. Twyman (Eds.), Handbook on personalized learning for states, districts, and schools (pp. 3-18). Philadelphia, PA: Temple University, Center on Innovations in Learning. Retrieved from www.centril.org

Reddy, W. B. (1996). Group-level team assessment: A 10-step sequence to a committed team. San Diego, CA: Pfeiffer

Richey, A., \& Petretti, D. (2002). Insights for interns: What can I do about teacher apathy? The English Journal, 92(2), 20-23.

Ross, S. M., \& Gil, L. (2004). The past and future of comprehensive school reform: Perspectives from a researcher and practitioner. Putting the pieces together: Lessons from comprehensive school reform research, 151-174. 
Rowan, B., Miller, R., and Camburn, E. (2009). School Improvement by Design: Lessons From a Study of Comprehensive School Reform Programs. CPRE Research Reports.

Rutherford, C. (2009). Planning to change: Strategic planning and comprehensive school reform. Educational Planning, 18(1), 1-10.

Sahabudin, N. A., \& Ali, M. B. (2013). Personalized learning and learning style among upper secondary school students. Procedia-Social and Behavioral Sciences, 103, 710-716. doi:10.1016/j.sbspro.2013.10.391

Saldana, J. (2016). The Coding Manual for Qualitative Researchers (3rd ed.). London: SAGE.

Schmidt, M., \& Datnow, A. (2005). Teachers' sense-making about comprehensive school reform: The influence of emotions. Teaching and teacher education, 21(8), 949965.

Sebba, J., Brown, N., Steward, M., Galton, M., \& James, M. (2007). An investigation of personalising learning approaches used by schools. Research report No. 843, University of Sussex.

Skinner, B., F., (1958). Teaching machines. Science, 128, 969-977

Slavin, R. E. (2008). Comprehensive school reform. 21st century education: A reference handbook, 2, 259-266. Retrieved April 20, 2020, from https://www.successforall.org/wp-content/uploads/2016/02/ComprehensiveSchool-Reform.pdf

Spillane, J. P., Reiser, B. J., \& Reimer, T. (2002). Policy implementation and cognition: 
Reframing and refocusing implementation research. Review of educational research, 72(3), 387-431.

Stevens, D. (2014). Relational culture among staff in an emerging urban STEM high school. (Electronic Thesis or Dissertation). Retrieved from https://etd.ohiolink.edu/

Strauss, A. L., \& Corbin, J. M. (1998). Basics of qualitative research: Grounded theory procedures and techniques (2nd ed.). Thousand Oaks, CA: Sage.

Summit Learning. (n.d.) Bring Summit Learning to your school Retrieved from: https://www.summitlearning.org/join-us/program.

U.S. Department of Commerce. (2012). The competitiveness and innovative capacity of the United States. US Department of Commerce, 1, 160.

U.S. Department of Education. (2002). Comprehensive School Reform (CSR) Program

Guidance. Retrieved April 20, 2020, from

https://www2.ed.gov/programs/compreform/guidance/guidance2002.pdf

U. S. Department of Education. (2010). Transforming American education: Learning powered by technology. Washington, DC: Author. Retrieved from http://www.ed.gov/technology/netp-2010.

Vaughn, L. (2014). Group level assessment: A large group method for identifying primary issues and needs within a community. SAGE Research Methods Cases.doi:10.4135/978144627305014541626

Vaughn, L. M., \& Lohmueller, M. (1998). Using the group level assessment in a support group setting. Organization Development Journal, 16, 99-99. 
Vollstedt, M. \& Rezat, S. (2019). An Introduction to Grounded Theory with a Special Focus on Axial Coding and the Coding Paradigm. 10.1007/978-3-03015636-7_4.

Wagner, T., \& Compton, R. A. (2015). Creating innovators: The making of young people who will change the world. New York, NY: Scribner.

Wagner, T., \& Dintersmith, T. (2016). Most likely to succeed: preparing our kids for the innovation era. New York, NY: Scribner.

Waldeck, J. H. (2006). What does “personalized education” mean for faculty, and how should it serve our students? Communication Education, 55(3), 345-352. doi:10.1080/03634520600748649

Waldron, N. L., \& McLeskey, J. (2010). Establishing a collaborative school culture through comprehensive school reform. Journal of Educational and Psychological Consultation, 20(1), 58-74.

Walters, H. (2004). Why teachers leave the profession. Delta Kappa Gamma Bulletin, 71(1), 58-60.

Wolf, M. A. (2010). Innovate to educate: System [re]design for personalized learning: A report from the 2010 symposium. Retrieved from http://www.ccsso.org /Documents/2010\%20Symposium\%20on\%20Personalized\%20Learning.pdf

Watson, J., (2008). Blended learning: The convergence of online and face to face education. promising practices in online learning. Washington, DC: North American Council for Online Learning.

World Economic Forum. (2016). The future of jobs employment, skills and workforce strategy for the fourth industrial revolution. Geneva, Switzerland 
Yin, R. K. (2018). Case study research and applications: design and methods. Los Angeles: Sage.

Zarif, T. (2012). Grounded theory method: An overview. Interdisciplinary Journal of Contemporary Research in Business, 4(5), 969-979.

Zmuda, A., Curtis, G., \& Ullman, D. (2015). Learning personalized: The evolution of the contemporary classroom. San Francisco, CA: Jossey-Bass. 


\section{APPENDIX A: SURVEY}

Which four of the following words or phrases best describe, in general, the expectations for students at your school?

Students are learning.

Students are busy.

Students understand.

Students know.

Students are able to explain.

Students are able to memorize.

Students should find it themselves.

Students should ask a teacher.

Students are expected to be good at everything.

Students are expected to be good at some things.

Which four of the following phrases best describe, in general, the kinds of things you say to your students?

What are you doing?

What are you thinking?

We will be working on...

You will be working on...

You are learning...

You are being taught...

Explain it. Repeat it.

You should do it this way.

You could do it this way.

You got it right!

You took the right approach.

I am interested in your answer.

I am interested in your thinking.

Which four of the following words or phrases best describe how you feel, in general, when trying to complete your responsibilities while at work?

Rushed.

Patient.

Hectic.

Calm.

Hurried. 
Deliberate.

Pressured.

Tense.

Never enough time.

Usually enough time

Relaxed

Which four of the following words or phrases best describes what you think of your colleagues, in general?

Real.

Honest.

Fun.

Interesting.

Permissive.

Inconsistent.

Consistent.

Caring.

Active.

Lazy.

Curious.

Uninterested.

Fake.

Untrustworthy.

Which four of the following words or phrases best describe, in general, what students most often DO in your classroom?

Classroom work.

Brief projects.

Long projects.

Write.

Think.

Worksheets.

Work with others.

Work alone.

Challenging work.

Easy work.

Presentations.

Papers.

Tests.

Listen to instruction.

Project demonstrations. 
Which four of the following words best describe the interactions you have with other teachers at your school?

Important.

Brief.

Trusting.

Respectful.

Supportive.

Helpful.

Useless.

Collaborative.

Isolating.

Empowering.

Rejecting.

Distant.

Which four of the following words best describe, in general, the physical spaces in which you spend most of your time while at your school?

Bright.

Unique.

Stressful.

Flexible.

Inviting.

Plain.

Chaotic.

Stable.

Comfortable.

Open.

Closed.

Neglected.

Which four of the following words best describe, in general, how you feel while at work?

Happy.

Angry.

Challenged.

Interested.

Afraid.

Appreciated.

Pressured.

Encouraged.

Confused.

Excited.

Lonely.

Supported.

Tired. 


\title{
APPENDIX B: GROUP LEVEL ASSESSMENT PROCESS
}

\author{
Group Level Assessment \\ Agenda \\ (Conducted Virtually)
}

Step 1---Climate Setting---Done through Email.

- Explain the GLA process (review the agenda)

- Assign groups (for Step 5)

- Have each group choose a facilitator

- Preview the prompts

Step 2---Generating---20 minutes

- Participants respond to the prompts

Step 3---Appreciating---5 minutes

- Large group review of prompt responses. Participants may add additional comments to any prompt and highlight any responses with which they agree by placing an asterisk at the end of the comment.

Step 4---Reflecting---5 minutes

- Participants individually reflect on the data as a whole---what means to them.

Step 5---Understanding---10 minutes

- Divide into 3 groups with assigned prompts to discuss and identify common themes in the responses.

- Reconvene the large group and have each small group report their findings. (5 minutes)

- Group 1 will be assigned prompts 1, 4, 8, 10, and 13 .

- Group 2 will be assigned prompts 2, 6, 9, 11, and 15 .

- Group 3 will be assigned prompts 3, 5, 7, 12, and 14 .

Step 6---Selecting---15 minutes

- In the large group, participants will clarify the most important themes from step 5.

- Participants will prioritize the themes based upon importance and feasibility

Step 7---Action---Incorporated with step 6

- Small groups list out next steps based on the priorities they have identified 


\section{APPENDIX C: GROUP LEVEL ASSESSMENT PROMPTS}

1. I define personalized learning as....? (RQ1)

2. Personalized is learning different from the traditional model of Learning because...? (RQ1)

3. Personalized learning looks like...? (RQ1)

4. Personalized learning is?...(RQ1)

5. After teaching in the personalized model, I...? (RQ2)

6. Planning for personalized learning is...? (RQ2)

7. With implementation of personalized learning your role as a teacher...? (RQ2)

8. With regard to teachers meeting student needs, personalized learning has...? (RQ2)

9. Transitioning from traditional teaching to personalized learning is...? (RQ2)

10. Successes of personalized learning are...? (RQ3)

11. Challenges of personalized learning are...(RQ3)

12. Implementing personalized learning can be improved by ...? (RQ3)

13. I was prepared for teaching in the personalized model by...? (RQ4)

14. My transition to personalized learning was assisted by...? (RQ4)

15. My transition to personalized learning was inhibited by...? (RQ4) 


\section{APPENDIX D: INFORMED CONSENT DOCUMENT}

\section{Project Title:}

THE SHIFTING ROLE OF TEACHERS: A CASE STUDY ON TEACHERS' PERCEPTIONS OF PERSONALIZED LEARNING IN A RURAL SCHOOL DISTRICT

Investigator(s) name \& address:

Dr. Kyle Ingle

College of Education and Human Development

University of Louisville

1905 South 1st Street Louisville, KY 40292

william.ingle@louisville.edu

Steve Miracle

1103 Summit Drive

Shelbyville, KY 40065

steve.miracle@bullitt.kyschools.us

Site(s) Where Study is to be Conducted: The Trimble County Extension Office and/or the Trimble County Public Library, Bedford, Kentucky

Phone number for subjects to call for questions: Steve Miracle (502) 220-9318

\section{Introduction and Background Information:}

You are invited to participate in a research study about the implementation of personalized learning. The study is being conducted by Steve Miracle, a doctoral student at the University of Louisville, who is being supervised by Dr. W. Kyle Ingle, Associate Professor in Educational Leadership. The study will take place at the Trimble County Extension Office in Bedford, Kentucky. Approximately 15 subjects will be invited to participate.

\section{Purpose of the Study:}

The purpose of this qualitative study is to examine the perceptions of teachers regarding the implementation of personalized learning to see if the role of the teacher has changed.

\section{Procedures:}

In this study, you will be asked to complete the Cognia teacher climate and culture survey as well as to be interviewed through Group Level Assessment (GLA). GLA is a 
participatory large group research method. Because of its participatory nature the process of GLA is interactive and collaborative. The GLA is a seven-step process in which you will respond individually, as small groups, and as a whole group to several prompts regarding the implementation of personalized learning. The large group segments will be video recorded for the researcher's benefit and the small group segments will be audio recorded for the researcher's benefit. The projected time allotted for the GLA process is three to four hours.

\section{Potential Risks:}

There are no foreseeable risks other than the sacrifice of your time to participate.

\section{Benefits:}

There are multiple potential benefits of this study: (1) the findings may influence change in how personalized earning is implemented in your school or district; (2) the findings may be helpful to other schools and districts who are beginning to implement personalized learning; (3) participants may better informed about their own practice of personalized learning from the going through the GLA process; and (4) significant challenges with implementing personalized learning along with suggestions of how teachers can be supported as they face those challenges.

\section{Compensation:}

You will not be compensated for your time, inconvenience, or expenses while you participate in this study, but drinks and refreshments will be provided during the GLA process and some door prizes will be provided to show appreciation for your participation.

\section{Confidentiality:}

Total privacy cannot be guaranteed. Your privacy will be protected to the extent permitted by law. Neither your name, nor the name of your school district, will be used. If the results from this study are published or used in reports, presentations your name will not be made public. Results will only be shared in aggregate form. The data will be stored on a recording device to allow the researcher to accurately transcribe the information from the recordings. Once transcription is complete, the video and audio recording will be erased. Only the researcher will have access to the initial data and paper records will be shredded.

\section{Voluntary Participation:}

Taking part in this study is voluntary. You may choose not to take part at all. If you decide to be in this study, you may stop taking part at any time. If you decide not to be in this study or if you stop taking part at any time, you will not lose any benefits for which you may qualify. You will be told about any changes that may affect your decision to continue in the study. 


\section{Contact Persons, Research Subject's Rights, Questions, Concerns, and Complaints}

If you have any concerns or complaints about the study or the study staff, you have three options. You may contact the principal investigator at (502) 852-6097 or william.ingle@louisville.edu If you have any questions about your rights as a study subject, questions, concerns or complaints, you may call the Human Subjects Protection Program Office (HSPPO) (502) 852-5188. You may discuss any questions about your rights as a subject, in secret, with a member of the Institutional Review Board (IRB) or the HSPPO staff. The IRB is an independent committee composed of members of the University community, staff of the institutions, as well as lay members of the community not connected with these institutions. The IRB has reviewed this study. If you want to speak to a person outside the University, you may call 1-877-852-1167. You will be given the chance to talk about any questions, concerns or complaints in secret. This is a 24-hour hot line answered by people who do not work at the University of Louisville.

If you have questions about the study, you can ask me now or anytime during the study. You can also call me at (502)869-6001 or e-mail me at steve.miracle@bullitt.kyschools.us. If you have any questions about your rights as a participant in this research or if you feel you have been placed at risk, you can contact the IRB Office at University of Louisville. You will receive a copy of this form for your records. This informed consent document is not a contract. This document tells you what will happen during the study if you choose to take part. Your signature indicates that this study has been explained to you, that your questions have been answered, and that you agree to take part in the study. You are not giving up any legal rights to which you are entitled by signing this informed consent document. You will be given a copy of this consent form to keep for your records.

\section{Acknowledgment and Signatures:}

This informed consent document is not a contract. This document tells you what will happen during the study if you choose to take part. Your signature indicates that this study has been explained to you, that your questions have been answered, and that you agree to take part in the study. You are not giving up any legal rights to which you are entitled by signing this informed consent document. You will be given a copy of this consent form to keep for your records.

Subject Name (Please Print)

Signature of Subject

Date Signed

Name of Investigator

List of Investigators

William Kyle Ingle, Ph.D.

Steve Miracle

\section{Signature of Investigator \\ Date Signed}

Phone Numbers

(502) 852-6097

(502) 216-9043 


\section{APPENDIX E: STRUCTURED ETHICAL REFLECTION}

\begin{tabular}{|c|c|c|c|c|c|c|c|c|}
\hline Values & $\begin{array}{l}\text { Developing } \\
\text { Partnerships }\end{array}$ & $\begin{array}{c}\text { Constructing } \\
\text { Research } \\
\text { Question }\end{array}$ & $\begin{array}{c}\text { Planning } \\
\text { Project/Action }\end{array}$ & $\begin{array}{c}\text { Recruiting } \\
\text { Participants }\end{array}$ & $\begin{array}{c}\text { Collecting } \\
\text { Data/ } \\
\text { Taking } \\
\text { Action }\end{array}$ & $\begin{array}{l}\text { Analyzing } \\
\text { Data/ } \\
\text { Evaluating } \\
\text { Action }\end{array}$ & $\begin{array}{l}\text { Member } \\
\text { Checking }\end{array}$ & $\begin{array}{c}\text { Going Public } \\
\text { (Presentation } \\
\& \\
\text { Publication) }\end{array}$ \\
\hline Integrity & $\begin{array}{l}\text { Having an } \\
\text { awareness } \\
\text { that } \\
\text { perceptions } \\
\text { of others } \\
\text { may not be } \\
\text { the same as } \\
\text { mine }\end{array}$ & $\begin{array}{l}\text { Ensuring } \\
\text { that the } \\
\text { research } \\
\text { questions } \\
\text { are seeking } \\
\text { valid } \\
\text { information } \\
\text { that can be } \\
\text { used by } \\
\text { others }\end{array}$ & $\begin{array}{l}\text { Ensuring that } \\
\text { the methods } \\
\text { used to collect } \\
\text { data treat the } \\
\text { participants } \\
\text { and audience } \\
\text { of the study } \\
\text { with equal } \\
\text { integrity }\end{array}$ & $\begin{array}{l}\text { Ensuring that } \\
\text { all applicants } \\
\text { with the } \\
\text { needed } \\
\text { experiences } \\
\text { are allowed } \\
\text { to participate } \\
\text { in the study }\end{array}$ & $\begin{array}{l}\text { Ensuring } \\
\text { the accuracy } \\
\text { of all data as } \\
\text { collected in } \\
\text { the words of } \\
\text { the } \\
\text { participants. }\end{array}$ & $\begin{array}{l}\text { Looking at all } \\
\text { perspectives } \\
\text { communicated } \\
\text { by the data } \\
\text { regardless of } \\
\text { how the } \\
\text { perspective } \\
\text { impacts the } \\
\text { study }\end{array}$ & $\begin{array}{l}\text { Providing } \\
\text { participants } \\
\text { to review } \\
\text { and validate } \\
\text { the } \\
\text { transcripts } \\
\text { from } \\
\text { interviews }\end{array}$ & $\begin{array}{l}\text { Being true to } \\
\text { the findings } \\
\text { of the study } \\
\text { whether they } \\
\text { have positive } \\
\text { or negative } \\
\text { implications } \\
\text { of the } \\
\text { research topic }\end{array}$ \\
\hline $\begin{array}{c}\text { Social } \\
\text { Responsibility }\end{array}$ & $\begin{array}{l}\text { Following } \\
\text { through } \\
\text { with what I } \\
\text { have } \\
\text { described as } \\
\text { the process } \\
\text { for } \\
\text { participants }\end{array}$ & $\begin{array}{l}\text { Developing } \\
\text { research } \\
\text { questions } \\
\text { that allow } \\
\text { can lead to } \\
\text { helping the } \\
\text { profession } \\
\text { and society }\end{array}$ & $\begin{array}{l}\text { Seeking to } \\
\text { plan a study } \\
\text { an authentic } \\
\text { issue in our } \\
\text { contemporary } \\
\text { society }\end{array}$ & $\begin{array}{l}\text { Ensure that } \\
\text { all } \\
\text { participants } \\
\text { are aware of } \\
\text { the social } \\
\text { implications } \\
\text { of the study }\end{array}$ & $\begin{array}{l}\text { Looking for } \\
\text { perspectives } \\
\text { that imply } \\
\text { an impact } \\
\text { on society }\end{array}$ & $\begin{array}{l}\text { Identify } \\
\text { perspectives } \\
\text { that support } \\
\text { or detract } \\
\text { from a societal } \\
\text { impact }\end{array}$ & $\begin{array}{l}\text { Ensure that } \\
\text { all } \\
\text { participants } \\
\text { can } \\
\text { understand } \\
\text { that their } \\
\text { perspectives } \\
\text { are utilized } \\
\text { in an } \\
\text { attempt to } \\
\text { better } \\
\text { society }\end{array}$ & $\begin{array}{l}\text { Clearly state } \\
\text { how the } \\
\text { findings may } \\
\text { help to } \\
\text { improve our } \\
\text { contemporary } \\
\text { society }\end{array}$ \\
\hline $\begin{array}{c}\text { Open } \\
\text { Mindedness }\end{array}$ & $\begin{array}{l}\text { Seeking } \\
\text { others in the } \\
\text { educational } \\
\text { profession } \\
\text { who may } \\
\text { benefit from } \\
\text { my research }\end{array}$ & $\begin{array}{l}\text { Allowing for } \\
\text { the } \\
\text { possibility } \\
\text { that the } \\
\text { research } \\
\text { questions } \\
\text { may need } \\
\text { adjustments }\end{array}$ & $\begin{array}{l}\text { Ensuring that } \\
\text { the advice of } \\
\text { my committee } \\
\text { and the } \\
\text { requirements } \\
\text { of the IRB are } \\
\text { followed }\end{array}$ & $\begin{array}{l}\text { Allowing all } \\
\text { qualified, } \\
\text { interested } \\
\text { applicants to } \\
\text { participate in } \\
\text { the study }\end{array}$ & $\begin{array}{l}\text { Actively } \\
\text { looking for } \\
\text { multiple } \\
\text { perspectives } \\
\text { in the data }\end{array}$ & $\begin{array}{l}\text { Keeping a } \\
\text { check on my } \\
\text { own bias } \\
\text { while } \\
\text { evaluating the } \\
\text { data }\end{array}$ & $\begin{array}{l}\text { Realizing } \\
\text { that there } \\
\text { may be } \\
\text { multiple } \\
\text { perspectives } \\
\text { in the data }\end{array}$ & $\begin{array}{l}\text { Realizing that } \\
\text { my findings } \\
\text { may } \\
\text { discourage } \\
\text { some in the } \\
\text { profession } \\
\text { regardless of } \\
\text { the data }\end{array}$ \\
\hline Honesty & $\begin{array}{l}\text { Sharing an } \\
\text { accurate } \\
\text { description } \\
\text { of the } \\
\text { research } \\
\text { process }\end{array}$ & $\begin{array}{l}\text { Ensuring } \\
\text { that that the } \\
\text { research } \\
\text { question } \\
\text { initiate an } \\
\text { honest } \\
\text { approach to } \\
\text { the study }\end{array}$ & $\begin{array}{l}\text { Recognizing } \\
\text { weaknesses } \\
\text { with the } \\
\text { methods and } \\
\text { adjusting } \\
\text { them as } \\
\text { necessary to } \\
\text { ensure an } \\
\text { honest, } \\
\text { unbiased } \\
\text { process }\end{array}$ & $\begin{array}{l}\text { Being honest } \\
\text { about the } \\
\text { qualifications } \\
\text { needed to } \\
\text { participate }\end{array}$ & $\begin{array}{l}\text { Creating } \\
\text { data } \\
\text { collection } \\
\text { methods } \\
\text { that ensure } \\
\text { honest } \\
\text { collection of } \\
\text { the data }\end{array}$ & $\begin{array}{l}\text { Review the } \\
\text { data from an } \\
\text { unbiased } \\
\text { position }\end{array}$ & $\begin{array}{l}\text { Sharing the } \\
\text { transcripts } \\
\text { with the } \\
\text { participants }\end{array}$ & $\begin{array}{l}\text { Reporting the } \\
\text { findings } \\
\text { completely } \\
\text { from all } \\
\text { perspectives }\end{array}$ \\
\hline Trust & $\begin{array}{l}\text { Ensuring } \\
\text { that } \\
\text { participants } \\
\text { can trust in } \\
\text { anonymity }\end{array}$ & $\begin{array}{l}\text { Developing } \\
\text { research } \\
\text { questions } \\
\text { that inspire } \\
\text { trust in the } \\
\text { results of } \\
\text { the research }\end{array}$ & $\begin{array}{l}\text { Creating a } \\
\text { plan that } \\
\text { inspires trust } \\
\text { by the } \\
\text { participants } \\
\text { and the } \\
\text { audience of } \\
\text { the research }\end{array}$ & $\begin{array}{l}\text { Sharing the } \\
\text { ethical } \\
\text { requirements } \\
\text { on the } \\
\text { researcher } \\
\text { and the study } \\
\text { with } \\
\text { participants }\end{array}$ & $\begin{array}{l}\text { Carrying out } \\
\text { the study } \\
\text { with } \\
\text { consistency } \\
\text { across all } \\
\text { participants } \\
\text { and in the } \\
\text { way they } \\
\text { agreed to } \\
\text { the study }\end{array}$ & $\begin{array}{l}\text { Honoring the } \\
\text { data as } \\
\text { collected and } \\
\text { respecting it } \\
\text { as an } \\
\text { extension of } \\
\text { the participant }\end{array}$ & $\begin{array}{l}\text { Reviewing } \\
\text { the process } \\
\text { of the study } \\
\text { with each } \\
\text { participant }\end{array}$ & $\begin{array}{l}\text { Having } \\
\text { transparency } \\
\text { about the } \\
\text { process of } \\
\text { building trust } \\
\text { with the } \\
\text { participants } \\
\text { from the } \\
\text { beginning to } \\
\text { the end of the } \\
\text { study }\end{array}$ \\
\hline
\end{tabular}




\begin{tabular}{|c|c|c|c|c|c|c|c|c|}
\hline Responsibility & $\begin{array}{l}\text { To ensure } \\
\text { that all } \\
\text { perspectives } \\
\text { are } \\
\text { accurately } \\
\text { reflected } \\
\text { and } \\
\text { protected }\end{array}$ & $\begin{array}{l}\text { To make the } \\
\text { appropriate } \\
\text { changes to } \\
\text { the research } \\
\text { question if } \\
\text { the needed }\end{array}$ & $\begin{array}{l}\text { Plan a method } \\
\text { of study that } \\
\text { will validity of } \\
\text { the research } \\
\text { process. }\end{array}$ & $\begin{array}{l}\text { Treat all } \\
\text { applicants } \\
\text { with fairness } \\
\text { and respect } \\
\text { throughout } \\
\text { the study }\end{array}$ & $\begin{array}{l}\text { Be thorough } \\
\text { in data } \\
\text { collection } \\
\text { methods }\end{array}$ & $\begin{array}{l}\text { Analyze data } \\
\text { thoroughly } \\
\text { and accurately }\end{array}$ & $\begin{array}{l}\text { Follow } \\
\text { through } \\
\text { with } \\
\text { allowing } \\
\text { participants } \\
\text { to check the } \\
\text { data }\end{array}$ & $\begin{array}{l}\text { Honor the } \\
\text { responsibility } \\
\text { to the } \\
\text { participants } \\
\text { and the } \\
\text { profession to } \\
\text { report the } \\
\text { findings of } \\
\text { the study }\end{array}$ \\
\hline Commitment & $\begin{array}{l}\text { Following } \\
\text { through } \\
\text { with the } \\
\text { research, as } \\
\text { designed, to } \\
\text { completion }\end{array}$ & $\begin{array}{l}\text { Ensure that } \\
\text { the research } \\
\text { questions } \\
\text { are what } \\
\text { drives the } \\
\text { study from } \\
\text { beginning to } \\
\text { end }\end{array}$ & $\begin{array}{l}\text { Meet all } \\
\text { deadlines and } \\
\text { requirements } \\
\text { to ensure the } \\
\text { study is } \\
\text { completed } \\
\text { successfully }\end{array}$ & $\begin{array}{l}\text { Meet all } \\
\text { commitments } \\
\text { made to the } \\
\text { participants } \\
\text { of the study }\end{array}$ & $\begin{array}{l}\text { Collect data } \\
\text { based upon } \\
\text { the agreed } \\
\text { upon } \\
\text { methods }\end{array}$ & $\begin{array}{l}\text { Protect the } \\
\text { perspectives } \\
\text { of all } \\
\text { participants }\end{array}$ & $\begin{array}{l}\text { Commitment } \\
\text { to allow } \\
\text { participants } \\
\text { to check the } \\
\text { data }\end{array}$ & $\begin{array}{l}\text { Be committed } \\
\text { to the } \\
\text { findings of } \\
\text { the study the } \\
\text { possible } \\
\text { implications } \\
\text { it may have } \\
\text { on the } \\
\text { profession. }\end{array}$ \\
\hline
\end{tabular}


APPENDIX F: STRATEGIC PLAN

\begin{tabular}{|l|l|l|}
\hline \multicolumn{3}{|c|}{ Trimble County Schools Strategic Plan 2017-2020 } \\
\hline \multicolumn{1}{|c|}{$\begin{array}{c}\text { Achieve Excellence In } \\
\text { Academics }\end{array}$} & $\begin{array}{l}\text { Achieve Excellence In } \\
\text { Leadership }\end{array}$ & $\begin{array}{l}\text { Achieve Excellence In } \\
\text { Resource Utilization }\end{array}$ \\
\hline $\begin{array}{l}\text { Students who earn a diploma } \\
\text { from Trimble County Schools } \\
\text { will be: self-motivated, resilient } \\
\text { and persevere through } \\
\text { challenges, confident, } \\
\text { innovative problem solvers, } \\
\text { critical thinkers, effective } \\
\text { communicators, goal-driven, } \\
\text { leaders who are ready for post- } \\
\text { secondary education/ careers, } \\
\text { and service oriented citizens. }\end{array}$ & $\begin{array}{l}\text { As leaders we will } \\
\text { demonstrate excellence } \\
\text { through: fidelity and } \\
\text { commitment to our mission } \\
\text { and vision, effective } \\
\text { governance, ability to } \\
\text { engage stakeholders in } \\
\text { meaningful ways, the } \\
\text { capacity to improve the } \\
\text { experience of the learner } \\
\text { and educator. }\end{array}$ & $\begin{array}{l}\text { We will utilize our resources } \\
\text { in an equitable manner so } \\
\text { the needs of all learners are } \\
\text { effectively addressed while } \\
\text { supporting staff to maximize } \\
\text { student learning through } \\
\text { streamlined operational } \\
\text { procedures and } \\
\text { organizational effectiveness. }\end{array}$ \\
\hline \multicolumn{2}{|c|}{ What will that look like? } \\
\hline
\end{tabular}


- All students will have the opportunity for personalized learning

- Classroom communities will be student centered

- All students will have opportunities to engage in academic dialogue to make meaning, determine importance, and increase understanding.

- All students will have collaborative opportunities (project based learning) that will foster creativity and develop problem solving skills in realworld situations.

- All students will have a go-to adult (mentor) to set personal and academic goals with on a weekly basis.

- All students will monitor their own learning through the use of rubrics and exemplars to review and revise their work.

- Teachers will provide targeted instruction and specific feedback based on relevant student data to support students' academic growth.

- Staff and student's actions, language, and behaviors will demonstrate a growth mindset.

- Staff will focus on recognizing and reinforcing appropriate behaviors through implementation of PBIS strategies.

- Through community partnerships, students will engage in service projects to enhance
- Parents will have opportunities to be active partners in the school community.

- District leadership will model high standards in accordance with state and local policies, procedures, and code of ethics.

- District leadership will conduct surveys and analyze the effectiveness of our governance for continuous improvement.

- District leadership will conduct surveys to gather feedback from stakeholders and will set goals to improve community relationships.

- District leadership will systematically refine evaluation practices that support building capacity of educators.

- District leadership will support professional practice of teachers through targeted monthly walkthroughs, specific feedback, professional learning cohorts, and instructional updates.
- Staff new to the district will participate in an induction program and will be assigned a mentor.

- Trimble County Schools will be represented at job fairs to recruit and promote our district.

- Trimble County Schools will actively participate in regional partnerships and professional learning opportunities.

- Professional learning will be personalized for certified personnel.

- PLC structures and processes at each building will enhance teacher collaboration and promote analysis of student data.

- A systematic process will be utilized to support the achievement of a balanced budget that reflects district needs.

- Systems, procedures, and expectations will be specifically defined and communicated through an Operations Manual and Employee Handbook. 


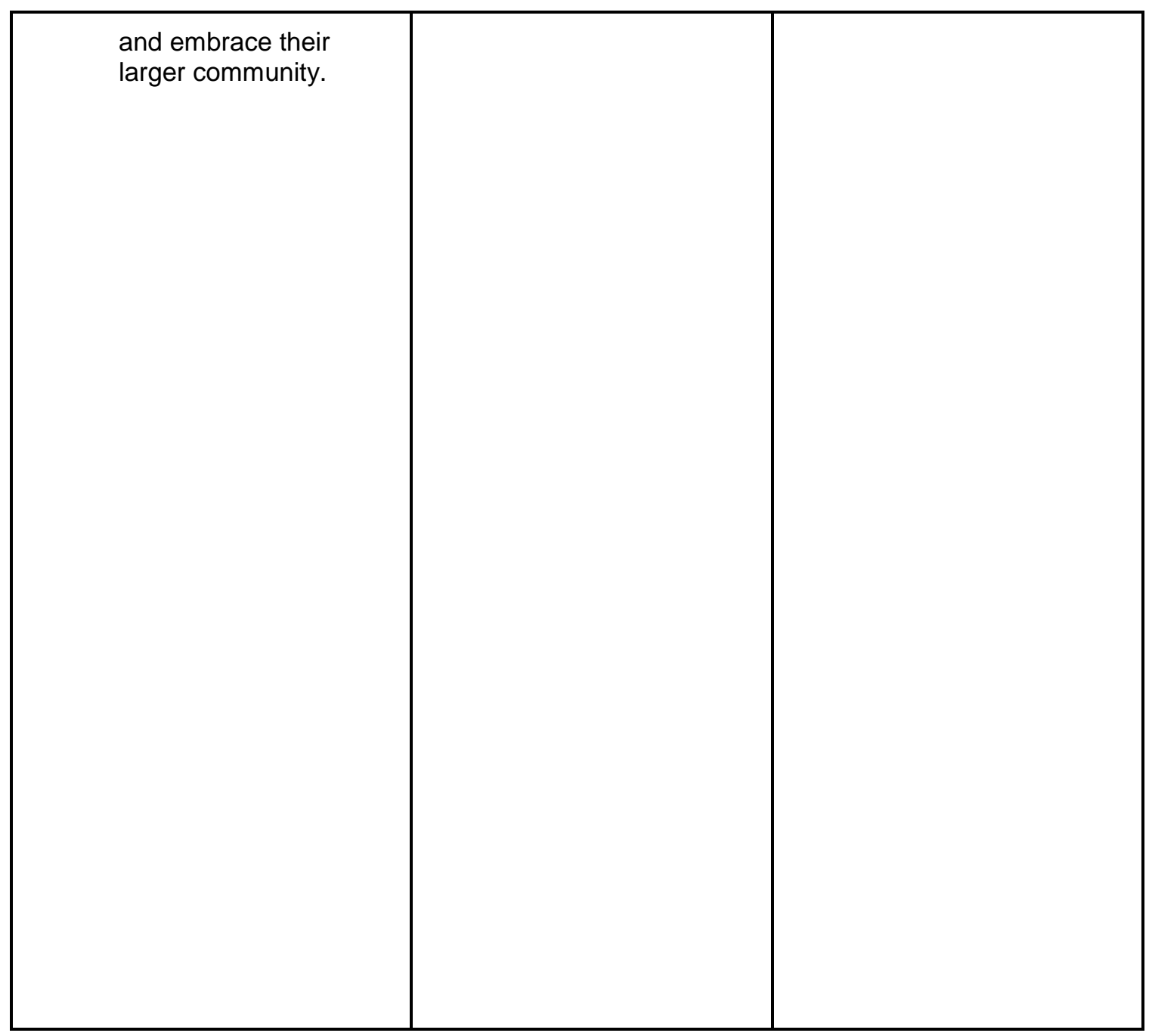




\section{APPENDIX G: LEARNING CENTERED ANCHOR CHART}

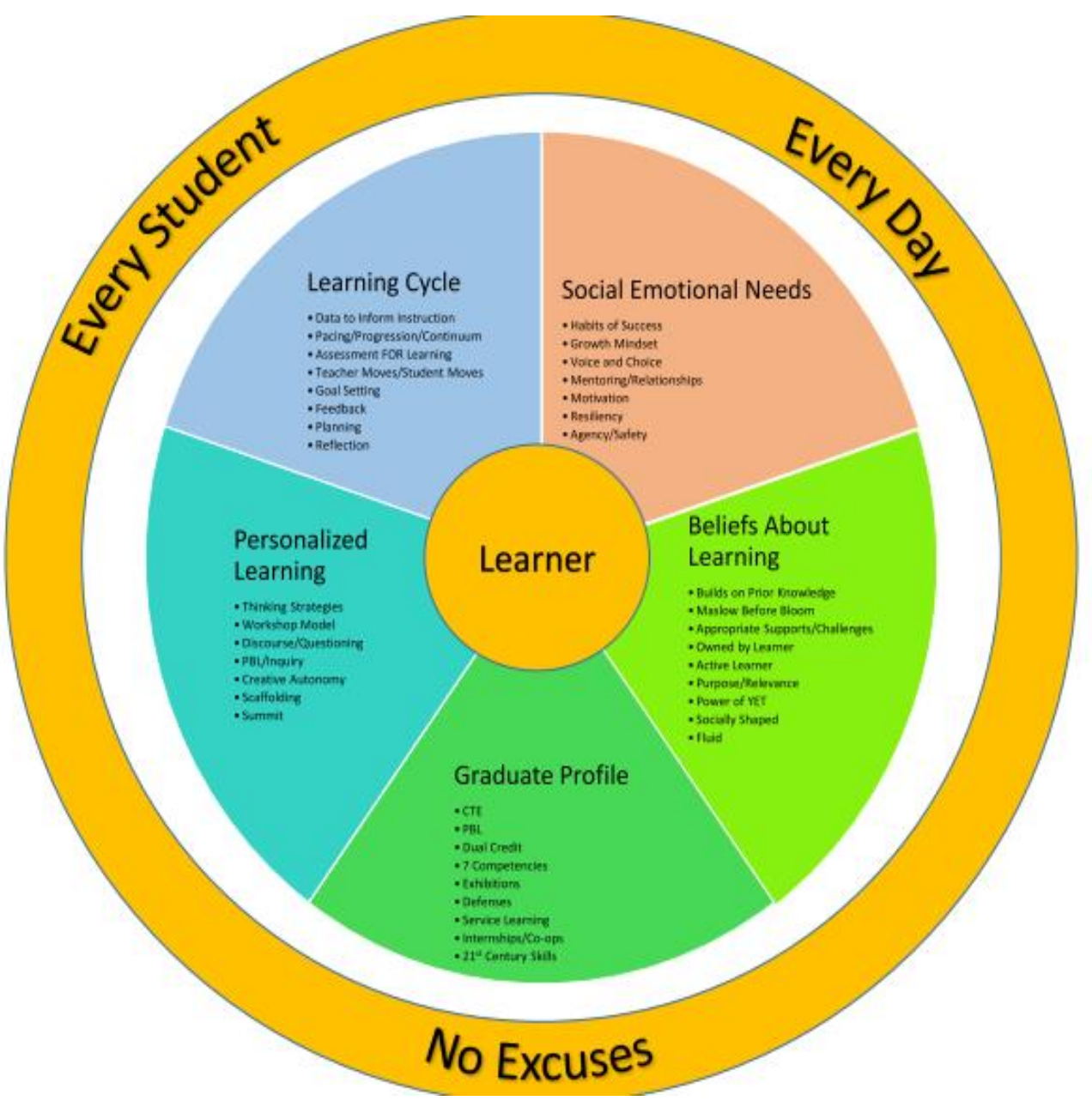


CURRICULUM VITA

Steve Miracle

E-mail: steve.miracle@bullitt.kyschools.us

Phone: H-502/647-3551/C-502/220-9318

\section{Area of Specialization}

Results-oriented educational leader driving school improvement through Innovative strategies and building strong and positive culture/climate. Excellent qualifications in implementing strong instructional and behavioral programs, from Personalized Learning, Graduate Profile, Professional Learning Community Process, PBIS, Thinking Strategies, Leader in Me, effective school scheduling and grant writing. Consistently successful in decision making, hiring and retaining quality educators; and building collaborative partnerships. Provide a decisive course of action for district improvement.

\section{Education}

\section{Doctor of Education}

Educational Leadership and Organizational Development University of Louisville

May, 2021

Louisville, KY

Rank I, DPP Certification, Superintendent Certification

May 2013

Educational Leadership and Organizational Development

University of the Cumberlands

Williamsburg, KY

Master Education and Principal Certification Level II May, 2010

Educational Leadership

University of Louisville

Louisville, KY

Master Education and Principal Certification Level I

Educational Leadership

University of Louisville

May, 2004

Louisville, KY

Bachelor of Arts

December, 1995

History Education

$\underline{\text { Kentucky State University }}$

Frankfort, KY

\section{Licensure \& Endorsements}


Professional Certificate for Instructional Leadership - School Superintendent Professional Certificate for Instructional Leadership - Director of pupil Personnel Professional Certificate for Instructional Leadership - Instructional Supervisor Professional Certificate for Instructional Leadership -Principal All Grades Provisional Certificate for Teaching -Social Studies Grades 9-12

\section{Employment}

\section{Bullitt Central High School \\ Shepherdsville, KY \\ Principal \\ July 2019-Present}

Providing leadership for Bullitt Central High School. Priority initiatives are to implement consistent and positive culture and climate through effective implementation of PBIS, effective Professional Learning Community processes, and improving customer service practices for the school. I have also been tasked with the development of three assistant principals and preparing them to be ready for the role of head principal in the near future.

Trimble County Public Schools

Superintendent
Bedford, KY

July, 2015-July, 2019

Providing leadership to the district to overcome severe financial and academic barriers. Managed the budget and resources from a $\$ 1,096,000$ deficit to being structurally balanced in two years. Consolidated middle and high school to save financially and to pool resources to provide better opportunities for students. Moved district from needs improvement to Distinguished in one year. Implemented improved systems for hiring, AdvancEd accreditation, and personalized learning.

\section{Hebron Middle School}

Principal
Shepherdsville, KY

July, 2010-July, 2015

Providing leadership for both Hebron Middle School and Discovery School, a 6-8

Science/Math magnet. Oversaw \$10 million renovation of building, implemented PBIS, Jostens Renaissance, Standards Based Grading, the Leader in Me, and Truancy Diversion Program. Implemented the data team process for PLCs and implemented the use of Data room. Developed course of study for 6-8 Science/Math magnet. Successfully obtained School Improvement grant and I AM A LEADER grant.

\section{Shelby West Middle School}

Assistant Principal

Shelbyville, KY

July, 2004-July, 2010

Implemented PBIS. Decreased discipline referrals every year. Averaged less than two referrals per day per month for an 800 student school. Bully-Free trainer and Safe Crisis Management Instructor for the district. Improved student attendance each year. Implemented BUGs (Bring Up your Grades) program through Kiwanis. Implemented Truancy Diversion Program.

Shelby West Middle School

$7^{\text {th }}$ Grade Social Studies Teacher
Shelbyville, KY

July, 2001-July, 2004 
Served as head football coach and athletic director. Taught $7^{\text {th }}$ grade World Civilization. Served as classroom to accept EBD students into collaborative setting.

Tri-County Education Center (Alternative School)

Teacher, 6-12 Social Studies
Carrollton, KY

July, 1999-July, 2001

Served as teacher for all students grade 6-12 for social studies, art, language arts, and physical education. Served as administrator in absence of building principal and managed and implemented a 200 acre outdoor classroom. Served as home school teacher for the district.

\section{SUMMARY OF QUALIFICATIONS}

Over 20 years of experience in progressively demanding, decision-making educational settings, over 22 years in administrative positions, and successfully implemented high yield initiatives such as Personalized Learning, Graduate Profile, Professional Learning Community Processes, and PBIS.

Proven strength in establishing and maintaining strong, long-term, positive cultures. The ability to promote the mission and vision of the district; provide teambuilding leadership; make informed, objective judgments; create an effective staff development plan, and engage in continuing professional development.

The talent to maintain a safe, respectful, positive, and effective learning environment, evaluate staff performance, and monitor financial procedures. 